Florida International University FIU Digital Commons

$12-1987$

\title{
Property rights and hospital behavior under DRGs : an examination of nonprofit, government, and forprofit sectors
}

Elizabeth M. Andal Sorrentino

Florida International University

DOI: $10.25148 /$ etd.FI14032312

Follow this and additional works at: https://digitalcommons.fiu.edu/etd

Part of the Public Administration Commons

\section{Recommended Citation}

Andal Sorrentino, Elizabeth M., "Property rights and hospital behavior under DRGs : an examination of nonprofit, government, and forprofit sectors" (1987). FIU Electronic Theses and Dissertations. 2157.

https://digitalcommons.fiu.edu/etd/2157 
PROPERTY RIGHTS AND HOEPITAL BEHAVIOR UNDER DRGG

AN EXAMINATION OF MONPROFIT,

GOVERNHENT, AND FORPROFIT SECTORS

BY

ELIZABETH M. ANDAL BORRENTINO, R. N.

\section{DIBSERTATION}

Bubmitted in partial fulf1liment of the requiremente for the degree of Doctor of Philosophy in Public Adminietration at the Bchool of Public Affaire and Borvices

Florida International Univareity

December 1987 


\section{PROPERTY RIGHTS AND HOSPITAL BEHAVIOR UNDER DRGS \\ AN EXAHINATION OF NONPROFIT, GOVERNMENT, AND FORPROFIT SECTORS}

BY

ELIZABETH M. ANDAL SORRENTINO, R. N.

\section{DISSERTATION}

Submitted in partial fulfillment of the requiremente for the degree of Doctor of Philosophy in Public Administration at the Bchool of Public Affair and Services

Florida International University

December 1987

Approved: 
Copyright 1987

ELIZABETH M. ANDAL SORRENTINO, R. N. 


\title{
PROPERTY RIGHTS AND HOBPITAL BEHAVIOR UNDER DREB AN EXAHINATION OF MOMPROFIT, GOVERHMENT, AND FORPROFIT SECTORS
}

BY

ELIZABETH M. ANDAL SORRENTINO, R. N.

\author{
ABgTRACT OF DIBEERTATION \\ Gubmitted in partial fulfillment of the requiremente for \\ the degree of Doctor of Philomophy in \\ Public Administration at the \\ Bchool of Public Affaire and Bervicen \\ Floride Internationel Und vareity \\ December 1987
}


This study compares nonprofit, government, and forprofit hospitals in South Florida. Property rights arrangement is defined as rights to residual profits in the forprofit hospitals, and the tax-exemption status on the part of nonprofit and government hospitals with obligations to serve charitable purposes in the public interest. This dissertation derives and tests implications about differences in behavior in the context of efficiency, equity, and quality of care delivered in nonprofit, government, and forprofit hospitals.

Fifty-six hospitals with Joint Commission on Accreditation of Hospitals (JCAH) accreditation were compared on institutional variables (bed size, location); efficiency variables (occupancy rates, ancillary expenses, bad debts, manhours per patient day, salaries per FTE, length of stay/DRG, charges/DRG, reimbursement/DRG (an twenty DRGs); equity variables (Medicare days, Medicaid days, and uncompensated care); and finally, the quality variable (death rates/DRG on twenty DRGs).

The immediate effects of profit maximization is considered as an incentive for managers in the forprofit hospitals. The social obligations attached to the taxexemption status can be argued as the underlying rationale for output maximization, i. e. maximizing 
benefits to society by serving more patients in the nonprofit and government hospitals.

Using analysis of variance, nonprofit, government, and forprofit hospitals were compared to determine if statistically significant differences were present at the . OS level of significance. Pairs of hospital types were tested for significant differences using ANQVA, Mann-Whitney, and multiple regression analysis.

The results provided mixed support for the property rights theory. Significant differences were found on institutional variables, bed size and location; efficiency variables, bad debts, manhours per patient day, and charges per DRG; equity variables Medicare days, Medicaid days, and uncompensated care. In terms of the quality variable, the death rates per DRG showed no statistical significance.

Unexpectedly, nonprofit hospitals were very similar to forprofit hospitals on the variables bad debts and Medicaid days. The relevance of this finding to health policy issues today, particularly tax-exemption privileges, warrant a suggestion for further evaluation of the performance of the nonprofit sector. 


\section{CONTENTS}

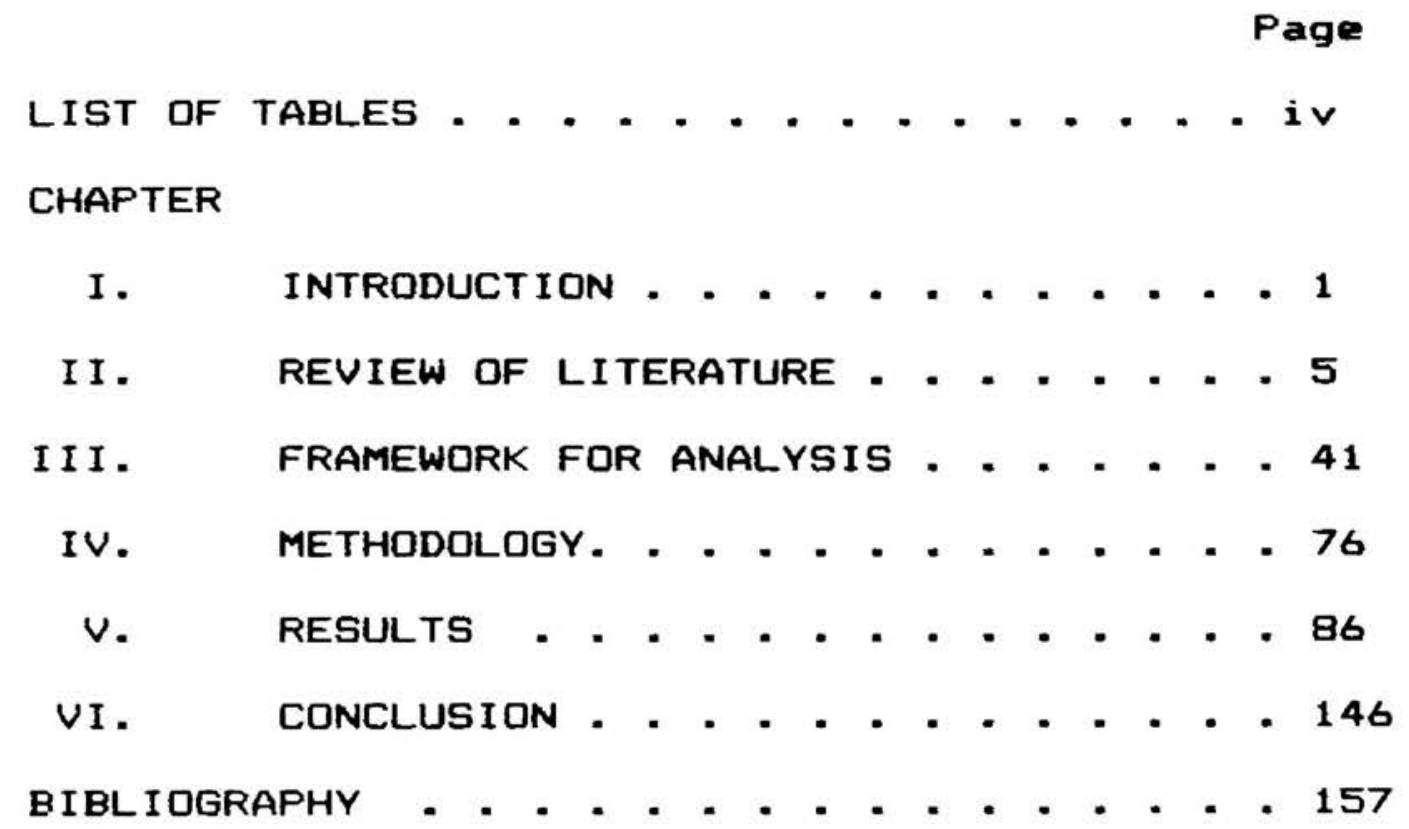


TABLES

Page

TABLE

I. BED CAPACITY BY OWNERSHIP . . . . . . 87

I I. CROSSTABULATION BY OWNERSHIP BY LOCATION. . . . . . . . . . . . . . . 88

I I . BED CAPACITY BY LOCATION. - . . . . . 89

IV. BED CAPACITY BY OWNERSHIP BY LOCATION 89

V. OCCUPANCY RATES BY OWNERSHIP. . . . . 92

VI. OCCUPANCY RATES [NP VS G, FP VS G, NP VS FP]. . . . . . . . . . . . . . 93

VII. STATE OF FLORIDA BEDS, PATIENT DAYS, hOSPITAL TYPE . . . . . . . . . . . 95

VIII. ANCILLARY SERVICES BY OWNERSHIP. . - 97

IX. ANCILLARY EXPENSES [NP VS G, FP VS G, NP VS FPJ. . . . . . . . . . . . 97

X. BAD DEBTS BY OWNERSHIP . . . . . . . 100

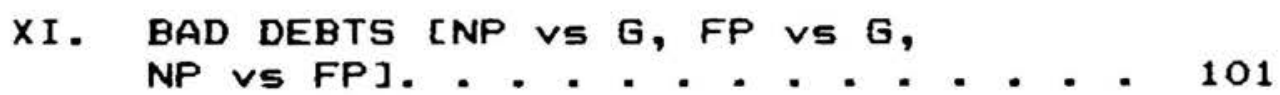

XII. MANHOURS PER PATIENT DAY . . . . . 102

XIII. MANHOURS PER PATIENT DAY [NP VS G,
FP VS G, NP VS FP]. . . . . . . . . 103

XIV. ANALYSIS OF VARIANCE FOR 1995 DATA - 103

XV. SALARIES FER FTE BY DWNERSHIP. . . . 107 
XVI. SALARIES PER FTE [NP VS G, FP VS G, NP VS FP]............. . . 107

XVII. LENGTH OF STAY BY DRG BY OWNERSHIP TYPE . . . . . . . . . . . 109

XVIII. LENGTH OF STAY BY DRG (NONPROFIT VS GOVERNMENT) . . . . . . . . . . . 111

XIX. LENGTH OF STAY BY DRG (FORPROFIT VS GOVERNMENT. . . . . . . . . . . . 111

$X X$. LENGTH OF STAY BY DRG (FORPROFIT VS NONPROF IT . . . . . . . . . . . . 112

XXI. CHARGES BY DRG BY OWNERSHIP TYPE . . 114

XXII. CHARGES BY DRG (FORPROFIT VS GOVERNMENT . . . . . . . . . . . . . 115

XXIII. CHARGES BY DRG (FORPROFIT VS NONPROF IT . . . . . . . . . . . . . 116

XXIV. CHARGES BY DRG (NONPRQFIT VS GOVERNMENT. . . . . . . . . . - . . 117

XXV. REIMBURSEMENTS BY DRG BY OWNERSHIP TYPE. . . . . . . . . . . 119

XXVI. REIMBURSEMENTS BY DRG (GQVERNMENT vS FORPROFIT. . . . . . . . . . . . . 120

XXVII. REIMBURSEMENTS BY DRG IFORPROFIT VS NONPROFIT. . . . . . . . . . . . 120

XXVIII. REIMBURSEMENTS BY DRG (NONPRQFIT vS GOVERNMENT . . . . . . . . . . . 121

XXIX. MEDICARE DAYS BY OWNERSHIP. . - . - 129

XXX. MEDICARE DAYS (NP VS G, FP VS G,
NP VSFP)................ 130

XXXI. MEDICARE DAYS BY LOCATION * * . . 132

XXXII. MEDICAID DAYS BY OWNERSHIP. - * - 132

XXXIII. MEDICAID DAYS (NP VS G, FP VS G,
NP VS FP) . . . . . . . . . . . 133

XXXIV. UNCOMPENSATED CARE. . . . . . . . . 135 


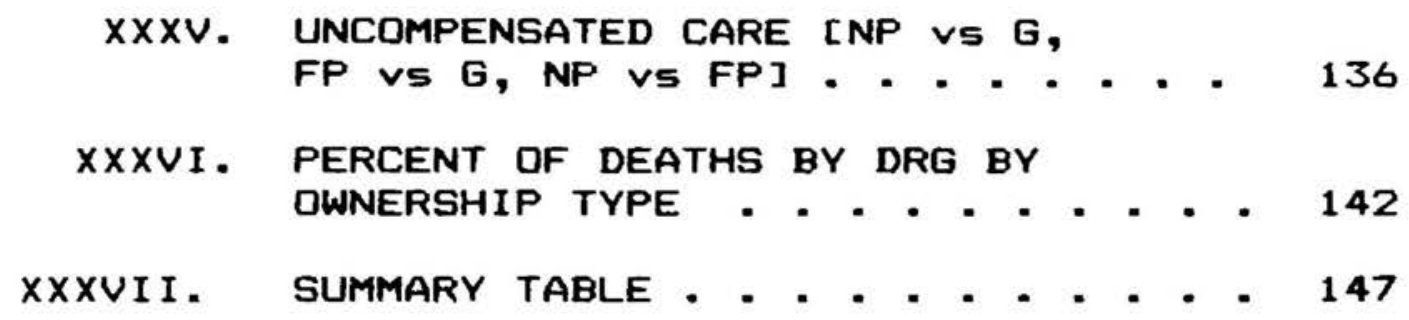




\section{CHAPTER I}

\section{INTRODUCTION}

Property rights arrangement, hospital ownership (nonprofit, government, and forprofit), and possible differences in behavior are factors to be explored as the focus in the health care environment shifts to effectiveness and cast containment. This study examines the behavior of nonprofit, government and forprofit hospitals in the context of efficiency, equity, and quality of services delivered.

$$
\text { Property rights theory posits that rights to }
$$

residual profits, as a reward for administrative effectiveness in the forprofit hospital, provides one underlying rationale for the differences in hospital behavior. Several hypotheses will be advanced regarding the behavior of the nonprofit, government, and forprofit hospitals. Forprofit hospitals are thought of as having economic incentives to be efficient as compared to the nonprofit and government counterpart. By virtue of their focus on profits, provision of care to patients in 
the hospital setting may be less equitable (as measured in terms of number of Medicare/Medicaid days and amount of uncompensated care). The quality of care provided is a function of the standards established by the state licensing and accreditation bodies. It is reasonable to think along the line that hospitals, regardless of ownership status, will attempt to meet minimum standards. The nonprofit and government hospital may expand their units of service (output maximization) to society at a level of quality that is within budget constraints. The forprofit hospitals will attempt to maintain a level of quality that ensures patients will patronize it and that it will attain accreditation.

The underlying premise for the output maximization rationale for the nonprofit and government hospital is that these hospitals do not have rights to residual profits but do have special tax-exemption status. As such, these hospitals are expected to serve charitable purposes in the public interest. This suggests that hospitals organized as nonprofit (or government-owned) will attempt to maximize benefits to society by expanding units of service.

Today, there is emphasis on cost containment in the provision of health care. Hospitals are faced with providing inpatient care according to the price limits set under the Diagnosis Related Groupings (DRGs) 
for all Medicare patients. The retrospective reimbursement system which encouraged the overutilization of many health services is now passe. Published work along the 1 ines of property rights have not examined the implications to the provision of health care in the context of efficiency, equity, and quality. Qver the years, studies have been done to explain differences in hospital behavior using economic models. With the exception of Clarkson's work (1972), theorybased explanation of differences is lacking.

There are five subsequent chapters which can be briefly described as follows:

Chapter II Literature Review is in three parts. The first part discusses some background information regarding the heavily regulated environment hospitals are in. The second part presents property rights research and economic models which explain some of the differences in behavior of the nonprofit and forprofit haspitals, thus providing groundwork for subsequent relationships that are examined further in the text. In the third part, 1 iterature is presented on studies comparing the performance of the three hospital ownership types and provides justification for the relevant variables pertinent to this dissertation.

Chapter III Framework for Analysis. The property rights theory is used as the rationale for why 
differences in hospital behavior according to ownership status might be expected. This chapter discusses the variables to be analyzed in the study. It explains some expectations regarding the behavior of nonprofit, forprofit, and government hospitals in the context of efficiency, equity, and quality. Specific hypotheses are identified for testing.

Chapter IV Hethodology This chapter describes the study population, data management, and statistical methods used for analysis. The unit of analysis is the hospital and the study setting is South Florida. This section gives information regarding the data used to allow insight on validity and generalizability concerns. Chapter $V$ Results This chapter presents the results of hypotheses-testing for institutional, efficiency, equity, and quality variables. Each area is summarized and conclusions presented.

Chapter VI Conclusion This chaptar shows a summary of the variables and pertirent findings regarding the behavior of the nonprofit, government, and forprofit hospitals. The generalizability of the findings is discussed in the light of the study limitations. Recommendations for future research are cited. The utility of the study findings from a practical and theoretical standpoint are discussed. 


\section{CHAPTER II}

REVIEW OF LITERATURE

This review of 1 iterature is divided into three parts. First is the area of health care policy which briefly describes the trends which led to the present changes in the health care delivery system. This will give an overview of the environment wherein hospitals operate and allude to the institutional variables which will be examined later (geographic location, size, and service type of hospitals). The second part focuses on the property rights research and economic models relating to differences in behavior of hospitals. Third and 1 ast, studies comparing nonprofit, government, and forprofit hospitals are cited and provides justification for relevant variables in the subsequent analysis.

\section{Health Care Policy}

From the standpoint of public policy, strategies to assure quality of care include regulatory measures which affect hospitals and licensed practicing professionals in the health care setting. The Hill-Burton Act of 1946 was aimed at increasing the availability and 
accessibility of facilities. The Social Security Amendments (Title VI of 1965) created the Medicare and Medicaid programs (Title XIX) to provide for the health care needs of the elderly and the indigent. Title XIX established a medical assistance program for all those regardless of age who qualified for public assistance and for those whose medical expenses threatened to produce future indigency (Marmor, 1982). The Comprehensive Health Manpower Training Act and the Health Professions Educational Assistance Act of 1971 were attempts to increase the availability and accessibility of manpower.

In 1972, the United States Congress attempted to "improve quality" through the establishment of peer review programs. The Social Security Amendment of 1972 (P. L. 92-603) created the PSROs (Professional Standards Review Organizations). The PSRQs monitor the appropriateness of utilization and the quality of institutional services provided to beneficiaries of Medicare and Medicaid programs. The explicit objectives of this legislation included the review of services provided to all federal beneficiaries, to evaluate the necessity for institutional admission, the duration of institutional service, appropriateness of the level of institutional care, and the adequacy and relevance (quality) of services provided. 
Although the Joint Commission on Accreditation of Hospitals (JCAH) was founded in the early 1950s, it was not until the birth of the PSROs that emphasis on the appraisal of health services quality would be given greater attention. In 1979, JCAH published its standards on quality assurance which focused on professional and organizational relationships. While PSROs involve peer review activities resting on the physicians, JCAH implies dual responsibility by administrators and physicians. Accountable to both institutions and physicians are also members of the nursing profession. State licensure rules and regulations govern practice of these professionals. The Nurse Practice Act (Florida Statute Section 464.003, 1979) defines what nurses are allowed to do and specifies its scope. Licensure renewals and disciplinary actions are subject to these mandates. Compliance with JCAH standards is needed by the hospital to achieve accreditation. The government requires that a hospital caring for patients on Medicare and Medicaid be accredited to be eligible for reimbursement. The standards for accreditation by the JCAH include the following (JCAH, 1987):

(1) the hospital maintains facilities, beds, and services that are available over a continuous 24-hour period, seven days a week. 
(2) the hospital has a median length of stay of 30 days or less (This differentiates hospitals from nursing homes or chronic care facilities.).

(3) the hospital provides for the following services:

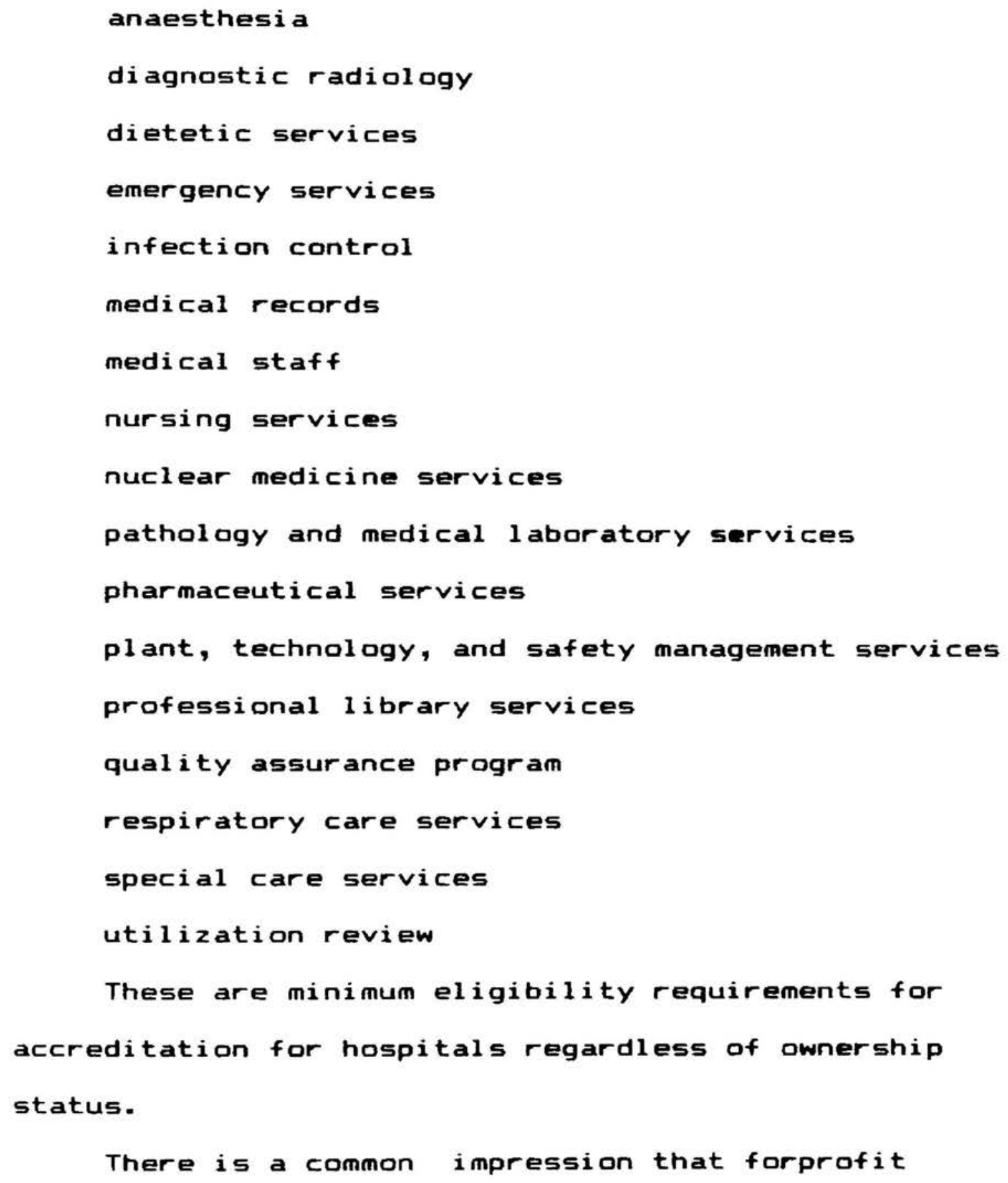


hospitals identify potential profitable markets and build or acquire hospitals in specific geographic areas. While this may be partly true, there are some regulations. Dne of them is Public Law 92-603, which restricted the construction of hospital beds and facilities under Section 1122. State laws such as Certificate of Need (CON) requirements mandate prior approval of the establishment of new health facilities or the expansion of health services.

In Florida, the Department of Health and Rehabilitative Services is responsible for reviewing applications and giving approval. Letters of intent regarding health facilities and services must also be submitted to local health councils serving the affected area. Thus, even the acquisition or replacement of certain types of equipment (i. e. CAT scanner, Nuclear Imaging devices, Dpen Heart surgery facilities) are under the purview of the government's administrative agencies. Not all states require C. O. N. approval. Hospital budgets also face review. In Florida, the Health Care Consumer Protection and Awareness Act mandated that hospital budget review be reinforced with regulatory provisions that allow the Hospital Cost Containment Board to adjust the budgets of hospitals whose gross revenues per adjusted admission both exceed their peers, and the national hospital market basket 
index. (Market Basket Index is an estimate of the annual rate of increase in the costs of certain goods and services used by hospitals in the production of inpatient care.) The items and services used in the market basket index have been selected and weighted to reflect the effect that general price changes have on the hospital inpatient operating costs (HCFA, 1984). The hospital budget review process is done by the Hospital Cost Containment Board (HCCB), which is appointed by the Governor and consists of three consumers, three purchasers, and three providers. The budget review process applies to all florida hospitals except those owned by the state and rehabilitation hospitals. These government regulations have been directed towards efficiency as measured by costs of health care services capped by cost ceilings established per DRG for all Medicare patients. Medicaid patients are not on DRG reimbursement. Hospitals are reimbursed for Medicaid patients on a per diem basis with records subject to the Professional Review Organization (PRO) reviews and possible approval or denial of payment.

The entire health care system faces the challenge of balancing what is socially equitable with issues of efficiency -- delivering needed health services with decreasing resources. With the growing popularity of propective payment systems (DRG-based reimbursement, 
preferred provider organizations, and health maintenance organizations), increasing competition for fewer and fewer government reimbursement dollars is the phenomenon of today. The responses of health care providers in the forprofit and nonprofit sector are multi-faceted and substantially complex. Hospitals may look critically at their internal operations where possibilities for costcutting may exist. They may also examine the type of their patient population. Additionally, hospitals may identify the most common DRG classifications their patients fall under and whether-or-not these types of patients require so much in resources. Hospitals may also examine the amounts of reimbursement dollars they have received per DRG and may utilize such information to their advantage in two ways: first, by increasing their patient population with specific types of DRGs and secand, by recruiting more physicians who specialize in diseases which pertain to the specific DRGs. These reactions are obviously directed at ensuring that reimbursed dollars exceed, if not equal, the costs of hospital care.

The hospital could, through its stringent requirements, limit medical staff privileges or revoke them as they see fit. In short, the medical staff may be limited to those who share the organization's philosophy of cost containment through patient 
selectivity and compliance to DRG reimbursement limitations such as length of stay of procedures performed.

This health care scenario is important in this analysis of nomprofit, government, and forprofit hospitals. Hospital ownership and subsequent differences in behavior have been observed in the past and several authors have attempted to explain them.

\section{Property Righte and Economic Theories}

A general view of property rights is equated with economic rights -- the right to exercise control over material possessions, the means of producing wealth, and the ability to enter into voluntary transactions of exchange (Malloy, 1986). Property rights refer to the sanctioned behavioral relations among men that arise from the existence of things and pertain to their use. Froperty rights are the expectations a person has that his decisions about the uses of certain resources will be effective. The stronger those expectations are upheld, in one way or another (custom, social ostracism, or government punishment of violators) the stronger are the property rigths (Alchian and Allen, 1969). The prevailing system of property rights in the community can be described, then, as the set of economic and social relations defining the position of each individual with respect to the utilization of scarce 
resources (Furubotn and Pejovich, 1972). Traditional microeconomic theory takes wants and technology as givens and proceeds to deduce from these the assumption of scarcity, testable implications and normative propositions (Demsetz, 1966).

In a private property system, there is control over scarce resources and their use. This includes the right to sell or transfer control. A private property right system requires the prior consent of "owners" before their property can be affected by others. The political system plays a role here in two ways: first, the government or court system helps to decide who possesses what property rights and therefore who has the power to claim control over resources; second, property rights so assigned are protected by the police power of the state.

The primary function of property rights is to guide incentives toward greater internalization of externalities. Every cost and benefit associated with social interdependencies is a potential externality. Demsetz (1967) makes clear the role of property rights in the internalization of externalities. A law which establishes the right of a person to his freedom would necessitate a payment on the part of a firm or of the taxpayer sufficient to cover such cost. In using a person's labor, the same holds true. Thus the costs of 
producing a good or service are internalized. Ownership which includes the right of sale, thus, is necessary for internalization. It is the prohibition of a property right adjustment, the prohibition or impossibility las in National Defense \& Security, Environmental Safety Clean Air) of the establishment of ownership title that can be exchanged which precludes the internalization of external costs and benefits.

The purpose of the property righte approach is to achieve a genaralization of the standard theory of production and exchange by considering the interconnectednese of ownerehip rights, incentives, and economic behavior. For example, in nonprofit organizations, the so-called owners or trustees do not have the right to decide or use the organizational wealth for personal use -- a right which is held by stockholders of private, forprofit corporations. Thus, wealth effects are more immediate to the stockholder than to the owner of an enterprise without capitalizable, saleable property rights (Alchian, 1969). Clarkson (1972) pointed out that in nonproprietary hospitals, trustees who find it relatively less rewarding (compared to proprietary stockholders) to increase the hospital's wealth also find it relatively unrewarding to enforce wealth maximizing performance by the individuals in the hospital. Hence, managers of 
nonproprietary hospitals will more often redistribute their effort towards work activities that are relatively more pleasant but have lower value to the organizations weal th.

There are restrictions on rights to benefits of business transactions. Stockholders' rights to capture profits may be restricted, as in the case of public utilities. The profits of public utilities are usually regulated by the state (for example, Florida Power \& Light Co.). Alchian (1969) indicated that nonprofit enterprises differ from profit-restricted enterprises in two respects. In the former, profits are not legally restricted and there is no restriction on entry. The nonprofit enterprise is entitled to retain any available economic profits, but its organizers may not capitalize the profits into personal take-home wealth. Thus, the nonprofit enterprise, if profitable, manifests and distributes net earnings via business related costs. Their costs may appear higher, but in fact those costs may be distribution of profit.

Changes in economic values, new advances in technology, and new markets bring changes to property right arrangements. This is particularly true when the costs of internalization increase. Such changes are notable behavior patterns in the hospital environment. Clarkson ( 1972 ) tested differences in hospital behavior 
resulting from property right arrangements. His central proposition is that effective constraints facing decision makers in proprietary hospitals differ from those in nonproprietary hospitals producing similar products and that observed differences in the combination of inputs used in production are direct consequences of differing constraints. The arrangements in nonproprietary nonprofit enterprises are different from those in proprietary, profit-seeking organizations because: (1) certain rights or claims to benefits in nonproprietary organizations are not transferable by sale as they are in proprietary organizations, and (2) managers or workers in nonprofit organizations do not have exclusive claim on residual products (the current flows of money and nonmoney benefits) that is characteristic of forprofit enterprises. Clarkson presented empirical findings to offer evidence of difference in (1) constraints, (2) distribution of work effort, (3) information used by proprietary and nonproprietary hospital administrators, and (4) variability of input selection.

Presenting evidence of differences in proprietary and non-proprietary constraints, Clarkson cited the study of Bower and Roemer (1963). Choosing only hospitals with fewer than 150 beds 145 proprietary hospitals and 22 nonproprietary hospitals), two 
conclusions were reached: (1) that proprietary hospitals have less explicit bylaws and (2) differences in bylaws "scores" were associated with differences in hospital performance.

Today, rules governing hospital budget approval, certificate of need requirements, utilization of beds, quality of care, practice of physicians and hospital practitioners are different from the 1970 era. Health care policies have been directed to ensure quality, contain cost, and allow access. In theory, a free market system is efficient when there is perfect competition and when there are zero transaction costs. In general, it is an accepted notion that government intervention is necessary to approach this goal (exemplified by antitrust laws which limit rights to transfer and ensure fair competition). The provision of health care services has been subject to numerous public policies applicable to all hospitals regardless of ownership status. For example, specific conduct of hospital committees must be identified in the bylaws. These requirements are standardized by the Joint Commission on Accreditation of Hospitals (JCAH). Minimum requirements in terms of administrators and those who implement patient care are specified. [For an indepth treatment of these standards for specific hospitals, please refer to the JCAH Manual on 
Accreditation, 1987]. As health care policies change, so do hospital behavior patterns evolve.

Previous property rights research implies that the restraint from accrual of residual profits is the primary source of operational differences between nonprofit and forprofit hospitals (Clarkson, 1972). Qther researchers noted that the nonprofit form may not be the viable form of organization in today's competitive environment (Clark, 1980; Hoff and Shaner, 1982). The economic incentives present in the hospital environment today impact on operations. Thus, hospitals organized as nonprofit, government, or forprofit need to be studied and compared.

There are also economic theories or models about the behavior of orgnizations that help provide insights into the possible operational differences among hospitals. Several authors have attempted to explain this by providing a rationale for the production of services by nonprofit firms. These are: (1) government failure; (2) inability to evaluate quality or quantity; (3) consumer desire for control; (4) as a physician's cooperative; (5) for recavery of costs; (6) for sales maximization; (7) to enhance managerial status or security; (8) conspicuous production; and (9) output maximization.

One general view is when the private sector does 
not produce certain goods or services, when the production is less than what the society desires, then the government supplies such services or goods (Musgrave and Musgrave, 1973). Additionally, these goods and services supplied by the government are intended to benefit consumers collectively rather than individually (Samuelson, 1967) and that all citizens have access (0kun, 1975). Failures by the government rather than failures by the private sector give rise to nonprofit organizations (Weisbrod, 1977). This is exemplified in one sense by the fact that organizations known as nonprofit exist must serve charitable public purposes.

The government's response to demands for public services is made known through the society's collectivechoice mechanisms. This implies that the presence of nonprofit organizations is brought about when the government's production does not meet the consumer's demands for public or quasi-public goods and services (Weisbrod, 1980). Health care is provided by nonprofit, government, and forprofit hospitals.

A hospital that is not owned by the government may be incorporated under state 1 aws as not for profit or for profit. As a nonprofit organization, the hospital operates under exempt status [Section 501 (a) (3), IRC] providing it performs a charitable, scientific, or educational purpose. To maintain tax-exempt status, no 
part of the hospital's net earnings should accrue to the benefit of any private shareholder or individual. Health institutions classified as government are owned and operated by federal, state or local governments. Government hospitals are directly or indirectly under the control of elected officials. Their financial resources for operations and capital expenditures come from government appropriations. Forprofit hospitals provide services with the intent of generating profits. These firms are accountable to their investors or stockholders who expect a return on their investment.

The production of goods and services by nonprofit firms can be seen in instances when the quantity of goods or services can not be observed or when the quality can not be accurately evaluated (Bays, 1983; Easley and 0'Hara, 1983). Beyond this, consumer desire for control has been proposed as a rationale for the nonprofit provision of certain goods or services (BenNer, 1983). Here, consumers choose to establish their own organization rather than take chances in the market place. An intuitive hypothesis for the nonprofit form is that it is a beneficient response to the problems of consumer lack of knowledge and vulnerability (Hansman, 1980). Another view, that of Pauly and Redisch (1973) explained the nonprofit hospital as a physicians' cooperative where their incomes could be maximized. 
This argument, though, undermines the physician's fiduciary responsibilities towards the patient and brings into mind whether medical practice, professional/ethical responsibilities can be reconciled with economic interests.

Karen Davis (1970) proposed that the nonprofit hospitals have objectives such as recovery of costs, and output, quality, and cash flow maximization. With recovery of cost as an objective, nonprofits would set prices of service equal to the average cost of providing the service. The assumption here is that nonprofit organizations serve public interest and being non-profit making, voluntary, charitable institutions, they aim primarily to recover costs (Ingbar and Taylor, 1968). This recovery of cost philosophy is further exemplified in policy guidelines set forth by the American Hospital Association on pricing of hospital services (AHA, 1966). It has been recommended that charges be set high enough to recover costs as well as cover funds necessary for plant expansion due to improvement of services required to keep abreast of scientific and technological advances. This difficulty in determining the rate of mark-up make empirical testing of cost-pricing difficult. Ordinarily, one would look at patient charges and this would be set equal to average operating costs to test the proposition that nonprofit hospitals 
are not profit maximizers.

Baumol (1959) argued for the sales maximization theory of the nonprofit firm in that managers are rewarded on the basis of firm revenues rather than profits. Finkler (1983) applied this theory to both nonprofit and forprofit hospitals. Hospital demand is modeled as a function of price and the number of physicians affiliated with the hospitals. Hospitals are believed to maximize sales subject to breakeven and minimum volume constraints. The constraints which face the forprofit hospital include the rules, regulations, and controls established by owners/trustees which ensure that the hospital services produced are the maximum for the associated inputs used. Hospital managers have delegated authority to work within these constraints. Clarkson's research on constraints (1972) were discussed earlier.

In the nonprofit hospital, the owners can not accrue profits or assign monetary benefits to themselves or the managers. Since there is nonsaleability of rights to future benefits and the absence of residual claim to income from profits, there is lower cost implication for non-maximization of outputs in the nonprofit haspital (Alchian, 1969; DeAlesi, 1969). Their managers have weaker proprietary rights to future benefits and hence direct actions to current benefits, such as plush 
office facilities and the like.

Williamson (1981) introduced the "manager status and security model." He asserted that profits permit the firm to expand and this also provides prestige and status to the manager. This model predicted that the firm will favor certain factors of production and will produce some outputs beyond profit-maximizing levels -behavior patterns attributed to the nonprofit firm and which implies nonefficient production. This study is quite similar to an earlier study by Lin (1971).

Lin (1971) asserted that in the classic competitive model, the concept of profit maximization provided an effective assumption about the behavior of business firms. He argued that most hospitals are not profitoriented enterprises. He advanced the conspicuous production theory of hospital behavior. His study assumes that as a producer of health care, each hospital has a desired status and an actual status. The hospital attempts to minimize the gap between its desired status and its prevailing status. It postulates defensive behavior on the part of hospitals. Lin argued that hospitals can be seen with duplication, overequipment, and overcapacity. Increase in inputs has been seen without associated increase in output. As such, net revenue and profit maximization do not provide a satisfactory explanation because without an 
increase in output, increased input expenditures have not been accompanied by increased revenue.

To the contrary, output maximization is proposed to explain the behavior of nonprofit hospitals by Long (1964), Klarman (1965), Reder (1965), Newhouse (1970), and Feldstein (1971). Long (1964) noted that nonprofit hospitals maximize the number of patients seen subject to financial limits specified by the sponsoring agency. Klarman (1965) reiterated the argument that voluntary hospitals maximize the welfare of society by serving as many patients as possible subject to certain specified 1 imits on deficits. Reder (1965) asserted that hospitals tend to be run as though their objective was to maximize the weighted number of patients treated per time period. Newhouse (1970) proposed an economic model of nonprofit hospital as a quantity and quality maximizer -- these were considered as elements of the decision-maker's maximands. There is concern for quantity of services because the nonprofit institution exists for a social purpose, receives donations, and tax exemption privileges. The element of quality is justified in using the 1 ine of reasoning that the laws of decision-making in the hospital rest on a board of trustees and the medical staff. Feldstein (1971) viewed the utilization of hospital resources in such a way that quantity of output is maximized (given quality) with the 
doctor as an independent agent of the patient.

To recapitulate, explanations regarding the

differences in hospital performance include: the

development of nonprofit hospitals as a function of the government's inability to meet consumer demand (Weisbrod, 1980); as a physician's cooperative (Pauly and Redisch, 1973); and nonprofit hospitals aim to recover costs or maximize output, quality, and cash flow (Davis, 1970). Other theorists (Baumol, 1959; Finkler, 1983) provided explanations such as sales maximization; while Alchian (1969) and DeAlesi (1969) rationalized that the nonsaleability of rights to future benefits and the absence of residual claim to income from profits imply lower cost implication for non-maximization of outputs in the nonprofit hospital. The conspicuous production theory of hospital behavior was raised by Lin (1971) and concluded that net revenue and profit maximization do not provide a satisfactory explanation because without an increase in output, increased input does not result in increased revenue. Along similar lines as Lin, Williamson ( 1981 ) explained the nonefficient production in the nonprofit hospital using a "manager status and security model." Long (1964), Klarman (1965), and Reder (1965) proposed the quantity maximization model of the nonprofit hospital, while Newhouse (1970) introduced quality as a maximand in the 
decision-making process. Feldstein (1971) considered quality as a given in output maximization.

These economic models, thus far, do not examine the differences in products (health services). In standard economic theory, assuming a competitive model, a firm that wants to maximize profits will produce outputs saleable at market price to anyone willing to pay the set price and anyone who can afford to pay. This implies that goods and services are distributed in accordance with the existing income distribution.

A voluminous amount of literature has been discussed. For clarity, let me point out that these can be grouped into two. One group is the set of economic models which relate to quantity maximization and the other to quality maximization. Several studies were related to the emphasis on increasing units of service or output. These models, thus far, do not consider exogenous changes in the environment, nor are sources of change considered. The determination of outputs are not clear and the pursuit of status, prestige, and security seem to portray hospitals in less than a professional, humanitarian way. With Newhouse's model (1970), some rational explanation was attempted with consideration of a very important dimension of service -- quality. Dne problem with this model is the failure to clearly identify what quality of inputs or outputs were being 
considered. Feldstein (1971) relied heavily on the demand and supply market mechanism and attempted to explain hospital cost inflation in this manner as well. Pauly and Redisch (1973) modeled the nonprofit institution as a physician's cooperative and suggested that there are residual profits (not to trustees) to physicians. An implication of this would be that the decision-making in the nonprofit hospital would be biased to the benefit of the physician. As a consequence, it is 1 ikely that costs of care would be higher since there is no incentive to keep costs down. [Note: If the hospital administration decreased patientstaff ratio, there may be operational inefficiencies which may not help the physician economize on his own time. For example, if a laboratory is unable to process the results of a test right away because of understaffing, the physician would have to wait longer and would not be able to see all of the patients within a shorter period of time.J

Using the property rights theory to explain differences in hospital behavior, Clarkson (1972) shed some light on the choices made by administrators. This work, unfortunately, can not withstand the test of time. The hospitals today, nonprofit as well as forprofit, are in an environment where there are pressures to deliver care at a certain level of quality. Additionally, the 
financial constraints (through prospective payment rather than retrospective payment) have been imposed to ensure cost containment.

The literature cited thus far predates DRGs. Empirical analyses tested implications for property right arrangements in settings were cost containment rules and reimbursement ceilings have not been in place. To gain better insight on hospital organizational form and its relationship to operational differences, several studies are discussed below which describe certain behavioral patterns by ownership type. Although the studies do not specifically relate differences to property right arrangements, they do provide some bases for the use of certain variables in the subsequent anal yses.

\section{Comparative Btudies}

This section deals with differences in trends of growth, size, insurance payors, costs, and charges by type of ownership.

Hospital Trends. There is a growing trend in the proliferation of forprofit hospitals (American Hospital Association [AHA], 1985). As of 1982, the number of proprietary hospitals canstituted $14.1 \%$ of all $U$. $S$. hospitals and $8.2 \%$ of all beds. In Florida, the number of nongovernment, nonprofit hospitals decreased from 206 
in 1982 to 84 in 1985 while the forprofit, investor owned hospitals increased from 48 in 1982 to 73 in 1984 (AHA 1982 and 1984 ).

The expansion of investor-owned hospitals has been observed in areas of growing demand for services (Mullner, Ross, and Hadley, 1984). The sun-belt area (California, Texas, and Florida) show $46 \%$ of all investor-owned hospitals (Federation of American Hospitals [FAH], 1984). As a percentage of non-federal, short-term general and other special hospitals by state, the states of Nevada and Florida show the highest investor-owned hospitals, with $50 \%$ and $44 \%$ respectively (FAH, 1984). Population, per capita income, and insurance coverage, as well as size, are factors in investor-ownership of hospitals (Lewin, et. al., 1981 and Watt, et. al., 1986). Thus, it is not surprising that certain geographic areas are found to have hospitals with a disproportionate number of nonprofit, government, and forprofit hospitals.

Hospital Size. American Hospital Association 1984 statistics show that of 252 hospitals in Florida, there were 74 hospitals with bed capacities of less than 100 , 73 hospitals with 100-199 beds, and 43 hospitals with 200-299 beds. Ferber (1971) noted that there were fewer clear distinctions between chain-operated and nonprofits except for those attributable to size. Investor- 
owned hospitals show selectivity in the size of hospitals they acquire or construct, this being affected by health planning agencies in the area of location as well as certificate of need requirements.

The importance of bed size is underscored for the simple reason that services offered may vary according to size. Dealing with the question of optimal size for hospitals, Berry (1973) noted that basic service hospitals (BSH) tend to have an average size well below 50. The author related the increasing average bed size to the availability of quality enhancing services (QESH), complex scope of services (CSSH), and provision of community services (CSH). The study results are meaningful and worth noting. For BSH, the mean bed size was 43; QESH with 93; CSSH with 231; and CSH with 450. This study showed that there was a clear relationship between the availability of facilities and sorvices and the capacity of hospitals to provide sfocific services. A clear relationship betwee: the provision of specific services and hosfital costs was also shown.

Groner (1979) studied proprietary chain hospitals and found that by virtue of their size, these hospitals can afford to pay for and are able to assign resource people which an individual hospital cannot afford to do. The proprietary chain hospitals are, therefore, able to prepare for contingencies and take advantage of 
opportunities which may arise.

Bed size, as a factor in the analysis of hospital performance, was also noted in another study (Pattison and Katz, 1983). In the study population, total assets per available bed were $15 \%$ lower in investor-owned chain hospitals than in voluntary institutions. Total assets reflected the measure of capital resources needed to produce an inpatient year of service. However, it should be pointed out that with bed size, occupancy rates vary. Thus, the analysis could be particularly problematic with large scale samples with state or nationwide variations.

Insurance Fayors. Ruchlin, Pointer, and Cannedy (1973) reported nonprofit facilities as having a greater proportion of their third-party payor revenues coming from city, county, state, and federal sources than their forprofit counterparts. Forprofit hospitals may favor patients who have the ability to pay with private insurance. A recent study of Pattison and Katz (1983) [using California data 1977-1982] revealed that in a cost-based reimbursement system, Medicare and Medicaid programs reimburse the hospitals for "reasonable costs" of providing care to their patients (including a "return on equity" payment to proprietary hospitals but not to non-profit institutions). They found, though, that the payer class of patients did not differ significantly 
according to hospital ownership category.

The literature underscores the importance of bed size. The payer class of patients might vary depending on location. Certainly, the population of predominantly aged 65 years and over will reflect a larger number of Medicare enrollees.

Costs and Charges. Bays (1979), using California data from 1971-1972, found that forprofit hospitals are significantly less costly than nonprofits after accounting for differences in case mix. This interpretation, though, is complicated by the systematic overtreatment of certain case types by independent, or nonchain forprofits. It is crucial to control for this and the use of diagnosie related groupe (DRGE) has been done in other studies.

Lewin, et. al. (1981) studied twelve selected diagnoses for both hospital types. Using 1978 Medicare cost reports for California, Texas, and Florida, fifty matched pairs of hospitals were compared. The findings revealed that forprofit chain hospitals were 23 percent, 17 percent, and 13 percent higher than the nonprofits in price per inpatient day, price per inpatient admission day for charge payers and price per inpatient day for cost payer, respectively. The in-patient charges in investor-owned hospitals were 8 percent higher for routine and 36 percent higher for ancillary 
services per admission. Expenses per day were 13 percent higher.

Pattison and Katz (1983), using data supplied by the California Health Facilities Commission in 1980, compared the economic performance of investor-owned and not-for-profit hospitals in California. The principal findings were: (1) during the study period, both costs and charges were higher in forprofit than in nonprofit hospitals (measured in patient days [29\%] or admission [24\%]); (2) the forprofit chains have used aggressive marketing and pricing strategies to generate high rates of profitability and growth.

Some arguments against cost studies have been that case mix differences are not accounted for. Frick, Martin, and Shwartz (1985), using 1979 data from the New York State Office of Health Systems Management, compared case 1 oads of 11 teaching and 20 nonteaching hospitals. Ueing the original 3 eJ diagnoeierelated grouplnge (DREe) to analyze the extent to which case-mix differences contribute to differances in average cost per case, their findings indicated that the case-mix differences explain one-fourth of the higher average cost per case in teaching hospitals. Watt, et. al. (1986) examined the differences in the economic performance of 80 matched pairs of investorowned chain and not-for-profit hospitals in eight states 
during 1978 and 1980 , and considered how their operating strategies might affect their relative success in a more price-conscious market [Data analysis used student's ttest to investigate the null hypotheses.]. The findings suggest that total charges (adjusted for case mix) and net revenues per case were both significantly higher in the investor-owned chain hospitals, mainly because of higher charges for ancillary services. There were no significant differences between the two groups of hospitals in regard to patient-care costs per case (adjusted for case $\mathrm{mix}$ ), but the investor-owned hospitals have significantly higher administrative overhead costs; investor-owned hospitals were more profitable; investor-owned hospitals had fewer employees per occupied bed but paid more per employee; investorowned hospitals had funded more of their capital through debt and had significantly higher capital costs in proportion to their operating costs; and the two groups did not differ in patient mix, as measured by their Medicare case-mix indexes or the proportions of their patients covered by Medicare or Medicaid. The authors concluded that investor-owned chain hospitals generated higher profits through more aggressive pricing practices rather than operating efficiencies.

In sum, several trends in the hospital industry have been identified. These are the increasing number 
of forprofit hospitals, bed size as an important factor in analyzing the differences in performance, and the role of insurance payers in hospital behavior. The literature comparing costs and charges has dealt with data before DRG-based reimbursement was put in effect (Tefra Act was signed into law in October, 1982). This meant that hospitals were reimbursed for patient care charges according to what they bill for. Now that the reimbursement system has changed, i. e. with fixed prices per DRG, a hospital may charge any amount of money but they will be reimbursed at a set price. Thus, comparisons of hospitals by ownership status before the new prospective payment system was in effect show differences in times when hospitals did not have much incentive to control costs of care.

The empirical evidence points to the higher charges on the part of the forprofit hospitals. Thus far, one might be tempted to draw causal linkages between the ownership status and resulting operational differences with existing property right arrangements. The restraint on rights to residual in the nonprofit sector may account for the lower charges. The nonprofit sector is assumed to pursue goals other than profit, such as charitable goals for the benefit of social good. This creates an important dimension in distinguishing nonprofit hopitals. Tax-exemption laws impose 
restrictions on the purposes for which nonprofit corporations can be organized and operated [See Section 501 (c) (s) Internal Revenue Code.]. To understand further the behavior of the nonprofit hospital, let us examine related concepts such as education and research. Education and Research. Activities such as education and research enhance organizational prestige (Goss, 1970). Costs to support such activities may come from grants or donations -- for the nonprofit hospital. The conduct or support of research is considered charitable -- for the public good. It was not until recently that forprofit organizations became eligible to receive research grants from the National Institutes of Health. Generating funds for research purposes come from government grants or charitable contributions both of which forprofit hospitals are not the preferred recipients. Additionally, there are numerous moral, ethical, and legal concerns associated with research activities on human subjects. This makes research participation on a small scale difficult. As mentioned earlier, most forprofit hospitals are smaller in size and may not have substantial resources to support a full time research staff.

Hospitals are either teaching or non-teaching. Affiliation with major universities make the hospital the site for training for students of nursing, medicine, 
biochemistry, and allied health sciences. Educational gaals (considered charitable and furthering public purpose) have been associated with both government and nonprofit hospitals. There are several factors which could have led to this trend. Government hospitals and nonprofit religious organizations were first in the industry to establish themselves in communities. By virtue of their size, various specialties can be made readily available for practitioners. Clinical practice requires certain types of specialties such as opthalmology, otorhinol aryngology, gastroenterology, pulmonary, cardiovascular, orthopedics, genito-urinary, endocrinology, musculo-skeletal, neuralogy, internal medicine, surgery, and pathology. The amount of resources (physical, human, and financial) necessary to provide the majority, if not all of these services obviously impact on the costs of delivering care in these hospitals. Hospital Data Center (1985) statistics showed the average number of residents and trainees per community hospital in 1983 as follows: state and local government hospitals with 300-399 beds had 48\%; 400-499 beds with 93\%; and 500-599 beds with 196\% (percent expresses that average number of residents and trainees per hospital bed).

It is common knowledge that forprofit hospitals hardly participate in teaching. In 1983, short-term 
forprofit general hospitals with medical and nursing school affiliations consisted of $4 \%$ cNonprofits $=46 \%$; Government $=30 \% 3$ (AHA, 1985). Teaching activities are considered costly and logically, if the generation of profits is the primary goal of a hospital, it would be difficult to substantiate carrying on an activity that does not increase return on investment to shareholders. Additionally, there are institutional concerns regarding the legal implications and the potential vulnerability of the hospital to lawsuits in the event of malpractice incidents (since student nurses and physicians are unlicensed practitioners).

The costs incurred in providing teaching impact on patient charges. Jones (1985) conducted a study in one large university teaching hospital, comparing four DRG categories. The findings show significantly higher charges for patients with faculty attending physicians placed on a teaching service as compared to private, nonteaching patients. Frick and others (1985) compared eleven teaching and twenty non-teaching hospitals using 383 original DRGs and found that costs per case in teaching hospitals are $60 \%$ higher than nonteaching hospitals.

The preceding reiterates two points: first, the property right arrangement for nonprofit hospitals to encourage and further charitable, public purposes; and 
second, forprofit hospitals will attempt to avoid activities (Note: Administrative decision-makers in the forprofit hospital are accountable to stockholders.) which are non-revenue producing (unless there are government subsidies for them). These phenomena are functions of the socio-political-legal-economic arrangement today in the health care environment. Perhaps things would have been different if the situation were reversed -- if federal and property tax exemptions, tax-exempt bonds for financing capital expenditures, and charitable donations were assigned to forprofit hospitals also. This would make the playing field equal and the pure analysis of hospital behavior in the light of property rights may allow causal 1 inkage.

Recent changes in health care policies, though, create new pressures for cost control and moderation in charges -- to which both types of hospitals must adapt. Numerous studies in the literature examined the hospital environment before the inception of the Tax Equity and Fiscal Responsibiltiy Act of 1982. So although these studies give us insight into relevant variables which might be considered in future studies, applicability in today's competitive environment is 1 imited.

The discussion in the following chapter focuses on the framework for analyses of hospital behavior under 
DRGs to test implications of the property rights theory to efficiency, equity, and quality of care. 


\section{CHAPTER I I I}

FRAMEWORK FOR ANALYSIS

In relating the differences of property right arrangements to hospital ownership status, data are examined to determine whether or not significant differences exist among nonprofit, government, and forprofit hospitals in the context of efficiency, equity, and quality of care. The schematic diagram below illustrates the analysis:

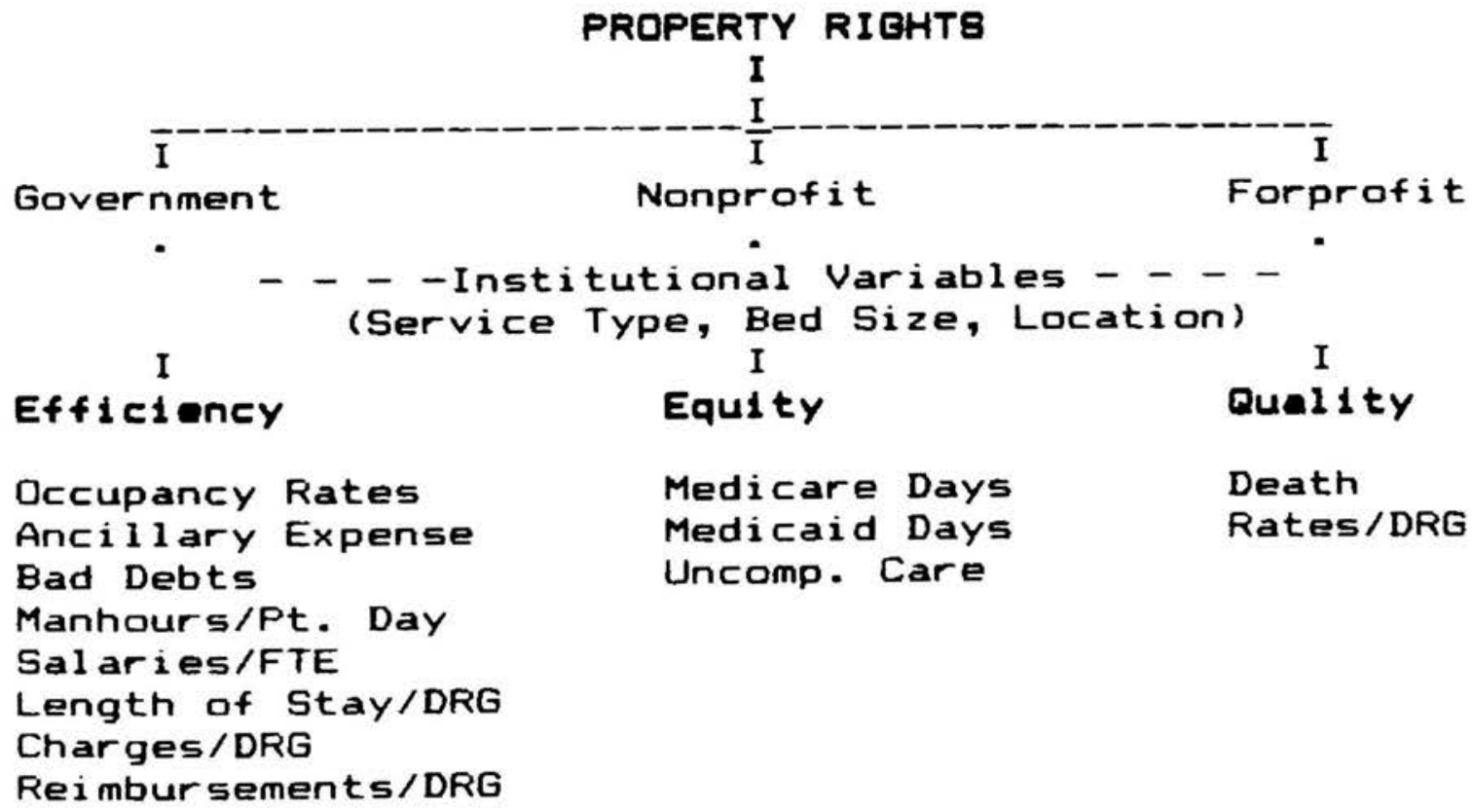

I

Efficiency

Equity

Qual 1 ty

Occupancy Rates Ancil 11 ary Expense Bad Debts Medicare Days Medicaid Days Uncomp. Care

Death

Rates/DRG

Manhours/Pt. Day

Sal aries/FTE

Length of Stay/DRG

Charges/DRG

Reimbursements/DRG 
The intent here, is to derive and test implications about differences in hospital behavior in the context of efficiency, equity, and quality. The differences in property right arrangements are explained as: rights to residual profits in the forprofit hospitals, and the tax exemption status on the part of nonprofit and government hospitals. This tax exemption status is tied in to the obligation to serve charitable purposes in the public interest.

There is reason to believe that the rights to residual profits in the forprofit sector might result in greater efficiency. The immediate effects of profit maximization is considered an incentive for managers in the forprofit hospital. Thus, performance of the forprofits compared to nonprofit and government hospitals may be different. The indicators of efficiency might be reflected as: increased occupancy rates, decreased ancillary expenditures, decreased bad debts, decreased manhours per patient day, higher salaries per FTE, decreased average length of stay per DRG, increased charges per DRG, and higher reimbursements per DRG.

The goals and social obligations attached to the 
tax-exemption status can be argued as the underlying rationale for output maximization, i. e. maximizing benefits to society by serving more patients. To examine the behavior of hospitals in this regard, equity variables are used. These are the number of Medicare days, the number of Medicaid days, and the amount of uncompensated care provided. The nonprofit and government hospitals are expected to have higher Medicare and Medicaid days, as well as provide more uncompensated care. Let us consider some possible interactions among these variables.

Nonprofit and government hospitals, along the lines of output maximization, might be seen with larger bed size, consequently these hospitals might be expected to have higher occupancy rates, ancillary expenses, bad debts, manhours per patient day, lower salaries per FTE, longer lengths of stay per DRG, lower charges per DRG, and lower reimbursements per DRG. The expectation that nonprofit and government hospitals should provide services to Medicare and Medicaid patients as well as uncompensated care might lead to increased occupancy rates, ancillary expenses, bad debts, manhours, and longer lengths of stay. On the other hand, forprofit hospitals with lower bed capacities might be observed with lower Medicare days, Medicaid days, and 
uncompensated care which impact on occupancy rates, the amount of ancillary expenses, and bad debts.

The quality of care delivered in nonprofit, government, and forprofit hospitals is seen as a function of regulatory requirements and the fiduciary responsibility that rests on hospital decision makers. A certain level of quality is conceptualized as similar among hospitals regardless of ownership status since: (1) a standard level of care is mandated by government agencies such as the Department of Health and Rehabilitative Services; (2) that for purposes of this study using death rates per DRG as an indicator -- an exceptional rise in death rates will bring investigations and affect hospital reputation adversely; and lastly, (3) the extent of services requiresexpenditures which are under budgetary constraints (such as DRGs) for all hospital types.

The following discussion will explain the rationale and justification for the variables used in this analysis in seeking evidence in support of the property rights theory.

\section{Institutional Variables}

Hospitals differ in many repects other than ownership. These are in terms of services offered, bed 
size and location.

Types of services. Hospitals may offer specialty services such as rehabilitation, psychiatry, general, or pediatrics. Services hospitals provide may vary or may be 1 imited to a certain extent for reasons such as in the case of the forprofit hospital): (1) certain services may be unprofitable, (2) certain services may require more resources (human, capital, equipment, technology), or certain types of resources specific to the service. The existence of appropriate types of equipment and technology parallels the services offered in a hospital i. e. whether it is a specialty hospital (rehabilitation, psychiatry, or pediatric) or if it offers acute or long-term care.

This analysis will focus on acute care, general hospitals only. Further controls for types of patients treated are necessary. Consequently, the top twenty DRG categories common to all hospitals in the study will be used.

$$
\text { DRGs are a classification system which groups }
$$
similar types of patients together based upon diagnostic and therapeutic characteristics. Each DRG is intended to imply equal resource consumption for patients belonging to a certain category. Numerous arguments 
have been raised by the medical and hospital community against the validity of using the classification system to assign payments.

One of the major points raised in most empirical analyses of hospitals is severity of illness, that DRG assignments are not specific enough. Let us analyze the major patient data elements which affect the DRG assignment and provide justification for its use (CFR, 1985). There are six of them: (1) Principal

Diagnosis: the condition established after study to chiefly responsible for the admission of the patient to the hospital for care. The principal diagnosis is utilized to identify the appropriate major diagnostic category (MDC). MDCs are organized by body systems. (2) Operating Room/Surgical Procedure: is a major decision point in DRG assignment. An operating room procedure differentiates the type of resources a patient receives and generally denotes a higher reimbursement. Every MDC (except no. 15 and 20) is split into surgical or medical groups based upon the presence or absence of an operating room procedure. (3) Age: affects 254 of 467 reimbursable DRGs. There are three major categories applied: $0-17 \& 18$ pediatric and adult age distinction; $0-69 \& 70$ most common age division; and o-35 \& 36 applicable only to diabetes patients; DRG 294 
and 295. Age groupings are significant in that medical resource consumption will vary dependent upon patient age. (4) Complications/Co-Morbidities are defined as secondary conditions which increase the patients' length of stay by at least 1 day in $75 \%$ of the patients. A separate complications/co-morbidities 1 ist has been developed for DRG assignment in 210 of 467 DRGs. (5) Sex is a determinant of DRG assignment when a specific DRG affects only one type of sex. (6) Discharge Status (expired, transferred to an acute care facility, or leaving a hospital against medical advice) affects only DRG assignments in MDC 5 (Diseases and Disorders of the Circulatory System), 15 (Newborns and Other Neonates with Conditions Originating in the Perinatal Period), 20 (Substance Abuse and Substance Induced Organic Mental Disorders) and 22 (Burns). The complexity of the classification is obvious. Analysis of hospital behavior is made difficult because of differences in outputs or products produced. The use of the top twenty DRGs common to all hospitals will allow a common ground for comparison.

The types of services each hospital offers is controlled for in this study by means of selection (i.e. only acute care, general hospitals will be included) and 
through analyses of the twenty diagnosis related groups common to all hospitals for the variables length of stay, charges per DRG, reimbursements per DRG, and death rates per DRG.

Bed Size [BEDS - Hypothesis A1].

A-1Ho: There are no differences among nonprofit, government, and forprofit hospitals in terms of bed size.

A-1H1: There are differences among nonprofit, government, and forprofit hospitals in terms of bed size.

Selectivity in the size of the hospital has been demonstrated in previous studies (Ferber, 1971). In the State of Florida, there are a total of 50,736 total beds. Of these nonprofit hospitals have 23,471 , government hospitals have 11,045, and forprofit hospitals have 15,720 beds (HCCB, 1984). American Hospital Association (1984) national data for the State of Florida showed that of 252 hospitals, there were 74 hospitals with bed capacities less than 100, 73 with 100199 beds, and 43 with 200-299 beds. Of these 85 were nonprofit, 57 were government, and 73 were investorowned (acute care, general hospitals). The mean bed size for acute care, general hospitals in florida is 257. Both nonprofit and government hospitals are larger 
with mean bed capacities of 381 and 375 respectively. In contrast, the forprofit hospitals were significantly smaller with mean bed size of 213 (Sorrentino, 1985). Bed capacity variation among hospitals also imply differences in resource requirements. It was made clear on page 29 that bed size is related to differences in facilities, services offered, hospital costs, and resources used (Ferber, 1971; Berry, 1973; Pattison and Katz, 1983). Small hospitals will tend to use less resources than would a large medical center. There is reason to suspect that forprofit hospitals may limit bed size. With output maximization, nonprofit and government hospitals would expand their services and thus have more beds (See pages 24-26). Property rights theory leads us to suspect this in regard to bed size. Thus, bed size remains an interesting and important institutional variable in the study of hospital behavior.

Location [LOC - Hypothesis A2]. A-2Ho: There are no differences among nonprofit, government, and forprofit hospitals in terms of location. A-2H1: There are differences among nonprofit, government, and forprofit hospitals in terms of 
location.

Rural counties are characterized by low population density and assumed to have shortages of both health manpower and health service delivery systems. The sparse population in the rural areas might make it less attractive to private forprofit investors to build hospitals there. On the other hand, one could argue that there is less competition in these areas (as compared to the urban areas). In this case, one can dictate the pricing system for health services and control the market. Another aspect of this would be attracting enough manpower (MDs and Nurses) to provide the service. A rationale for migration to these areas has been offered in that there would be greater opportunities for advancement because competition is 1ess, MDs may have lower malpractice insurance costs and it may be easier to obtain medical staff privileges in these hospitals. The urban poor population in inner cities do have problems as well. For example, the mortality rate for infants in urban poverty areas is $50 \%$ higher than in nonpoverty areas (Rudov and Santangelo, 1979). The health needs also differ because of the prevalence of certain diseases in particular areas. Tuberculosis is three times more prevalent in poverty areas; young adults and middle-aged people earning less 
than $\$ 5000$ per year had $30 \%$ more chronic illness and $50 \%$ higher rates of diabetes, hypertension, and visual impairment than people in the same age cohort earning more than $\$ 5000$ and that disability is strongly correlated with poverty. Additionally, making informed decisions regarding health needs for the urban poor is unlikely. Lack of knowledge regarding disease risk factors and medical services offer a serious impediment to the urban poor (Kane, et. al., 1979).

It has been shown in the literature that forprofit hospitals do not avoid counties with relatively high poverty or nonwhite populations. More forprofit hospitals (compared to nonprofit hospitals) are located in counties with slightly higher rates of poverty and nonwhite populations (Watt, et. al., 1986). These differences, though, were not statistically significant. Property rights theory would lead us to suspect that profit-driven hospitals may select locations where there is a profitable market for services; this study will test for this.

The institutional variables service type, bed size, and location have been described and the rationale for their use specified. In particular, the population selection and subsequent analyses of hospitals on the 
different dependent variables using the institutional variables as controls are explained in the methodology section.

\section{Efficiancy Variablas}

Property right arrangements and ownership status are related to the variables identified in the context of efficiency. Controlling variables for these analyses will be discussed in the methodology section. The following hypotheses will be tested: B-Ho: There are no differences among nonprofit, government, and forprofit hospitals on occupancy rates [B1Ho], ancillary expences [B2Ho], bad debts [B3Ho], manhours per patient day [B4Ho], salaries per FTE [BSHo], lengths of stay per DRG [B6Ho], charges per DRG [B7HO], and reimbursements per DRG [B8Ho]. B-H1: There are differences among nonprofit, government, and forprofit hospitals on accupancy rates [B1H1], ancillary expences [B2H1], bad debts [B3H1], manhours per patient day [B4H1], salaries per FTE [B5H1], lengths of stay per DRG [B6H13, charges per DRG [B7H1], and reimbursements per DRG [B8H1].

There are certain expectations regarding differences in hospital behavior related to ownership status. One is that economic incentives in the 
forprofit hospital may be associated with efficient use of resources. The other is that while rights to residuals do not exist for the nonprofit and government hospital, there may be other reasons why there may be nonefficient production in the nonprofit hospital (Note pages 14-19).

It must be clarified that contrary to its nomenclature, nonprofit hospitals are not restricted from earning profits. It is the prohibition of the right to residual by organizational members that account for the fundamental distinction. No individual, including the board, can exercise "ownership rights" in the hospital's assets as shareholders. As previously proposed, it is this restraint of ownership rights to residual profits that accounts for operational differences among nonprofit, government, and forprofit hospitals. As mentioned earlier, Clarkson (1972) identified different constraints, distribution of work effort, information use, and variable input selection that account for differences in hospital performance. There is reason to believe that the present regulatory environment with changed incentives for all hospitals regardless of ownership status will encourage the efficient use of resources. This will be reflected and seen in several variables used as indicators of 
efficiency in this study. At this point, the direction of these differences will not be discussed. As we uncover evidence in this regard, further analysis to determine whether one hospital type is more efficient than another (using the variable applicable in this regard) will be done.

The literature cited is replete with studies that predate DRGs. In a regulated environment that encourages hospitals to deliver care at a cost which meets or does not exceed fixed reimbursement, the scenario becomes interesting. The reason is that nonprofit and government hospitals may not have rights to residual profits but the budget constraints with DRGs may act as a pressure to limit services and expenditures. This means that the ability of these hospitals to provide services can only be maximized to the extent allowed by their budget. The hospital behavior is now examined in the context of efficiency by looking at the following variables: occupancy rates, ancillary expenses, bad debts, manhours per patient day, salaries per FTE, length of stay per DRG (on twenty DRGs), charges per DRG (on twenty DRGs), and reimbursements per DRG (on twenty DRGs).

$$
\text { Occupancy Rates [OCC - Hypothesis B1]. Occupancy }
$$


rates reflect the number of patients occupying the hospitals beds throughout the year. It is the seasonal character of hospital occupancy in Florida that make for lower occupancy rates during the summer in some areas. In 1984, occupancy levels in Florida declined from $73.6 \%$ in 1983 to $73.0 \%$ in 1984. However, this 1984 occupancy level remains higher than 1979 occupancy levels (68.5\%) in the State (HCCB, 1984). In 1985, mean accupancy rates for acute care, general hospitals with 100 beds and over in Florida $(\mathrm{N}=160)$ was $64 \%$ (Sorrentino, 1985).

An indicator of economic performance, occupancy rates have long been used to make projections regarding a hospital's ability to meet break-even points, operational losses, or profits. Consequently, forprofit hospitals would attempt to maximize their occupancy rates to maintain a reasonable level of profitability. The nonprofit and government hospitals would attempt to ensure that their occupancy rates are maintained at a level where outputs are maximized subject to budgetary constraints.

Ancillary Expenses [ANCI - Hypothesis B2].

Forprofits are entitled to saleability of rights, as well as sharing of profits made (as incentives to minimize expenses and gain profits). In the provision of inpatient services, costs for ancillary services and 
their utilization can be allowed to reach either a break even point or lowered (where professional standards of care are met and potential threats to 1 awsuits or patient safety avoided), ensuring profits (Ancillary Expenses used as an indicator). Ancillary services include diagnostic or therapeutic services performed by specific departments as distinguished from general or routine patient care such as room and board. Generally, ancillary services are those special services for which charges are customarily made in addition to routine charges and include services such as laboratory, radiology, and surgical services (HCCB, 1985).

If forprofit hospitals are to gain profits, they may decrease use of ancillary services to minimize costs of production. Nonprofit and government hospitals do not necessarily have to make profits but reimbursement constraints limit utilization of ancillary services to the point allowable under DRG rules. More importantly, budgetary constraints also limit appropriations for certain services in the government hospital. The earlier discussion on the relationship of basic services, complexity and extent of services offered, and increasing costs per patient day (Berry, 1973) points to the fact that the production of goods at 
a fair market value depends on expenditures incurred. In the study cited earlier (Watt, 1986), you will recall that the findings suggested that total charges and net revenues per case were higher in investor-owned chain hospitals due to higher charges for ancillary services. The analysis for this study does not look at ancillary charges per case because the relevance of charges have limited applicability when one considers a fixed-rate prospective payment system. When reimbursement to a hospital for expenses incurred is fixed, then a profitmaximizing toospital, in theory, will minimize expenses to insure profitability. Thus, looking at overall expenditures for ancillary services offered per hospital over one year will allow us to see if this behavior is true of forprofit hospitals.

Bad Debts [DEBT - Hypothesis B3]. The payment for health care incurred is obtained either through Medicare for the elderly, through Medicaid for the indigents, or through private insurance companies. Bad debts for nonMedicare patients is not an allowable cost under Medicare's cost-based reimbursement rules. If hospitals continue to provide care that is not paid for, these costs will have to be borne by themselves. Logically, the hospital may limit services only to those able to pay. Some hospitals may elect not to accept "charity" 
patients or may set quotas. This has occurred in south Florida where it is alledged that some investor-owned hospitals have dumped Medicare, Medicaid, and charity patients on the nonprofit hospitals (Johnson, 1982 and Demkovich, 1982).

The financing of health care for those who are unable to pay depends on the resources of health care providers. Current reimbursement rules today reflect the shift of responsibility for care away from the public sector Government hospitals are considered providers of health care). Thus, there is tremendous concern for the behavior of hospitals, particularly the forprofits as they attempt to recover costs and generate profits. The amount of bad debts expressed as a revenue deduction (percentage) will be examined here to understand hospital behavior among nonprofit, government, and forprofits.

\section{Manhours Per Fatient Day [HoUR - Hypothesis B4].} Human resources utilized in hospitals vary but because there are 1 imitations on practice of nurses (the largest member of the hospital workforce) through the Nurse Practice Act, inspection and reviews by the Department of Health and Rehabilitative Services (HRS) ensure and safeguard patient safety, and compliance with 
accreditation standards of the Joint Commission on Accreditation of Hospitals (JCAH), hospitals are not at a liberty to hire the cheapest and the least number of personnel. Forprofit hospitals have been theorized to minimize costs to ensure profits. It has been supposed that there are incentives in the forprofit hospitals for its decision-makers/managers to ensure decreased cost because of potential rewards in the form of profit-sharing, salary increases, or promotions. This incentive of immediate wealth effects in the forprofit institution has been pointed out in earlier literature (Alchian, 1969). To the contrary, there is no immediate wealth effect in the nonprofit hospital because of the constraints on rights to residual (Clarkson, 1972).

The attempt to decrease cost is approached in terms of manpower and salaries since the hospital industry is labor-intensive. It can be argued that the forprofit hospital will attempt to decrease cost assaciated with manpower to a point where they are in compliance with the appropriate agencies and where the quality of care does not jeopardize patient safety. Unusually high death rates has been used as a broad indicator. In this study, Death Rates per DRG will be examined later.

The nonprofit and government hospitals may not make profit but theoretically would have to ensure that 
costs and expenditures do not exceed revenues (Davis, 1972). Thus, the number of manhours per patient day in nonprofit and government hospitals may reflect expansion of services subject to budgetary constraints. In theory, we said that this expectation is a natural extension of increasing output to maximize benefits to saciety.

\section{Salaries per FTE [SAL - Hypothesis B5]. Since} providing health care is labor intensive, nurses and allied health staff are necessary on a 24-hour basis, seven days a week. Limiting types of services would be an indirect way of decreasing labor requirements up to the point where quality of care ensures patient safety and meets accepted standards. In this study, we control for this by population selection, as well as statistical controls by using bed size as a covariate in statistical analysis. The analyses on the top twenty DRGs compares hospitals on similar products (types of patients) using charges per DRG as a measure of costs incurred by the hospital.

The forprofit hospitals may limit total number of employees (Manhoure per Patient Day), but offer higher salaries. Higher salaries may be indicative of distribution of residual profits. While the nonprofit 
hospital would not have similar incentives to curtail human resources, the argument has been posed that these hospitals' fiduciary motive is to ensure quality. Arguably, one can say that quantity of manpower does not necessarily mean quality. Also, there are JCAH and HRS standards which must be met by all hospitals regardless of ownership status. At a certain level, forprofit, nonprofit, and government hospitals would provide the quality of health services which does not reflect negatively towards the hospital ( as indicated by Death Rates por DRG). It has been alluded to earlier that there are economic incentives in the forprofit sector such as profit-sharing or bonuses, these tied to the property rights argument for ownership rights to residual. Thus, higher salaries may be used as an indicator of distribution of profits.

In the nonprofit and government hospitals, salary rates and position controls are subject to budget limits. The property rights theory would lead us to suspect that salaries in nonprofit and government hospitals would be lower than the forprofit hospitals because of this constraint in budget.

Length of Stay [STAY - Hypothesis B6], Charges [CHARG - Hypothesis B7], Reimbursements [REIM Hypothesis $\mathrm{B} 8 \mathrm{~J}$ on the top twenty DRGs common to all 
hospitals. Nonprofit and government hospitals by virtue of being larger in bed size, thus having more services than their forprofit counterpart, may be able to offer needed services to more patients. Arguably, one can say that restricting services to specific patient populations would be a deliberate way on the part of forprofits to ensure profitability (they may not offer obstetrical or nursery services, etc.) by offering only those services where they could recoup costs and get the most reimbursements. This may indeed be plausible given the Diagnosis Related Groupings (DRGs).

With the agreed upon social arrangements using an output maximization rationale, it can be expected that nonprofit and government hospitals would serve indigents (Medicaid patients) and the elderly (Medicare patients), regardless of the type of illness and ensure that quality of care meets accepted standards. This has been a justification for their existence: that certain health care needs are addressed. Additionally, purposes which advance public interest such as education and research have been mentioned. In this 1 ine of thinking, it has been a common perception that nonprofit and government hospitals provide care to patients whose illnesses are more severe. Therefore, their patients 
tend to stay longer and their occupancy rates remain high); that they are located in areas that are in greatest need; because greater demands for health care exist they would have a greater number of beds. As a function of size (being larger), they would have sufficient numbers of patients and provide a variety of services to allow for affiliation with university medical or nursing schools. It has been contended that a patient's stay may be longer in these hospitals by virtue of illness severity or to allow for clinical teaching-learning process to occur for residents, interns, and student nurses. Thus, the average length of stay per DRG is compared among nonprofit, government, and forprofit haspitals.

Charges made by each hospital per DRG will be compared. There are problems in using charges as an indicator of actual costs. Many financial analysts will contend that charges made by hospitals do not reflect actual costs incurred. In the case of the forprofits, it is assumed that their numbers are padded to recover costs, bad debts, or uncompensated care, or to generate profits. If this is true, then this might be reflected in the higher charges per DRG in the forprofit hospitals.

Forprofit hospitals do not receive tax deductible 
donations and must pay income and property taxes. Does this mean that patient charges in forprofit hospitals would be higher because these costs are passed on to the recipients of care? Alternatively, would patient charges be lower in the nonprofit and government hospitals since they receive tax exemptions, philantropic donations and grants? In the business world, one has to remain price competitive lassuming consumers have knowledge about price differences). It has been posed that forprofit hospitals treat nonprofit/government prices as the ceiling. Therefore, all three hospital types could have similar patient charges (per DRG).

Charges per DRG would reflect at least $30 \%$ of true costs in the delivery of care \& Note: This is a commonly accepted standard in the hospital industry.). With DRGs, even if a hospital tried to price its services high, reimbursements remain fixed. Because of the phase-in period aver three years for DRG-based reimbursements, patient charges per DRG remains an important variable to consider.

The amount reimbursed to the hospital is fixed according to the patient's discharge diagnosis. The creativity by which hospitals may maneuver to generate 
revenue reflects its ability to adjust its patient operations in the most cost-effective manner. The hospital which operates under DRGs could react in such a way that patients are properly classified in DRGs that will allow them to be reimbursed the most. Property rights theory will predict that forprofit hospitals will most likely behave in this manner.

Thus, we will examine the variables indicating efficiency: occupancy rates, ancillary expenses, bad debts, manhours per patient day, salaries per FTE, length of stay per DRG, charges per DRG, and reimbursements per DRG. Property right arrangements and ownership status have been related to the variables identified in the context of efficiency. The hypotheses will be tested as stated previously. As we uncover differences, further analyses on the direction of these differences and their significance will be done.

\section{Equity Variablas}

Medicare [CARE - Hypothesis C1], Medicaid [CAID Hypothesis C2], and Uncompensated Care [UNCOM Hypothesis [3]. The following hypotheses will be tested:

C-Ho: There are no differences among nonprofit, government, and forprofit hospitals in the number of 
Medicare days [C1Ho], Medicaid days [C2Ho], and Uncompensated Care [CJHo].

C-H1: There are differences among nonprofit, government, and forprofit hospitals in the number of Medicare days [C1H1], Medicaid days [C2H1], and Uncompensated Care [C3H1].

One philosophy of health care is that it is a right. Health care can be viewed in the class of basic liberties. John Rawls (1967) delineated two basic principles of justice: (1) that each person has an equal right to the most extensive total system of equal basic liberties; and (2) that social and economic inequities are to be arranged so that they are to the greatest benefit of the least advantaged. Assuming that the availability of health services is associated with better health, society should attempt to achieve an equality in the distribution of health services or an equality in physical, mental, and social well-being. Rawls (1971) has alluded to the satisfaction of the two principles of justice in a constitutional democracy through a government that regulates a free economy. In an economic orientation, the goals would be full employment, competition, price stability, and growth measured in terms of dollars. Health policy, along the same lines, will identify what is the socially 
acceptable health status of the citizens. In regulating health, the government attempts to control costs while improving quality and ensuring access.

The assumed role of the nonprofit and government hospital is to further public purpose (i. e. provision of care to the society's underprivileged--aged and poor reflected in the number of Medicare and Medicaid patients cared for). Attached to the tax exemption status is the necessity of fulfilling its charitable goals. As a consequence, nomprofit and government hospitals are seen as output maximizers. Property rights theory leads us to suspect that the nonprofit and government hospitals should have greater numbers of Medicare and Medicaid patients as compared to forprofit hospitals.

Uncompensated Care. One could suppose that nonprofit and government hospitals now have the increased burden of caring for the elderly and indigent patients lassuming forprofits decrease production of services to Medicare and Medicaid patients -particularly because Medicare patients are reimbursed under DFG limitations and Medicaid patients are sicker, requiring more resources). The costs of uncompensated care in the nonprofit and government hospitals 
might be different in comparison to their forprofit counterpart. There may be 1 imited care provided to those for whom financing is not available or by limiting the care provided to those for whom limits have been set on reimbursement.

The hypotheses have been stated preceding the thoughts we have regarding expected relationships of hospital behavior, given the implications of the property rights theory. Possibly, nonprofit and government hospitals are expected to provide for Medicare and Medicaid patients. However, because government monies are available for these patients, it would be logical to suppose that forprofit hospitals would see this as a market for certain services if reimbursed monies meet costs with an acceptable profit margin. All three hospital types are subject to HRS/JCAH certification, potential threats of malpractice suits, and moral-ethical obligations to preserve 1 ife, maintain health, and alleviate suffering. All must maintain patient safety and meet accepted standards of patient care. Previous 1 iterature cited alluded to the concept of nonprofit hospitals as output maximizers (Long, 1964; Klarman, 1965; Newhouse, 1970). As we examine the number of Medicare and Medicaid days in the three types of hospitals, the percentages of bad debts 
and uncompensated care, we take special note that further analyses may be needed upon uncovering significant differences.

\section{Ruality of Cara}

Death Rates Per DRG [Hypothesis-D]. There is a concern for quality of care delivered as emphasis on generating profits and decreasing costs are made and the role of the forprofit sector in the provision of services. The following hypothesis will be tested: D-1Ho: There are no differences among nonprofit, government, and forprofit hospitals on death rates per DRG.

D-1H1: There are differences among nonprofit, government, and forprofit hospitals on death rates per DRG.

The difficulty in this study is that various hospitals do not necessarily offer the exact same services. Service differences are further complicated by differences in the clientele who avail themselves of these products. The concepts relevant to the assessment of the quality of in-patient care in the hospital setting are discussed to justify the methodology appropriate for its evaluation.

Health care evaluation is complicated by the fact 
that "quality" is not easy to define much more quantified and measured. The importance of evaluating quality of care is repeatedly underscored when issues on pricing, access and availability are discussed. It becomes further clouded when quality is not operationally defined. Issues of quality and how it is defined is of initial importance prior to evaluation.

Payne ( 1967 ) defined quality of care as that level of excellence produced and documented in the process of diagnosis and therapy based on the best knowledge derived from science and the humanities, and which results in the least morbidity and mortality rates. Quality consists of the "goodness" or "badness" with respect to this dimension. He cautions that there is a multitude of possible dimensions and criteria which when used to define quality will have a profound influence on the approaches and methods one may employ in the assessment of medical care. DeGendt (1970) defined quality as the degree of conformity to preset standards and deals exlusively with patient care as contrasted to medical care or health care. Brook (1973) points out that the phrase quality of care is vague and has numerous emotional overlays but delineated that concern should be on thase measures of health components which 
can be altered by the medical care process and are considered indicators of quality of care.

The issue in providing care to the client (patient) in addition to cost is quality. Members of the medical and nursing professions have been trained with respect to the humanitarian ideals of providing the best possible care without regard for cost. With decreasing government subsidies to health care, clearly the health care providers are underfire to provide effective care with 1 imitations on cost. The problem of accountability for the actions of health care professionals is quite vague and fragmented. Both medicine and nursing practitioners are subject to state licensure laws. However, they do not have direct accountability, to the public for their actions and performance unlike our elected officials who are subject to public scrutiny. Hospitals, while subject to numerous federal and state controls, also do not have direct accountability to the public.

Assessing the quality of care given is difficult. Ideally it should include a study of inputs, pracesses, and outcomes in the provision of health care. Heydebrand (1973) and Georgopoulos (1962) have studied the relation of hospital structure to hospital performance. Thus, the relation of inputs to the 
outcome. Organizational inputs include resources -physical, financial, and human (physicians, nurses, and allied health employees). The relationship of resource utilization to hospital performance has been the subject of numerous economic studies of Feldstein (1971), Newhouse (1970), Pauly \& Redisch (1973), and Berry (1973). Efficiency issues are addressed in terms of costs incurred providing services. Hospital effectiveness of care delivered is reflected in the quality of the outcomes. Starfield (1973) identified five organizational variables which facilitate the patient care outcomes in the hospital. These are personnel, facilities and equipment, the organization's leadership - politics - planning - goals -control consumer invalvement, information, and finance. Donabedian (1966, 1968) notes the complexity of evaluating the quality of medical care and that issues such as availability of care (access and appropriateness); prevention; patient-physician relationship; client and provider satisfaction are crucial. He pointed out that quality measurement must include structural, procedural, and outcome components. The strengths and weaknesses of these are identified by Griffith (1978). Structural measures tend to advocate 
high quality but not guarantee it. Procedural measures are highly technical and specific. Outcome measures look at the end point; the difficulty lies in relating specific events to the outcome.

The view of hospitals as complex systems with defined, explicit purposes comes from the social science perspectives of Etzioni (1961), Blau and Scott (1962), and Perrow (1965). The relationships of various organization structures, attributes, or goals to determining organizational effectiveness, or the quality of care have been studied in one form or another by numerous researchers. Shortell and Brown (1976) reviewed 19 comparative empirical studies of hospitals and classified these organizational variables into six major categories. These are: the environment, goals, technology, decision-making structure, reward system, and modes of coordination.

Moseley and Grimes (1976) presented an analytical framework to measure the hospital effectiveness. There were two broad measures: (1) patient care measures and (2) administrative measures. Under these were structural, process, outcome, and attitudinal measures. At best, outcome measures of quality of care are the most important indicators. Diagnostic specific mortality and morbidity rates have been useful in 
determining needs for specific services. When used in comparative studies, this is useful in determining effectiveness of different treatments. While this can be done, an important consideration is how severe an illness suffered is and how the quality of life is after discharge, if death did not occur. Morbidity and mortality statistics are helpful and continue to be an important element of medical care appraisal.

To measure quality, the indicator used for purposes of this study will be DRG specific death rates expressed as a percentage of deaths over one year statistically controlling for the number of discharges per DRG category. In the literature review, we mention the conspicuous production theory of the nonprofit firm (Lin, 1971) which models the hospital with decision makers who are driven by prestige and work towards transforming their organization into its "desired status (prestigious)." Newhouse (1970) reiterated a similar argument but extended this to include quality and quantity. In our model here, death rates per DRG is used as a criterion to indicate that level of quality that all hospitals meet. Regardless of ownership status, all hospitals are under regulatory constraints, fear of malpractice suits, and have the potential threat 
to the hospital's reputation or status.

As presented in the preceding pages, the framework for this analysis include institutional variables such as bed size and location. Efficiency variables are measured in terms of occupancy rates, ancillary expenses, bad debts, manhours per patient day, salaries per FTE, average length of stay per DRG, charges per DRG, and reimbursements per DRG. As measures of equity, the number of Medicare and Medicaid patients days will be examined; also, the amount of uncompensated care expenditures will be included in the analysis. As an indicator of quality, death rates per DRG among nonprofit, government, and forprofit hospitals are compared.

The succeeding chapter will describe the methods used for this study. It describes the selection of the population, data management, and data analysis. 


\section{CHAPTER IV}

\section{METHODOLOGY}

In the preceding chapter, the framework for analysis was described and several hypotheses were stated. The study population, data management, and statistical methods for analysis will be described in the following pages.

Study Population. In selecting the study setting, there were numerous limitations related to logistics as well as our present knowledge of the hospital setting. The State of Florida is one of the sun-belt regions where growth of both nonprofit and forprofit hospitals has been observed. Most notably, Florida has $44 \%$ of forprofit hospitals as a percentage of nonfederal shortterm general hospitals, second only to the state of Nevada with 50\% (AHA, 1984; FAH, 1984). The attractiveness of Florida to retirees means that enrollees in Medicare will be substantial. This is important because DRG reimbursement rules apply to Medicare patients. Our analysis on the top twenty DRGs apply to Medicare patients only. Thus, a study setting 
in this area is appropriate. As of July, 1983 there were over $1.5 \mathrm{milli}$ on persans enrolled in Medicare (Florida Statistical Abstract 1985). There is a clear preference by forprofit haspitals for areas such as Florida. Preferred locations are those noted to be with greatest increases in per capita income and population and widespread insurance coverage (Mullner and Hadley, 1984). Some of these considerations make florida ideal as the setting for this study.

The area of South Florida with three counties [Palm Beach, Broward, and Dade] is selected because of the availability of data for the variables under investigation. With $35 \%$ of hospitals with over 100 beds, offering acute, general care located in South Florida, the advantages of using the existing data set far outweighed extending the sampling throughout the State (considering the unavailability of data for other areas).

In South Florida, there are over half a million Medicare enrollees. There are 140,608 in Palm Beach, 212,293 in Broward, and 226,625 in Dade (FSA, 1986). This is important for this study since one focus of the analysis deals with the issue of equity measured in terms of the number of Medicare days, Medicaid days, and amounts of Uncompensated care. Considering this, let us look at the economic status in these areas. The median 
family income for Palm Beach for a family of two is $\$ 16,665$, and for a family of three, $\$ 19,817$. The percentage of families with incomes below the poverty level is 6.7. In Broward, the income for a family of two was $\$ 16,580$ and $\$ 19,592$ for a family of three. The percentage of families with incomes below poverty level was 6.3. In Dade, with incomes of $\$ 15,571$ for a family of two and $\$ 18,642$, the percentage of families with incomes below the poverty level was highest of the three counties at 11.9 (FSA, 1985).

The hospitals in the three counties which will be selected shall be those which offer acute care, general services with at least 100 beds. It was explained earlier that smaller bed size may account for certain services not being offered by a haspital. By virtue of the size, resource requirements would vary also. Therefore, population selection using a minimum bed size as a criterion is important. Fifty-six hospitals in south Florida met the preceding criteria.

Data Management. The data were obtained from the Hospital Cost Containment Board (HCCB) and the Professional Review Organization (PRO). Since the DRGbased reimbursement provision of the Tefra Act was signed in 1982, there was a three-year phase in period for all hospitals. Hospitals ended their fiscal years differently, hence each hospital had a different base 
year. To ensure hospitals were at least one year under DRG-based reimbursement, 1984 data were obtained. The ideal study would track results over the entire phase-in period. However, data processing takes time. Medicare billing claims have not been completely processed and can not be made available for this study by the PRO. These PRO data were submitted by the hospitals to a Fiscal Intermediary who processed the claims. The Intermediary then provided the PRO with the electronic copy of the processed claim. The data passed through numerous edits and were in excess of $98 \%$ correct. The data for the following variables were derived from this report: average length of stay per DRG, average patient charges per DRG, average hospital reimbursement per DRG, and percent of death rates per DRG. The data from the Hospital Cost Containment Board were compiled from each hospital budget submitted to the Board for approval. These budgets are compiled annually and reports are published by the Board which are available for public information. Copies of the budgets were purchased from the Board. Data for specific variables under study were derived from these reports (Occupancy Rates, Ancillary Expenses, Bad Debts, Manhours per Patient Day, Salaries per FTE, Medicare, Medicaid, Uncompensated Care).

Data Analysis. The primary method for analyses of data is analysis of variance using the Statistical 
Package for the Social Sciences (SPSS). This program was run via Xerox mainframe computers at the Computer Services Division of the Miami Heart Institute. Because of limitations inherent in the computer hardware, the two data sets (1) 1984 PRO DRG data and (2) 1984 HCCB Budget data were entered under separate files.

The coding scheme utilized for hospitals by ownership was derived from the grouping system by the HCCB:

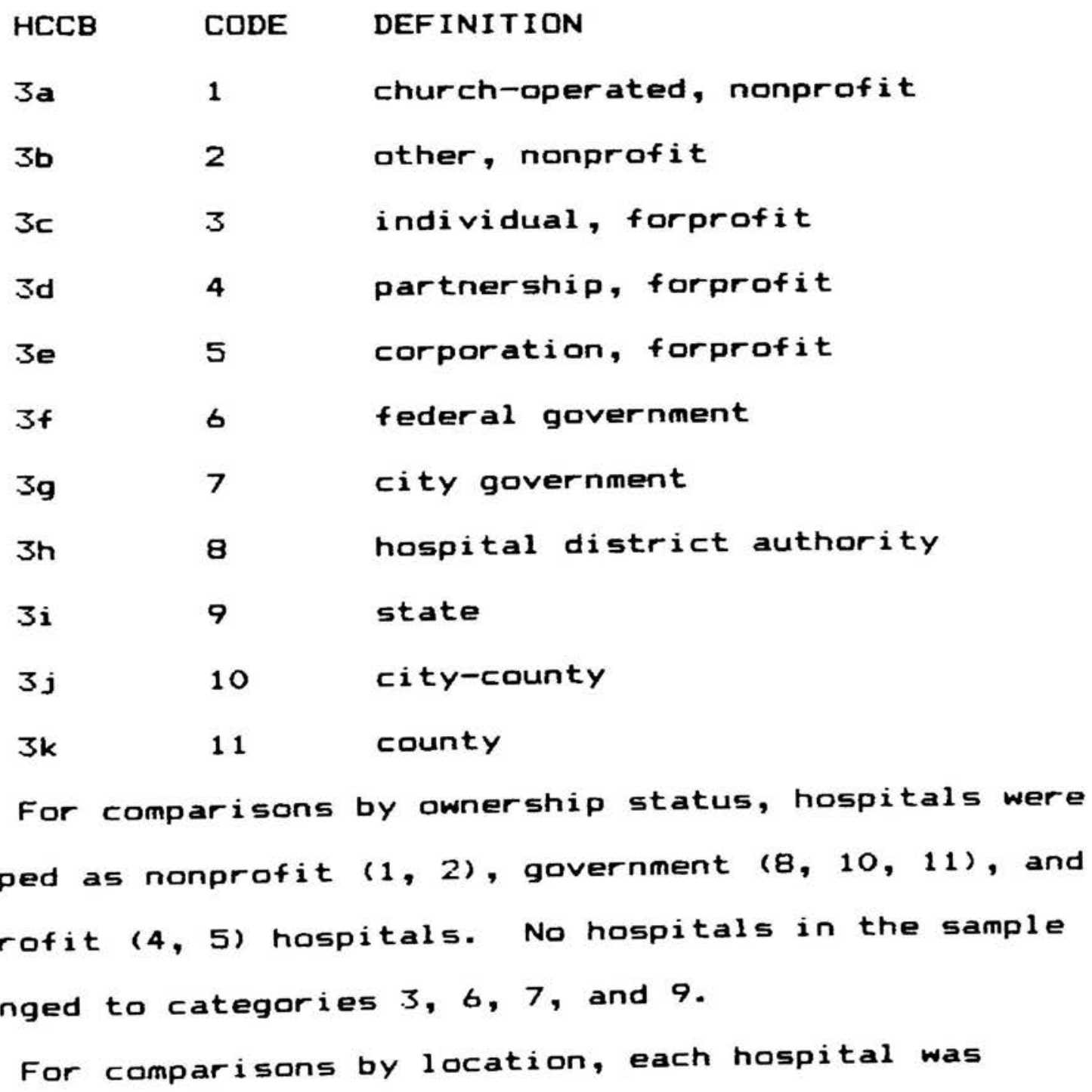


categorized according to its geographic area based on the standard Metropolitan Statistical Area (MSA). The following scheme was used for coding purposes:

$$
\begin{aligned}
& 10=\text { Palm Beach County } \\
& 20=\text { Broward County } \\
& 30=\text { Dade County }
\end{aligned}
$$

The statistical methods employed to analyze the data include the following:

(1) Descriptive Statistics were obtained by using subprogram Condescriptive, Frequencies, and Breakdown.

(2) The three hospital ownership types were compared on the Institutional Variables using one-way analysis of variance.

[ BEDS ] bY [ NONPROFIT, GOVERNMENT, FORPROFIT ]

[ LOC ] bY [ NONPROFIT, GOVERNMENT, FORPROFIT ]

(3) If necessary, dependent variables are compared on paired hospital ownership types, i. e. nonprofit vs. forprofit or forprofit vs. government.

For the analyses, involving the Efficiency Variables, the following ANOVA model was used for the hospital budget data comparisons:

[ OCC, ANCI, DEBT, HOUR, SAL ] BY

[ NONPROFIT, GOVERNMENT, FORPROFIT ] WITH

[ BEDS, LOC]

For the DRG data analysis of the top twenty DRGs, each DRG category was analyzed using the following 
model :

[ STAY, CHARGES, REIM PER DRG ] BY

[ NONPROFIT, GOVERNMENT, FORPROFIT ] WITH

[ DISCHARGES ]

For the analyses, involving the equity variables, the following ANOVA model was used for the hospital

budget data comparisons:

[ CARE, CAID, UNCOMP ] BY

[ NONPROFIT, GOVERNMENT, FORPROFIT ] WITH

[ BEDS, LOC ]

For the quality variable, analysis was done using the following madel:

[ DEATH RATES PER DRG ] BY

[ NONPROFIT, GOUERNMENT, FORPROFIT ] WITH

[ DISCHARGES ]

The fit of the model using bed size was judged better than the model using occupancy rates based on trial statistical analyses made using ANOVA, and later analysis of covariance. $R$ squares and ETAs were compared. In general, R-squares with [ BEDS ] rather than [ ocC ] as a covariate were higher. The tables report the F-scores for the ANOVA runs with [ BEDS ] and [ LOC ] as a covariate. Paired tests [ i. e. NP vs FP, etc ] used [ BEDS ] only as a covariate.

Using Options 7 and 10 of SPSS ANDVA, the effect of covariates was assessed concurrently with the factors. 
This option allows to remove (statistically) extraneous variation in the dependent variable that is attributable to covariates included in the model. This increases measurement precision. In this case, the decomposition of explained variance in the dependent variable would be quite similar to a regression analysis involving both metric and dummy variables as predictors. Each printout was examined in terms of main effects and the contribution of each factor to the overall significance of differences. Because the model used here is essentially a factorial design with unequal cell frequencies, the component sums of squares do not add up to the total sums of squares since the main effects and the interaction effects are not independent. Thus, even if the F-value for the additive model is significant, one or more of the factors may or may not be significant. Therefore, each F-value is examined for significance and the F-value for the specific factor (not the additive main effects) is reported in all the tables throughout the text. For interactions, covariate by factor analyses were processed. [ Note: Factors are the nonmetric categorical variable i. e. ownership status of hospitals: nonprofit, government, forprofit. Covariates are used to designate a metric independent variable i. e. number of beds or number of discharges. ] Hospital budget data analyses showed 
significant interaction effects. Consequently, multiple classification analyses become meaningless (Andrews, 1973; Nie, et. al., 1975). For analyses which do not show significant interaction effects, the deviations from the mean adjusted for independents and covariates are reported to clarify the directian (positive or negative deviation from the grand mean) of differences among nonproiit, government, and forprofit haspitals. Obtaining the data for all variables for different hospitals falling under specific ownership categories was limited to the South Florida area. Because the sample is small, statistical validity concerns arise. As in the case of this study, the criteria for hospital selection i. e. acute care only with 100 beds and over brought us fifty-six hospitals. Three ownership categories resulted to unequal cell sizes which complicate the use of ANOVA.

There are problems regarding the potential violation of the ANOVA assumptions such as normality of distribution and homogeneity of variance. To address this, nonparametric tests of significance were done on the budget data set using Mann-Whitney. The computation of the test statistic can be described as follows: The two samples are combined and assigned a rank from smaliest to 1 argest. The sum of ranks from the first population is obtained. If the location parameter of 
population 1 is smaller than the location parameter of population 2, we expect the sum of the ranks for population 1 to be smaller than the sum of the ranks for population 2, or vice versa. The test statistic is based on the rationale that depending on the null hypothesis, either a sufficiently small or a sufficiently large sum of ranks assigned to sample observations from population 1 causes us to reject the null hypothesis (Daniel, 1978).

The significance level of the results of MannWhitney tests are reported for each table comparing pairs of hospitals. It is important to note that MannWhitney analyses does not allow us to control for bed size or location. Thus, tables on paired tests report both ANOVA and Mann-Whitney results. In addition, ane government hospital outlier was dropped in separate analyses. These results are indicated as well.

Other appropriate tests of significance were also used where appropriate, such as Chi-square for the analyses on distribution of hospitals by location. Multiple regression analyses with and without dummy variables were used in certain instances. 


\section{CHAPTER $V$}

\section{REBULTB}

This chapter presents the study results following the framework for analysis presented in Chapter III.

\section{Institutional Variables}

Fifty-six hospitals met the criteria for inclusion in the study with reference to types of service offered. These hospitals offered acute care, general services and all have current 1 icenses required by governmental authorities having jurisdiction. The study population are subcategorized into nonprofit (21 hospitals: 1 church-operated, 20 non-church operated), government (8 hospitalse 1 county, 7 hospital district authority), and forprofit \& 27 hospitals: 2 partnership, 25 corporation owned). According to location, 18 percent of hospitals are located in Palm Beach; 32 percent in Broward; and 50 percent in Dade County.

Two hypotheses were advanced in Chapter III regarding bed size [A1], and location [A2]. We test these two hypotheses using analysis of variance. 


\section{Bed Size [ Hypothesis A1]. Table I shows that} government hospitals have the highest mean bed size of TABLE I: BED CAPACITY BY OWNERBHIP

QWNERSHIP

NONPROF IT

GOVERNMENT

FORPROF IT

GRAND MEAN
MEANS

338

450

246
F-gCORE

BIt.

R2

$$
310
$$

4.21 .02 .14

450 and forprofit hospitals with the least at 246 . The differences were statistically significant at $<.05$. Comparing the forprofit hospitals and the nonprofit hospitals only $[$ Mean $=286 ; F=5.91 ; 5 i g .=$ $.01 \mathrm{~J}$, the results show that differences were statistically significant. In comparing nonprofit hospitals and government hospitals, the results show no statistical significance [ Mean $=369 ; \mathrm{F}=1.34$; Sig. $=$ NS $\mathrm{J}$.

As cited previously, a study of 1985 data for 160 Florida hospitals, forprofit hospitals are significantly smaller (Sorrentino, 1985). This is consistent with the analysis of the 56 south Florida hospitals. Forprofits by virtue of their smaller size, thus, would have different resource requirements -- probably less if the 
property rights view is true. This further justifies the need to control for bed size in data analysis. Location [Hypothesis A2]. The tabulation on hospital location is shown in Table II.

TABLE II CRQBBTABULATION BY OWNERBHIP BY LOCATION

\begin{tabular}{lccc} 
OWNEREHIP & PALM BEACH & BROWARD & DADE \\
\hline NONPROFIT & 4 & 2 & 15 \\
\hline GQVERNMENT & 3 & 4 & 1 \\
\hline FORPROFIT & 3 & 12 & 12 \\
\hline PERCENT & 17.86 & 32.14 & 50.00 \\
\hline
\end{tabular}

Note the distribution of hospitals in the three counties by ownership status according to location. Dade County has the largest share of hospitals at $50 \%$, followed by Broward at $32 \%$. Differences in bed capacity by location were insignificant with the mean bed size in Palm Beach at 232, Broward at 310, and Dade at 337 ( See Table III).

To test $A 2$, analysis of variance showed the relationship of bed size by ownership status to location as significantly different at less than .05 ( $F=4.04$; $r-$ square $=.24$ ), note Table IV. Further analyzing the relationship, to test for differences in the number of hospitals by ownership type in the three geographic areas, chi-square test was done. The results of chi- 
TABLE III: BED CAPACITY BY LOCATION

\begin{tabular}{lllll} 
LOCATION & MEANB & F-gCORE & 8IO. & R2 \\
\hline PALM BEACH & 232 & & & \\
BROWARD & 310 & & & \\
DADE & 337 & & & \\
GRAND MEAN & 310 & 1.08 & $\mathrm{NB}$ & .04 \\
\hline
\end{tabular}

TABLE IVI BED CAPACITY BY OWNERBHIP GY LOCATION

DWNERBHIP

NONPROF IT

GOVERNMENT

FORPROFIT

GRAND MEAN
MEANS 338

450

246

310
F-SCDRE

BIE.

R2

square at 12.85 was significant at .01.

In Dade, there is a majority of nonprofit

hospitals. Both Dade and Broward have higher over age 65 population enrolled in Medicare 1227,729 for Dade and 215,873 for Broward; 147,242 for Palm Beach). Income levels for both Dade and Broward counties are lower than Palm Beach ( For a family of 3 average income in Palm Beach is $\$ 19,817$; Broward with $\$ 19,592$ : Dade with \$18,642). Note that there are more forprofit hospitals in Dade and Broward than in Palm Beach, even if the average income here is lower. It is important to 
consider, though, that population density may play a role in location preferences. Government hospitals, though, are seen in greater proportion in Palm Beach and Broward counties. In both areas, fewer nonprofit hospitals exist in proportion to Dade County (There are 12 nonprofit hospitals in Dade as opposed to 10 in Broward and 4 in Palm Beach). To illustrate this, note that in 1985, Dade ranked third in Florida in terms of population density with 900 persons per square mile or $15.59 \%$ of the State population. Broward ranked second with a population density of 928 persons per square mile or $9.96 \%$ of the state population. Palm Beach ranked tenth in the state with 358 persons per square mile or $6.32 \%$ of the state population. Qverall, hospital beds per person are highest in Dade County. The total beds per 100,000 persons are as follows: state $=456$; Dade $=$ 550; Broward $=514$; Palm Beach $=388$ (FSA, 1986). Conclusion. The study findings showed that government and nonprofit hospitals have larger bed size than forprofits. Chapter II and III explained why bed size differs among hospital ownership types. Specifically, we alluded to the profit maximization behaviar in the forprofit haspital by limiting resource requirements thru bed size limitations; the nonprofit and government hospital behavior point to output maximization. Property rights suggest output 
maximization in the nonprofit and government hospital because of the social obligations attached to their tax exemption status. These expectations mean that these hospitals would maximize quantity of service. In order to render services, the hospitals must have enough beds. Therefore, we see the larger bed size in the nonprofit and government hospitals (See discussion on pp. 29-31; 48-49). The evidence is consistent with the property rights argument.

The analyses on location show evidence in support of the property rights view. Location preferences by forprofit hospitals depend on barriers to entry such as certificate of need requirements and potential profitability in certain geographic areas depending on market share, competition, demand and health insurance reimbursement rules. In this regard, occupancy rates indicate hospital utilization which reflects the behavior of the hospital and is discussed in the latter pages. Because this study was done in one homogeneous area, the potential confounding variable of reimbursement rules is contralled for. Forprofit hospitals prefer to locate in areas where the hospital can project a reasonable census even during the summer months. The study results confirm this as shown in the population densities in Dade and Broward Counties and the preponderance of forprofit hospitals in these areas. 
It should be pointed out that in this study, the hospital age has not been explored. This is an interesting variable to consider from an institutional standpoint because of its potential role in what types of hospitals are built in certain locations. Particularly with newer hospitals, the restriction on where to build and how much to build may depend on what types and number of hospitals are already present in a locale.

Efficiency Variables

The tests for significance of differences were done following the model specified in Chapter IV. Bed size and location were used as covariates in the analyses for three categories.

\section{Qccupancy Rates [Hypothesis B1]. Table $V$ shows}

TABLE VI DCCUPANCY RATEB BY OWNERBHIP

OWNERBHIP MEAN MEDIAN F-SCORE SIG.

NONPROFIT 74.7

76.9

GOVERNMENT 7B. 7

79.6

FORPROF IT

66.6

65.6

GRAND MEAN 71.4 4.36 .01

significant results.

These findings are consistent with the findings for the entire state of Florida in 1985 (Sorrentino, 1985). Both nonprofit and government hospitals show higher 
occupancy rates. Further testing for differences, nonprofits were compared with forprofits. Significant differences were at the . OS level; note Table VI.

TABLE VII OCCUPANCY RATES BY OWNEREHIP

\begin{tabular}{lccc} 
& F-SCORE & $\begin{array}{c}\text { ANOVA } \\
8 I 0\end{array}$ & $\begin{array}{c}\text { M-W } \\
8 I B\end{array}$ \\
\hline NP VE FP & 4.88 & .05 & .052 \\
\hline NP VE G & .87 & NB & NB (N8*) \\
\hline FP VE G & 5.59 & $<.05$ & $<.05(.055 *)$
\end{tabular}

(*) Indicates Mann-Hhitney significance with one government hospitel outlier with over 900 beds onitted from the andysis.

Nonprofits have higher occupancy rates as compared to forprofit hospitals by $8.1 \%$. An implication cited earlier in this framework was that government hospitals and nonprofit hospitals may attempt to expand units of service, i.e. output maximization. When nonprofits were compared to government hospitals, no significant difference was found ( $F=.87)$. However, government hospitals had higher occupancy rates than nonprofits by $4 \%$. Forprofit hospital occupancy rates were lower in relation to the government hospital by $12.1 \%$.

Note the differences when examining median values. Testing these differences using Mann-Whitney analyses show that nonprofits compared to forprofits are not 
significantly different at the .05 level. Eliminating one government hospital outlier, forprofit hospitals compared to government hospitals did not show significant differences at the. Os level. Thus, using this sample in South Florida, we fail to find support for the property rights theory.

The forprofit hospital has been proposed to ensure profitability in two ways: (1) increase occupancy rates, and (2) reduce staffing levels and other associated expenses. The forprofit hospitals, on a national average consistently run lower occupancy rates (AHA, 1984). According to HCCB data on occupancy rates for all hospital types, occupancy rates are down $6.7 \%$ in the state as of the last half of 1985 (HCCB, 1985). Nonprofit and government hospitals showed significantly higher occupancy rates than forprofit hospitals (Sorrentino, 1985). This trend can be viewed as a product of increasing competition among hospitals rather than a failure on the part of forprofit hospitals to maximize utilization of hospital beds.

There is movement towards greater market competition among individual facilities within various areas. In Florida, the difficulty in examining interhospital competition vis-a-vis ownership type differences is complicated by the effect of population size on natural monopoly. In 1980, only seven of the 
nineteen Metropolitan Statistical Areas (MSAs) in Florida $(36.3 \%)$ continued to have $50 \%$ or more of all patient days delivered by a single institution. All nineteen MSAs, except for Tallahassee and Fort Walton Beach, showed declines in market shares. Miami, St. Fetersburg, and Fort Lauderdale all showed declines in the market share of the top four hospitals (FSA, 1986). These changes in hospital market structure are reflected in hospital ownership in the State; note Table VII.

TABLE VII: GTATE OF FLORIDA BEDE PATIENT DAYG AND HOBPITAL TYPE

\section{Bede}

\begin{tabular}{cccc}
1970 & $55.3 \%$ & $31.9 \%$ & $12.8 \%$ \\
\hline 1980 & 49.8 & 20.3 & 30.9 \\
\hline PCT. CHANGE & -6.5 & -11.6 & 18.1 \\
\hline
\end{tabular}

Patient Daye

\begin{tabular}{cccc}
1970 & 57.7 & 33.5 & 8.8 \\
\hline 1990 & 55.5 & 18.6 & 25.9 \\
\hline PCT. CHANGE & -2.2 & -14.9 & 17.1 \\
\hline
\end{tabular}

Hoepltele

\begin{tabular}{rrrr}
1970 & 48.7 & 27.9 & 23.4 \\
\hline 1990 & 42.5 & 17.1 & 40.3 \\
\hline PCT. CHANGE & -6.2 & -10.8 & 16.9 \\
\hline
\end{tabular}

In 1980 , the market share of forprofit hospitals 
was doubled (from $23.4 \%$ in 1970 to $40.3 \%$ in 1980 ). This reflects a $16.9 \%$ increase in a decade. Their share of beds grew by $141 \%$ and patient days by $194 \%$. The nonprofit and government hospitals lost market shares in all categories between 1970 and 1980 . The proportion of government hospitals decreased by $10.8 \%$, their market share of beds by $11.6 \%$, and the total patient days declined by $14.9 \%$. The nonprofit hospitals showed declines as well. So, when one looks at occupancy rate statistics, even if occupancy rates were higher in nonprofit and government institutions, despite controlling for bed size and location, it is important to consider the effect of increased competition. We need to consider the fact that even though forprofit hospitals have lower occupancy rates, it is possible that the types of patients occupying forprofit beds differ. A profit seeking hospital might prefer to have lower occupancy rates providing that services are reimbursed through private insurance or by the patients themselves paying out-of-pocket. Therefore, when examining occupancy rates, it is wise to investigate the differences in types of insurance payors, i. e. patients accupying beds who are Medicare recipients and under DRG reimbursements or patients who do not have the means to pay. The number of Medicare and Medicaid days will be examined later. In addition to this, the amount of bad 
debts incurred by the hospital is examined with the thought that caring for patients who do not have the means to pay might cause the hospital to have higher bad debts.

\section{Ancillary Expenses [Hypothesis B2]. Note Table}

VIII. Differences were significant at less than .01.

TABLE VIII, ANCILLARY EXPENBES BY OWNERBHIP

\begin{tabular}{lcccc} 
OWNERBHIP & MEAN & MEDIAN & F-BCORE & 8IE. \\
\hline NONPROFIT & 13.6 & 11.6 & & \\
GOVERNMENT & 19.1 & 12.4 & & \\
FORPROFIT & 8.0 & 7.4 & & $<.01$ \\
GRAND MEAN & 11.7 & & 49.48 & $<$
\end{tabular}

Hospital ownership types were paired to test if differences were significant; note Table IX.

TABLE IX: ANCILLARY EXPENBES

\begin{tabular}{|c|c|c|c|c|c|c|}
\hline & & & $\begin{array}{l}\text { ANDVA } \\
\text { F-BCORE }\end{array}$ & $\begin{array}{l}\text { ANOVA } \\
\text { BIG }\end{array}$ & $\begin{array}{l}M-W \\
\text { gIC }\end{array}$ & \\
\hline NP & $v e$ & Q & 16.67 & $<.01$ & NB & (NB*) \\
\hline FP & $v=$ & E & 53.34 & $\leq .01$ & NB & (NB*) \\
\hline NP & $v s$ & $F P$ & 38.56 & $<.01$ & .05 & \\
\hline
\end{tabular}

Analysis of variance results comparing mean differences show significance at <.01. Comparing nonprofit and government hospitals only, the results show that nonprofit hospitals spent less than the 
government hospitals $(\$ 5.5 \mathrm{mil}$.). Comparing the forprofits to gavernment hospitals, government hospitals spent more than forprofits by $\$ 11.1 \mathrm{million}$. Comparing nonprofit hospitals to forprofit hospitals, forprofits spent less by $\$ 5.6 \mathrm{million}$.

Mann-Whitney results comparing medians show nonprofits with lower ancillary expenses than government hospitals by $\$ .8 \mathrm{million}$; this is not significant. Forprofits compared to government hospitals were lower by $\$ 5.0 \mathrm{million}$; this is not statistically significant. Comparing nonprofits to forprofits, forprofits were lower by $\$ 4.2 \mathrm{million}$; this is statistically significant at. 05 .

This discrepancy in findings suggests that the distribution of ancillary expenses in government hospitals may not be normal. Also, bear in mind that Mann-Whitney analyses did not control for bed size and location.

To examine further what might explain these differences in ancillary expenses, attention should be given to the fact that ancillary expenses here are not broken down by disease category. At best it is a very gross measure. Let us analyze the relationship of this measure with several indicators in the study sample. Using multiple regression analysis, beds, the percentage of bad debts, uncompensated care, the number of Medicare 
days, and Medicaid days were used as predictors for ancillary services. The findings show $R$ square at $91.2 \%$ with beds (<.001), Medicare days (<.05), and Medicaid days (<.005) as statistically significant predictors. This finding is relevant in our analyses on hospital ownership. Clearly, this shows that bed size is a definite factor in determining ancillary service expenditures. We look into the possibility that the number of Medicare days and Medicaid days among three hospital types might contribute to the variation in ancillary expenses. Regression analysis is done with five predictors (nonprofit, government, bed size, Medicare days, and Medicaid days). No statistically significant difference was discerned on ownership categories. However, bed size, Medicare days, Medicaid days ( $t$-ratios $5.97,1.96,2.64$ respectively) were statistically significant predictors for ancillary expenses ( $R$ square $=91.3 \%$ ). We regress ancillary expenses on three predictors: bed size, nonprofit, and government hospitals (with forprofits used as a reference category). Our findings confirm beds as a statistically significant predictor with a t-ratio of 19.77 (R square $=90 \%)$. Nonprofit and government hospitals failed to show statistical significance. Note that in our earlier analysis we found higher occupancy rates in the government and nonprofit hospitals. 
Regression analysis is done with three predictors (occupancy rates, nonprofit, and government). We find that occupancy rates and government hospitals as statistically significant (t-ratios were 2.63 and 1.98 respectively). The $R$ square is $25 \%$..

The findings we have show that variations in ancillary expenses can be attributed to variations in bedsize, occupancy rates, Medicare days, and Medicaid days. The Mann-Whitney analysis showed significantly higher ancillary expenses in the nonprofit hospitals as compared to the forprofit hospitals. However, multiple regression analysis failed to show statistically significant differences between nonprofit/government hospitals compared to the forprofit hospital. This analysis of ancillary expenses failed to show support of the property rights theory.

Bad Debts [Hypothesis B3]. Table $X$ below shows statistically significant differences at less than . 01 . Government hospitals have the highest percent of bad

TABLE $X:$ BAD DEBTB BY OWNERBHIP

DWNERBHIP

NONPROF I T

GOVERNMENT

FORPROF IT

MEAN

3.78

10.48

3.91

4. 80
MEDIAN

3.20

9.55

3.30 
debts. Table XI shows the paired analyses. Comparing nonprofit hospitals with government hospitals, note that bad debts in the government hospitals were significantly higher (6.70\%). Compared to forprofit hospitals, forprofits have lower bad debts (-6.57\%) than government hospitals. See Table XI below:

TABLE XII BAD DEBTB

\begin{tabular}{|c|c|c|c|c|c|c|}
\hline & & & $\begin{array}{l}\text { ANQVA } \\
\text { F-BCORE }\end{array}$ & $\begin{array}{c}\text { ANOVA } \\
\text { BIE. }\end{array}$ & $\begin{array}{l}M-W \\
\text { BIO. }\end{array}$ & \\
\hline NP & $v e$ & B & 17.45 & $<.01$ & $<.01$ & $(<.01 *)$ \\
\hline FP & vS & G & 24.68 & $<.01$ & $<.01$ & $(<.01 *)$ \\
\hline NP & $v=$ & FP & .05 & NB & NB & \\
\hline
\end{tabular}

There appears to be a similarity between the nonprofit and forprofit hospital. Comparing nonprofit hospitals to forprofit hospitals in terms of bad debts, the difference was not statistically significant. This lends support for hospital behavior along the lines of the recovery of cost or meeting budget constraints for the nonprofit sector, and profit maximization in the forprofit sector. This could also be a reflection of output maximization in the government hospital. The similarity between nonprofit and forprofit hospitals on bad debts may suggest that some factor other than property rights could explain the difference. Lower bad debts may imply internal operations which facilitate 
processing of bills or the collection of unpaid ones. It could also mean that the patient clientele of the hospital are insured; therefore, bills are paid or they have patients who have the means to pay, and thus do not incur bad debts. Attempting to explore these possibilities, we regress bad debts on bed size, Medicare days, Medicaid days, and the percentage of uncompensated care. Our findings show that only uncompensated care was a statistically significant predictor (<.01). We will do further analysis on uncompensated care as an equity variable later. Manhours [Hypothesis B4]. Comparing all three hospital types controlling for bed size, differences were statistically significant at less than .01.

TABLE XII, MANHOURE PER PATIENT DAY BY OWNERSHIP

QWNERSHIP

NONPROF IT

GOVERNMENT

FORPROF IT

GRAND MEAN
MEANB MEDIAN F-SCORE

21.17

21.99

21.76

20.97

17.94

1日. 04

There were fewer manhours per patient day in the forprofit hospital. This was statistically significant compared to nonprofit and government hospitals (Table XII). 
TABLE XIIII MANHOURS PER PATIENT DAY

\begin{tabular}{|c|c|c|c|c|c|c|}
\hline & & & $\begin{array}{l}\text { ANOVA } \\
\text { F-BCORE }\end{array}$ & $\begin{array}{c}\text { ANQVA } \\
\text { BIE. }\end{array}$ & $\begin{array}{l}\text { M-W } \\
\text { BIE. }\end{array}$ & \\
\hline NP & $v e$ & $\mathbf{E}$ & .04 & $\mathbf{N B}$ & NS & (NB*) \\
\hline FP & $v e$ & $\mathbf{E}$ & 20.12 & $\leq .01$ & $<.01$ & $(<.01 *)$ \\
\hline NP & $v e$ & (FP) & 39.86 & $<.01$ & $<.01$ & \\
\hline
\end{tabular}

The difference was not significant between the nonprofit and the government hospital.

The importance of manhours in determining costs of delivering care is further exemplified as follows. In the analysis of 160 acute care general hospitals in the state of Florida using 1985 HCCB budget data, the number of manhours per patient day was demonstrated to be a significant predictor in the variation of average cost per patient day (DAYCOST) and average cost per admission (ADMCOST). Analysis of variance results (Note Table $X I V)$ shows manhour differences among nonprofit, government, and forprofit hospitals at 1 ess than . 01 (Sorrentino, 1985).

TABLE XIV: ANALYSIS OF VARIANCE RESULTS FOR 1985 DATA

\begin{tabular}{llll} 
VARIABLE & F-BCORE & SIE. & R2 \\
\hline DAYCOST & 2.93 & NS & .12 \\
\hline ADMCOST & 2.45 & NS & .42 \\
\hline MANHOURS & 26.26 & $<.01$ & .39 \\
\hline
\end{tabular}


A cost-conscious, profit-seeking hospital has been theorized to reduce manhours per patient day to reduce costs associated with labor. Multiple regression analysis was done using nonprofit, government, bed size, Medicare days, and Medicaid days as predictors. We find the $R$ square at $47.1 \%$. We confirmed differences in ownership categories but failed to see statistically significant t-ratios on bed size, Medicare days, and Medicaid days $(1.56,-1.06,-.62$ respectively).

Our results give support for cost-reducing behavior in the forprofit sector and this could also mean differences in services offered. You will recall that other goals such as education and research were identified with nonprofit and government hospitals. At the same time, there may be certain services provided to patients in government and nonprofit hospitals which could affect their resource requirements. Although the study population selected only hospitals offering acute care general services, within these groups of hospitals, there are other sources of variations such as whether or not a hospital has resources to allow specialty services such as open heart surgery. This type of surgical

procedure is resource intensive. It requires a specially trained staff of physicians, nurses, and technicians, as well as sophisticated operating rooms, cardiac catheterization laboratories, heart/lung bypass 
machines, intra-aortic counterpulsation devices, and hemodynamic monitoring of all cardiac function parameters. Let us examine closely, this aspect of service in the three hospital types.

As of 1986, there were twenty centers in Florida with capabilities to provide for open heart surgery. Nine hospitals in our study population for Dade County offer this service. Of these, seven (7) are nonprofit, one (1) government, and one (1) forprofit (The hospital used to be nonprofit until it was purchased by an investor-chain corporation.). In Dade County, from the period of January 1 to December 1, 1985, a total of 1874 open heart surgeries were performed (HCSF, 1986). Of these, nonprofit hospitals did $84 \%$ (1560), the government hospital did $11 \%$ (216), and the forprofit hospital did $5 \%$ (98). Actual cost to a hospital for doing these procedures are unobtainable. However, through personal communications, it was determined that the amounts reimbursed under DRG 1 imitations for a simple cardiac catheterization (required prior to open heart surgery) is only $\$ 6,935$ and for a coronary artery bypass graft is $\$ 16,314$. Administrators contend that in general, these patients are "money-losers" because more often than not, the patients require a longer hospitalization period than projected under DRGs. Obviously, forprofits will not have the incentive to 
perform this kind of procedure.

Each hospital was examined for the number of manhours per patient day. It was not surprising to find that the mean of 24.40 hours for these hospitals was statistically different from the grand mean of 20 for all hospitals in the study. Thus, a hospital that seeks to maximize profits would reduce costs by decreasing labor requirements. The obvious way, as we have seen here, is not to offer certain types of services that are resource intensive.

We analyze the data further in our study population, relating variation in manhours with ancillary expenses. Using multiple regression, we use ancillary services, nonprofit, and government as predictors for manhours. With an $R$ square of $48.4 \%$, we note that ancillary expenses, nonprofit, and government hospitals as statistically significant predictors of manhours ( $t$-ratios of $2.42,5.27,3.0$ respectively).

In sum, a forprofit hospital seeking to maximize profits may limit its services to those who do not require substantial resources that impinge on residual profits. From what is demonstrated at the micro level, it is notable that there is output maximization (in terms of cardiac surgeries) in the nonprofit hospitals. This finding also helps to explain hospital behavior using the "desired status" rationale by Lin (1971). As 
a high-tech procedure, one might say that open heart surgeries are "prestige enhancers."

In Chapter III, it was noted that reducing costs associated with labor would be a mechanism to maximize profits. Seeking proof of this, the salaries per FTE were compared.

Salaries per FTE [Hypothesis B5]. Here, the results were not significant. Note Table xV.

TABLE XVI BALARIES PER F. T. E. BY OWNERSHIP

\begin{tabular}{llll} 
OWNERSHIP & MEAN & MEDIAN & SIQ. \\
\hline NONPROFIT & 19792 & 20320 & \\
GOVERNMENT & 18654 & 19457 & \\
FORPROFIT & 19795 & 19260 & \\
GRAND MEAN & 19631 & & NS \\
\hline
\end{tabular}

Nonprofit hospital salaries were practically identical to forprofit salaries, but paid slightly more in comparison to government hospitals.

TABLE XVI: GALARIES PER F. T. E

\begin{tabular}{|c|c|c|c|c|c|c|c|}
\hline \multirow[b]{2}{*}{ NP } & \multirow[b]{2}{*}{$v e$} & \multirow[b]{2}{*}{ (G) } & \multirow{2}{*}{$\begin{array}{l}\text { ANOVA } \\
\text { F-BCORE } \\
3.25 \\
\end{array}$} & \multicolumn{2}{|c|}{$\begin{array}{c}\text { ANOVA } \\
\text { SIG. }\end{array}$} & \multicolumn{2}{|c|}{$\begin{array}{l}M-W \\
\text { SIG. }\end{array}$} \\
\hline & & & & NB & (NB) & NB & (NB) \\
\hline FP & $v e$ & (E) & 2.06 & NB & (NB) & NS & (NB) \\
\hline NP & $v e$ & (FP) & 0 & NB & & NE & \\
\hline
\end{tabular}


There is no support for the property rights position as it relates to salaries per FTE; note Table $X V I$. Although we did not find differences as to ownership categories, the comparisons by location did show statistically significant differences at <. 01 with Palm Beach having the lowest and Dade having the most. It is important to note, though, that there are other factors to consider, such as bonuses or profitsharing plans for administrative staff which are not reflected under salaries per FTE. Stock options, for example, can not be measured in terms of salaries per FTE.

In search of evidence of hospital behavior differences, using the top twenty DRGs for all the hospitals under study, the length of stay per DRG, charges per DRG, and reimbursements per DRG were analyzed yielding the following results.

Length of Stay per DRG [Hypothesis B6]. Note Table XVII showing all twenty DRGs by hospital ownerhip status. The findings show that only 7 of 20 DRGs $(35 \%)$ were significantly different in terms of length of stay. These were DRG 82 (Respiratory Neoplasms), DRG 140 (Angina), DRG 24.3 (Medical Back Problems), Drg 296 (Nutritional and Miscellaneous Metabolic Disorders; age over 69), DRG 320 (Kidney and Urinary Tract Infections; 
TABLE XVII, LENGTH OF STAY BY DRE BY OWNERBHIP

\begin{tabular}{|c|c|c|c|c|c|c|}
\hline DRG & $\begin{array}{l}\text { GRAND } \\
\text { MEAN }\end{array}$ & NONPROF & $\begin{array}{l}\text { ELL ME } \\
\text { BOVT }\end{array}$ & $\begin{array}{l}\text { EANB } \\
\text { FORPROF }\end{array}$ & F-8CORE & s10. R2 \\
\hline$\underline{14}$ & 10.46 & 10.89 & 10.95 & 9.94 & .84 & .07 \\
\hline 15 & 5.61 & 5.47 & 5.39 & 5.80 & .37 & .07 \\
\hline 82 & 8.70 & 9.70 & 9.98 & 7.46 & 3.59 & .18 \\
\hline 88 & 7.84 & 8.28 & 8.02 & 7.41 & 1.14 & .13 \\
\hline 89 & 9.49 & 9.70 & 9.12 & B. 80 & .47 & .32 \\
\hline 96 & 7.05 & 7.59 & 6.03 & 6.91 & 2.91 & .15 \\
\hline$\underline{122}$ & 9.25 & 9.54 & 8.85 & 9.13 & .46 & .18 \\
\hline$\underline{127}$ & 8.08 & 8.39 & 7.99 & 7.86 & 1.03 & $n=\quad .32$ \\
\hline 138 & 5.76 & 5.78 & 6.09 & 5.64 & .35 & ne $\quad .17$ \\
\hline 140 & 5.34 & 5.73 & 5.19 & 5.06 & 6.65 & $<.01 .32$ \\
\hline 148 & 16.38 & 16.07 & 14.51 & 17.22 & 1.73 & $n=\quad .22$ \\
\hline 174 & 6.71 & 6.98 & 5.92 & 6.73 & 1.50 & $n=\quad .18$ \\
\hline 182 & 5.70 & 5.62 & 5.75 & 5.76 & .10 & .07 \\
\hline 210 & 15.01 & 15.89 & 13.00 & 15.13 & 1.36 & .29 \\
\hline 243 & 7.45 & 7.96 & 6.35 & 7.36 & 4.18 & $.05 \quad .39$ \\
\hline 294 & 7.80 & 7.80 & 7.74 & 7.83 & .01 & $n=.18$ \\
\hline 296 & 7.72 & 6.95 & 9.79 & 7.73 & 4.85 & $.01 \quad .17$ \\
\hline 320 & 7.97 & 8.47 & 6.57 & 7.90 & 3.73 & .05 .26 \\
\hline 336 & 7.65 & 7.59 & 6.01 & B.21 & 3.36 & .05 .33 \\
\hline 468 & 14.44 & 13.83 & 21.50 & 12.79 & 6.81 & $<.01 .22$ \\
\hline
\end{tabular}


over 69 with complications and comorbidity), DRG 336 (Transurethral Prostatectomy; age over $69 \mathrm{with}$ complications and comorbidity), and DRG 468 (Unrelated Operating Room Procedure to a given Medical Diagnostic Category). On 13 out of 20 DRGs (65\%), the length of stay was not statistically different.

The analytical framework implied that government hospitals by virtue of their size may be able to offer needed services. This is consistent, as well, with the public interest motive or expansion of services to society. Note that on Table XVIII, government hospitals had the highest lengths of stay on five DRG categories, nonprofits were highest on ten DRG categories, and forprofits were highest in five DRG categories. We test for significance to see evidence of longer lengths of stay, even though with DRG reimbursement rules there is increased incentive to decrease lengths of stay. The DRG analysis was done on all DRGs where differences were significant [ DRG 82, 140, 243, 296, 320, 336, 468 ].

Controlling for the number of discharges per DRG, government hospitals were compared to nonprofit hospitals on length of stay (note Table XVIII). Statistically significant differences on DRG 296, 320 , and 468 were discerned with government hospitals having significantly higher lengths of stay in two DRGs only. 
TABLE XVIII: LENGTH OF BTAY BY DRG

\section{NONPROFIT VS. GQVERNMENT}

\begin{tabular}{|c|c|c|c|c|c|c|}
\hline DRG & MEANB & F-BCQRE & SIG. & R-SQ. & $\begin{array}{l}\text { ADJUETED } \\
\text { FOR INDEP. } \\
\text { NONPRQF. }\end{array}$ & $\begin{array}{l}\text { DEVIATIONB } \\
\text { \& CQVAR. } \\
\text { GOVT. }\end{array}$ \\
\hline 82 & 9.73 & .03 & NS & .10 & -.03 & .09 \\
\hline 140 & 5.58 & 2.47 & N8 & .09 & .13 & -.38 \\
\hline 243 & 7.53 & 3.78 & NB & .25 & .37 & -1.02 \\
\hline 296 & 7.70 & 6.67 & .01 & .21 & .77 & 2.11 \\
\hline 320 & 7.97 & 5.50 & $<.05$ & .20 & .47 & -1.29 \\
\hline 336 & 7.17 & 1.97 & NB & .07 & .39 & -1.97 \\
\hline 468 & 15.87 & 5.24 & $<.05$ & .17 & -2.02 & 5.55 \\
\hline
\end{tabular}

TABLE XIX: LENGTH DF STAY BY DRG

GQVERNMENT VB FORPROFIT

\begin{tabular}{|c|c|c|c|c|c|c|}
\hline DRG & MEANS & F-SCORE & SIG. & R-EQ. & $\begin{array}{l}\text { ADJUBTED D } \\
\text { FOR INDEP. } \\
\text { FORPROF. }\end{array}$ & $\begin{array}{l}\text { DEVIATIONB } \\
\text { \& COVAR. } \\
\text { COVT. }\end{array}$ \\
\hline 92 & 8.05 & 4.15 & .05 & .14 & -.66 & 2.16 \\
\hline 140 & 5.08 & .24 & N8 & .03 & -.02 & .09 \\
\hline 243 & 7.12 & 2.08 & $\mathrm{NB}$ & .18 & .24 & -.79 \\
\hline 296 & E. 21 & 4.43 & $<.05$ & .19 & -.52 & 1.70 \\
\hline 320 & 7.65 & 3.44 & NB & .13 & .32 & -1.04 \\
\hline 336 & 7.70 & 4.73 & $<.05$ & .15 & .53 & -1.73 \\
\hline 468 & 14.84 & 7.54 & $\leq .01$ & .21 & -2.25 & 7.31 \\
\hline
\end{tabular}

Significant differences were present in DRG 82, 296 , 336 , and 468 with government hospitals having longer 
lengths of stay in three DRGs $(82,296,468)$; note Table XIX.

The forprofits compared to government hospitals limit length of stay at statistically significant levels on three DRGs $(82,296,468)$. This behavior can be viewed as an effort to decrease costs, particularly when reimbursement 1 imits are in place. If a hospital consistently has their patients exceed allowable length of stay under DRGs, costs per patient day are bound to increase (See 1985 data: regression analysis reflect average length of stay as a significant predictor

TABLE $X X:$ LENGTH OF STAY BY DRE

FORPRQFIT VB. NONPROFIT

\begin{tabular}{|c|c|c|c|c|c|c|}
\hline DRQ & MEANS & F-BCQRE & BIO. & R-gn. & $\begin{array}{l}\text { ADJUETED } \\
\text { FOR INDEP. } \\
\text { FORPRDF. }\end{array}$ & $\begin{array}{l}\text { DEVIATIONB } \\
\text { \% COVAR. } \\
\text { NONPROF. }\end{array}$ \\
\hline 82 & 0.48 & 7.52 & $<.01$ & .16 & -1.16 & 1.37 \\
\hline 140 & 5.36 & 10.34 & $<.01$ & .19 & $=.29$ & .35 \\
\hline 243 & 7.63 & 2.79 & NB & .11 & -.22 & .26 \\
\hline 296 & 7.35 & 2. 88 & NB & .13 & .45 & -.53 \\
\hline 320 & 8.21 & 1.27 & N8 & .03 & -.24 & $.2 \theta$ \\
\hline 336 & 7.93 & 1.02 & NB & .04 & -.20 & -.24 \\
\hline 468 & 13.26 & .98 & NB & .15 & .001 & .001 \\
\hline
\end{tabular}

Sorrentino, 1985). The forprofits were compared to nonprofit hospitals (Table $X X$ ). Note that out of seven DRGs, there were only significant differences in two 
diagnostic categories. In comparison to the nonprofits, the lengths of stay were significantly lower in the forprofit hospitals on DRG categories 82 and 140.

In general, though, there were thirteen (13) DRGs which showed no statistically significant differences. Thus, with regard to length of stay by DRG, we fail to find evidence in support of the property rights view. Charges Per DRG. Note Table XXI. On 13 out of 20 DRGs (65\%), charges were statistically different among three hospital types. These DRGs were: DRG 15 (Transient Ischemic Attack), DRG 89 (Simple Pneumonia and Pleurisy, age over 69 with complications and comorbidity), DRG 127 ( Heart Failure, Shack), DRG 140 (Angina), DRG 148 (Major Small and Large Bowel Procedure, age over 69 with complications and comorbidity), DRG 174 (Gastrointestinal Hemorrhage, age over 69 with complications and comorbidity), DRG 182 (Esophageal, Gastrointestinal, Miscellaneous Digestive Disease, age over 69 with complications and comorbidity), DRG 210 (Hip and Femur Procedure, except major joint, age over 69 with complications and comorbidity), DRG 243 (Medical Back Problems), DRG 296 (Nutritional and miscellaneous Metabolic Disorders, age over 69 with complications and comorbidity), DRG 320 (Kidney and Urinary Tract Infections; age over 69 with complications and comorbidity), DRG 336 (Transurethral 
TABLE XXI, CHARGES BY DRG BY OWNERBHIP

\begin{tabular}{|c|c|c|c|c|c|c|}
\hline DRE & $\begin{array}{l}\text { GRAND } \\
\text { MEANB }\end{array}$ & NONPROF & $\begin{array}{l}\text { CELLL ' } \\
\text { GOVT }\end{array}$ & $\begin{array}{l}\text { ANE } \\
\text { FORPROF }\end{array}$ & F-8CORE & 810. \\
\hline$\underline{14}$ & $728 \theta$ & 7005 & 6920 & 7640 & .45 & .13 \\
\hline$\underline{15}$ & 3343 & 2984 & 2673 & 3053 & 4.16 & $.05 \quad .13$ \\
\hline 82 & 6008 & 5872 & 6386 & 6007 & .12 & .09 \\
\hline 88 & 6194 & 6158 & 5988 & 6287 & .05 & .05 \\
\hline 89 & 7945 & 7101 & 6777 & 8803 & 5.05 & $.01 \quad .36$ \\
\hline 96 & 5129 & 5141 & 4283 & 5378 & 1.98 & .23 \\
\hline$\underline{122}$ & 6675 & 6389 & 5944 & 7142 & 2.18 & .28 \\
\hline$\underline{127}$ & 6022 & 5565 & 5295 & 6633 & 4.55 & $<.01 \quad .33$ \\
\hline 138 & 4180 & 3851 & 4134 & 4489 & 1.53 & .17 \\
\hline$\underline{140}$ & 3730 & 3589 & 3185 & 4017 & 3.91 & $.05 \quad .57$ \\
\hline 148 & 17252 & 15229 & 13363 & 20159 & 7.83 & $<.01 \quad .40$ \\
\hline 174 & 5073 & 4756 & 3857 & 5703 & 6.06 & $<.01$ \\
\hline 182 & 3469 & 3136 & 3006 & 3893 & 3.98 & .05 \\
\hline$\underline{210}$ & 11175 & 10368 & 8531 & 12672 & 7.58 & $.01 \quad .38$ \\
\hline$\underline{243}$ & 3581 & 3499 & 2595 & 3956 & 10.24 & $.01 \quad .52$ \\
\hline 294 & 4300 & 3928 & 4115 & 4691 & 1.59 & .21 \\
\hline 296 & 4699 & 3826 & 5187 & 5286 & 4.39 & $.01 \quad .21$ \\
\hline 320 & 5057 & 4872 & 3552 & 5677 & 7.51 & .01 \\
\hline 336 & 5586 & 5159 & 3825 & 6480 & 10.83 & $.01 \quad .43$ \\
\hline 468 & 12926 & 11699 & 16737 & 12801 & 3.05 & $.05 \quad .36$ \\
\hline
\end{tabular}

Prostatectomy; age over 69 with complications and comorbidity), and DRG 468 (Unrelated Operating Room Procedure to a given 
Medical Diagnostic Category).

TABLE XXII CHARGES BY DRG

FORPROFIT VQ GOVERNMENT

\begin{tabular}{|c|c|c|c|c|c|c|}
\hline DRG & MEANS & F-BCORE & SIE. & $\begin{array}{r}A D \\
F O F \\
R-8 Q .\end{array}$ & $\begin{array}{l}\text { JBTED DEV } \\
\text { INDEP. } \\
\text { FORPROF. }\end{array}$ & $\begin{array}{l}\text { IATIONB } \\
\text { COVAR. } \\
\text { GOVT. }\end{array}$ \\
\hline 15 & 3575 & 4.34 & .05 & .12 & 277 & -901 \\
\hline 89 & 8327 & 3.21 & NE & .10 & 471 & -1532 \\
\hline 127 & 6318 & 5.02 & $<.05$ & .15 & 328 & -1067 \\
\hline 140 & 3821 & 7.32 & .01 & .19 & 196 & -636 \\
\hline 148 & 18560 & 7.55 & $\leq .01$ & .51 & 1871 & -6082 \\
\hline 174 & 5269 & 0.33 & $\leq .01$ & .22 & 449 & -1460 \\
\hline 192 & 3684 & 3.17 & NE & .02 & 200 & -653 \\
\hline 210 & 11698 & 8.95 & $<.01$ & .28 & 1119 & -3637 \\
\hline 243 & 3633 & 14.19 & $<.01$ & .40 & 327 & -1063 \\
\hline 296 & 5263 & .01 & NS & .01 & 10 & -32 \\
\hline 320 & 5177 & 11.89 & $<.01$ & .32 & 488 & - 1597 \\
\hline 336 & 5862 & 14.91 & $<.01$ & .34 & 637 & -2071 \\
\hline 468 & 13727 & 2.96 & NB & .11 & -778 & 2529 \\
\hline
\end{tabular}

Froperty rights theory would predict that nonprofits and government hospitals will demonstrate lower charges per DRG. Forprofit hospitals attempting to maximize profits would have higher charges per DRG. To test for this, the forprofit hospitals were compared to government hospitals on the DRGs where initial comparisons showed statistical significance. 
At a glance (Table XXII), the forprofit hospitals show higher charges on 12 out of 13 DRGs. On 9 DRGs, charges were statistically higher. Comparing the forprofits to the nonprofits (Table XXIII), the forprofits had significantly higher charges on ten DRGs.

TABLE XXIII: CHAREES BY DRG

FORPROFITS VS. NONPROFIT

\begin{tabular}{|c|c|c|c|c|c|c|}
\hline DRE & MEANB & F-SCQRE & SIE. & $\begin{array}{r}A D \\
F D \\
R-8 Q .\end{array}$ & $\begin{array}{l}\text { JBTED DEV } \\
\text { INDEP. } \\
\text { FORPROF. }\end{array}$ & $\begin{array}{l}\text { IAT IONB } \\
\text { COVAR. } \\
\text { NONPROF. }\end{array}$ \\
\hline 15 & 3455 & 5.24 & $<.05$ & .10 & 398 & -470 \\
\hline 89 & 8024 & 5.53 & $<.05$ & .11 & 785 & -928 \\
\hline 127 & 6143 & 5.07 & $<.05$ & .10 & 515 & -609 \\
\hline 140 & 3820 & 2.83 & NS & .06 & 206 & -244 \\
\hline 148 & 17900 & 8.93 & $<.01$ & .44 & 2440 & -2883 \\
\hline 174 & 5280 & 4.43 & $<.05$ & .11 & 360 & -445 \\
\hline 182 & 3546 & 5.59 & $<.05$ & .12 & 324 & -383 \\
\hline 210 & 11616 & 7.06 & $<.01$ & .14 & 1003 & -1185 \\
\hline 243 & 3747 & 3.52 & NB & .12 & 242 & -286 \\
\hline 296 & 4617 & 10.22 & $<.01$ & .23 & 757 & -895 \\
\hline 320 & 5300 & 3.74 & $<.05$ & .12 & 401 & -474 \\
\hline 336 & 5879 & 8.49 & $<.01$ & .17 & 546 & -646 \\
\hline 468 & 12291 & .73 & NS & .12 & 1025 & -1212 \\
\hline
\end{tabular}

Forprofit hospital behavior was consistent with profit maximization as reflected by higher charges. There is evidence to support this. This is consistent 
with the expectation that charges in nonprofit and government hospitals would be lower since they receive tax exemptions and philantropic donations. The results on Table XXIV below show that nonprofits

TABLE XXIV: CHARGES BY DRG

$$
\text { NONPROFITS VS. GOVERNMENT }
$$

\begin{tabular}{|c|c|c|c|c|c|c|}
\hline DRG & MEANS & F-SCDRE & SIG. & $\begin{array}{r}\text { AD } \\
F Q \\
\text { R-SQ. }\end{array}$ & $\begin{array}{l}\text { JETED DEV } \\
\text { INDEP. } \\
\text { NONPROF. }\end{array}$ & $\begin{array}{l}\text { I AT IONS } \\
\text { COVAR. } \\
\text { GOVT. }\end{array}$ \\
\hline 15 & 2901 & .71 & NS & .04 & 73 & -201 \\
\hline 99 & 7015 & .03 & NB & .02 & 51 & -142 \\
\hline 127 & 5493 & .17 & $\mathrm{NB}$ & .02 & 66 & -103 \\
\hline 140 & 3481 & 1.08 & NB & .05 & 99 & -274 \\
\hline 148 & 14731 & .69 & NE & .16 & 519 & -1429 \\
\hline 174 & 4508 & 1.87 & NB & .06 & 246 & -647 \\
\hline 182 & 3101 & .18 & NS & .03 & 26 & -72 \\
\hline 210 & 9878 & 1.10 & NS & .05 & 476 & -1300 \\
\hline 243 & 3255 & 4.81 & $<.05$ & .23 & 221 & -609 \\
\hline 296 & 4189 & 3.67 & NB & $.1 \theta$ & 384 & 1058 \\
\hline 320 & 4520 & 6.07 & $<.05$ & $.2 \theta$ & 309 & -851 \\
\hline 336 & 4803 & 2.55 & NB & .09 & 350 & -962 \\
\hline 460 & 13035 & 5.77 & $<.05$ & .18 & -1361 & 3744 \\
\hline
\end{tabular}

compared to government hospitals show statistically higher charges in only two (2) DRGs [DRG 243 and 320]. In all other DRGs, there was no statistical significance of the lower charges in government hospitals in 
comparison to the nonprofits.

Reimbursements Per DRG. The present reimbursement system sets fixed prices for hospital services. Note Table XXV. In the majority of the DRGs (70\%), the findings indicate no significant differences. The differences were significant in six DRGs $(30 \%)$ : DRG 14 ( Specific Cerebrovascular Disorders except for Transient Ischemic Attack), DRG 174 (Gastrointestinal Hemorrhage, age over 69 with complications and comorbidity), DRG 210 (Hip and Femur Procedure, except major joint, age over 69 with complications and comorbidity), DRG 243 (Medical Back Problems), DRG 320 (Kidney and Urinary Tract Infections, age over 69 with complications and comorbidity), DRG 336 (Transurethral Prostatectomy, age over 69 with complications and comorbidity).

According to the property rights theory, a forprofit hospital would demonstrate higher reimbursements to maximize return on investment. Even though pricing is fixed, accurate classification of patients by coding, thorough physician documentation of all complications and associated procedures, allow recouping the most reimbursement monies.

Noting Table XXV, forprofit hospitals show statistically higher reimbursements in four DRGs (14, $210,320,336)$. Nonprofits were statistically higher in 
two DRGs $(174,320)$.

TABLE XXV : REIMBUREEMENTS BY DRG BY OWNERBHIP TYPE \begin{tabular}{llllll} 
GRAND & \multicolumn{2}{c}{ CELL MEANS } \\
DRG & MEAN & NONPROF GQVT FORPROF & F-BCORE & SIG. R2 \\
\hline
\end{tabular}

$\begin{array}{llllllll}14 & 4336 & 4397 & 3778 & 4464 & 3.30 & .05 & .37\end{array}$

$\begin{array}{llllllll}15 & 1969 & 1923 & 1869 & 2039 & .91 & \text { n日 } & .21\end{array}$

\begin{tabular}{llllllll}
\hline 2 & 3689 & 3768 & 3400 & 3709 & 2.34 & $n=$ & .43 \\
\hline
\end{tabular}

\begin{tabular}{llllllll}
89 & 3256 & 3128 & 3054 & 3210 & 1.02 & $n=$ & .20 \\
\hline
\end{tabular}

$\begin{array}{lllllllll}89 & 3774 & 3577 & 3203 & 4116 & .93 & \text { ne } & .08\end{array}$

\begin{tabular}{llllllll}
96 & 2467 & 2515 & 2260 & 2490 & 2.32 & $n$ & .43 \\
\hline
\end{tabular}

$\begin{array}{lllllllll}122 & 4240 & 4254 & 3699 & 4394 & 1.81 & \text { nE } & .26\end{array}$

$\begin{array}{llllllll}127 & 3330 & 3383 & 3059 & 3369 & 2.66 & \text { n } & .47\end{array}$

\begin{tabular}{llllllll}
138 & 2877 & 2849 & 2721 & 2947 & .55 & nE & .21 \\
\hline
\end{tabular}

$\begin{array}{llllllll}140 & 2310 & 2363 & 2097 & 2330 & 2.93 & \text { ne } & .46\end{array}$

\begin{tabular}{llllllll}
149 & 8189 & 8232 & 7135 & 8474 & 1.83 & nE & .30 \\
\hline
\end{tabular}

$\begin{array}{lllllllll}174 & 2891 & 2979 & 2424 & 2963 & 5.00 & .01 & .42\end{array}$

$\begin{array}{llllllll}182 & 1865 & 1901 & 1692 & 1896 & 2.30 & \text { ne } & .41\end{array}$

$\begin{array}{llllllll}210 & 6565 & 6700 & 5033 & 6922 & 5.35 & .01 & .30\end{array}$

\begin{tabular}{llllllll}
243 & 2332 & 2329 & 1889 & 2471 & 3.62 & .05 & .31 \\
\hline
\end{tabular}

$\begin{array}{llllllll}294 & 2491 & 2522 & 2289 & 2526 & 2.41 & \text { nE } & .46\end{array}$

$\begin{array}{llllllll}296 & 2897 \quad 2918 & 2692 & 2922 & 1.65 & \text { nE } & .43\end{array}$

$\begin{array}{llllllll}320 & 2533 & 2611 & 2110 & 2596 & 6.10 & <.01 & .46\end{array}$

$\begin{array}{llllllll}336 & 3035 & 3076 & 2321 & 3220 & 5.55 & .01 & .36\end{array}$

$\begin{array}{llllllll}468 & 6854 & 7043 & 6676 & 6750 & .41 & \text { ne } & .20\end{array}$

Government hospitals were consistently lowest in reimbursements per DRG. 
TABLE XXVI: REIMBUREEMENTE BY DRO

GOVERNMENT VB. FORPROFIT

\begin{tabular}{|c|c|c|c|c|c|c|}
\hline DRE & MEANB & F-SCORE & 8IO. & R-8R. & $\begin{array}{c}\text { ADJUBTED DEV } \\
\text { FOR INDEP. } \\
\text { FORPROF. }\end{array}$ & $\begin{array}{l}\text { IATIONB } \\
\text { COVAR. } \\
\text { GOVT. }\end{array}$ \\
\hline 14 & 4303 & 3.64 & NS & .11 & 173 & -562 \\
\hline 140 & 2275 & 2.63 & NS & .09 & 54 & -177 \\
\hline 174 & 2936 & 4.23 & .05 & .12 & 130 & -424 \\
\hline 210 & 6477 & 7.69 & $<.01$ & .24 & 505 & -1640 \\
\hline 243 & 2333 & 3.95 & .05 & .12 & 137 & -447 \\
\hline 320 & 2482 & 5.23 & $<.05$ & .18 & 111 & -362 \\
\hline 336 & 3008 & 7.50 & .01 & .20 & 215 & -699 \\
\hline
\end{tabular}

TABLE XXVII: REIMBURBEMENTS BY DRG

FORPRQFIT VS. NONPROFIT

ADJUSTED DEVIATIONS FOR INDEP, \& COVAR. DRE MEANB F-SCORE SIG. R-BQ. FDRPROF. NONPROF.

\begin{tabular}{lllllll}
14 & 4429 & .15 & $N 8$ & .01 & 12 & -14 \\
140 & 2345 & .12 & N8 & .02 & -23 & -27 \\
\hline 174 & 2970 & .01 & $N 8$ & .09 & -46 & 57 \\
\hline 210 & 6820 & .30 & $N 8$ & .007 & 112 & -132 \\
\hline 243 & 2405 & .79 & $N 8$ & .02 & 64 & -76 \\
320 & 2603 & .02 & $N 8$ & .00 & 7 & -6 \\
\hline 336 & 3154 & .60 & N8 & .02 & 45 & 53 \\
\hline
\end{tabular}


TABLE XXVIII: REIMBURSEMENTS BY DRG

NONPROFIT VB. GOVERNMENT

\begin{tabular}{|c|c|c|c|c|c|c|}
\hline DRE & MEANS & F-SCORE & SIO. & R-8R. & $\begin{array}{l}\text { ADJUSTED DE } \\
\text { FOR INDEP. } \\
\text { NONPRQF. }\end{array}$ & $\begin{array}{l}\text { I AT IONS } \\
\text { COVAR. } \\
\text { GOVT. }\end{array}$ \\
\hline 14 & 4225 & 3.08 & NB & .13 & 154 & -424 \\
\hline 140 & 2345 & .12 & NB & .02 & 27 & -23 \\
\hline 174 & 2826 & 4.13 & .05 & .14 & 152 & -400 \\
\hline 210 & 6255 & 3.66 & NS & .21 & 424 & -1167 \\
\hline 243 & 2211 & 4.59 & $<.05$ & .17 & 111 & -305 \\
\hline 320 & $247 \theta$ & 4.91 & $<.05$ & .19 & 123 & -340 \\
\hline 336 & 2875 & 3.19 & NS & .12 & 185 & -509 \\
\hline
\end{tabular}

Forprofit hospitals had significantly higher reimbursements than government hospitals on five DRG categories (Table XXVI). In comparison to the nonprofit hospitals, though, differences were not significant at all (Table XXVII). Nonprofit hospitals were compared to the government hospitals (Table XXVIII). Government hospitals show lower reimbursements, but these were statistically significant in only three DRGs.

Analyzing for trends, note that where there are differences in lengths of stay in seven DRGs ( 81,140 , $243,320,336,468)$, we find that $5 i x$ of these DRGs $(140,243,296,320,336,468)$ were significantly 
different in charges as well. Only in two of these DRGs ( 320 and 336$)$ were reimbursements statistically different.

Thus, our findings showed that reimbursements per DRG were higher in the forprofit hospitals than both nonprofit and government hospitals. Although the sophisticated classification of the DRGs is complicated, and the amount reimbursed to the hospital should be the same regardless of ownership status, there are factors to consider which may account for differences. As indicated earlier, operational efficiencies, such as ensuring detailed physician documentation and proper coding in the medical records department, allow accurate patient classification in the appropriate DRG categories. Again, we did not find the difference we expected according to the property rights theory.

Conclusion. In the context of efficiency, the evidence for property rights is mixed. Hospitals differed significantly on bad debts, manhours, and charges per DRG. In terms of occupancy rates, the study findings showed both nonprofit and government hospitals with higher occupancy rates. However, we found significant differences between nonprofits and forprofits only. Nonprofit hospital behavior here is consistent with the output maximization rationale. Our analyses did not support the property rights argument in 
the forprofit hospitals. Other possibilities which might explain differences include variations in cases treated in each hospital; the patients may stay longer such that occupancy rates show a high figure. Our analyses on length of stay by DRG ruled this out. Another possibility is the factor associated with physician affiliation with certain hospital ownership types. Early on, this study referred to the physician's cooperative hypothesis advanced by Pauly and Redisch (1973) for the nonprofit hospital. The indirect implication would be the economic interests of the physician as far as being a "high admitter." As one looks at the advantages of admitting to a certain hospital as opposed to another, the picture becomes more obscure because the physicians are the primary decision-makers in hospital admissions. Their obvious authority is needed, by the same token, to discharge a patient. Physician practice patterns in the three ownership categories could affect occupancy rates. This factor is interesting but access to this type of information is extremely 1 imited. Subsequent studies should consider this measure in the future.

In relation to ancillary expenses, we found no support for the property rights theory. One of the concerns regarding DRGs was that profit-seeking hospitals will attempt to minimize the expenditures 
associated with delivery of care by decreasing utilization of ancillary services because reimbursement of expenses is fixed. Regardless of the amount of ancillary services provided, the monies a hospital would receive will be dependent on the amount allotted for that particular DRG. It is logical that a profitseeking hospital would minimize ancillary service expenditures. The ancillary expenses in the forprofit hospital were lower. The higher ancillary service expenditures in the government hospitals, although not statistically higher in our sample, could be attributed to many factors, such as: (1) government hospitals are larger (although comparisons have been controlled for bed size); (2) government hospitals have affiliating medical and nursing schools, and as such, adherence to standard treatment protocols requiring certain ancillary services may be routine; and (3) there was a higher number of Medicaid patients for the government hospitals in this study. Their health status could have been poorer. They may have been sicker, as well. In the case of the forprofits, we know that they have fewer Medicaid patients than government hospitals. Thus, these factors which affect variability in expenses for ancillary services due to differences in utilization by patient type need to be kept in mind. The analyses here were not on ancillary expenses by DRG category (These 
data were not available.). Our multiple regression analysis on ancillary expenses showed bed size, Medicare days, and Medicaid days as significant predictors. This confirmed the first and third possibility. In this sample, there was one nonprofit hospital with an active affiliation with a medical and nursing school. This study was 1 imited in that the thorough investigation of this aspect was not done. Future studies should examine this area closely.

What is surprising is the behavior of the nonprofit hospitals, particularly in terms of bad debts, charges and reimbursements. Their behavior mimics that of the forprofit hospitals. This makes less clear the distinction between nonprofit and forprofit hospitals. In terms of operational efficiency, these analyses imply that nonprofit hospital behavior approximates that of the forprofits in certain ways. This was evident particularly when bad debts were examined. When this is related to the finding that the amount of uncompensated care is a statistically significant predictor of bad debts, the behavior of the nonprofit hospitals does seem to be consistent with the expectation.

The evidence seen in this study on manhours per patient day showed that both nonprofit and government hospitals had higher hours than the forprofits. Earlier in this study, it was noted that nonprofit and 
government hospitals were larger (in terms of bed size). This study controlled for this statistically.

It has also been mentioned that human resources are required to staff more hospital beds. As such, manpower on a twenty-four hour basis is shown as its highest operational expenditure. The rational response from a profit-maximization standpoint would be to decrease manhours per patient day.

By the same token, if one is to decrease the number of manhours to decrease expenditures, one would also decrease expenditures associated with salaries. The study results showed no significant difference among nonprofit, government, and forprofit hospitals. Nonprofit and forprofit salaries were practically identical; government hospitals were the least. However, bear in mind that manhours per patient day in both the government and nonprofit hospitals were higher than the forprofits. It is amazing to find the nonprofits with higher manhours and yet, with pay similar to the forprofits. This can be construed as a "fringe benefit" for the employees of the nonprofit and government hospitals. With higher manhours, workload per FTE is lower than the forprofits. In essence, this strengthens the property rights position.

The concern for variability of cases treated in the hospitals brought us to analyze for each of the twenty 
DRGs, the length of stay, charges, and reimbursements. On length of stay, the findings showed that there were no significant differences among hospitals on $65 \%$ of the DRGs. On examining each average length of stay per DRG in the forprofit hospital, it was consistently lower in 8 out of 20 DRGs (although not necessarily significant). Yet, this did not translate into lower charges per DRG. The charges per DRG were significantly different among the three hospital types on $65 \%$ of the DRGs. Consistently, charges per DRG in the forprofit hospital were higher. Nonprofit hospital charges were higher than government hospitals but lower than forprofit hospitals.

As can be expected, fixed reimbursement rule effects are demonstrated in the study results. The majority of reimbursements (70\%) per DRG were not significantly different. The higher reimbursement to the forprofit hospitals on 12 out of 20 DRGs (although not significantly higher) shows us that there are ways by which hospitals can, within a DRG category, recoup the most amount of monies. These creative strategies make future analyses of hospital behavior challenging, particularly when there are difficulties associated with retrieval and access to most relevant data.

Let us reiterate, though, that there were a number of cases in which property rights theory could predict 
differences that were not found. These were in regard to occupancy rates, ancillary expenses, salaries per FTE, lengths of stay per DRG, and reimbursements per DRG. Nonprofit, government, and forprofit hospitals were not significantly different in terms of salaries per FTE. In the majority of the DRGs, lengths of stay and reimbursements were not significantly different. The provision of health care in the nonprofit form is encouraged through the tax incentives and on the forprofit side by accrual of net revenues to shareholders. Several variables of efficiency were explored to compare nonprofit, government, and forprofit hospitals to obtain evidence in support of the property rights theory. Some mixed evidence supporting the property rights theory has been presented. However, caution must be exercised in generalizing the findings of this study. Several questions remain unanswered. Of particular importance is the aspect of what purchasers of health care services are willing to pay. Private insurance companies pay differently as opposed to Medicare or Medicaid. Although twenty DRGs were investigated in this study across all hospital types in an attempt to control for product differences, the extent to which hospitals may shift costs of care among different payors would be a crucial dimension for future studies. 
If there is an economic orientation on the part of nomprofits in the 1 ight of the present cost-containment policies, to what extent do nonprofit hospitals fulfill their social obligations? The question lingers for all other types of hospital ownership status, as well. In this context, further analysis was done to better understand issues relating to equity.

\section{EQUITY}

Nonprofit, government, and forprofit are now compared in the context of equity by analyzing data on Medicare, Medicaid, and Uncompensated Care.

Medicare [Hypothesis C1]. Note Table XXIX which shows statistically significant differences by ownership status:

TABLE XXIX: MEDICARE DAYS BY QWNEREHIP

\begin{tabular}{lllll} 
OWNERBHIP & MEAN & MEDIAN & F-BCDRE & 8IO. \\
\hline NONPROFIT & 54102 & 57752 & & \\
GOVERNMENT & 48804 & 59455 & & \\
FORPROFIT & 34578 & 29891 & & \\
GRAND MEAN & 43932 & & 7.55 & $<.01$ \\
\hline
\end{tabular}

Comparing nonprofits to the government hospitals, note that the government hospitals had fewer Medicare days by 5298. This was not statistically significant (Table $x(x)$. 
TABLE XXX: MEDICARE DAYB

\begin{tabular}{lcccc} 
& $\begin{array}{l}\text { ANOVA } \\
\text { F-8CDRE }\end{array}$ & $\begin{array}{c}\text { ANOVA } \\
\text { SIG. }\end{array}$ & $\begin{array}{l}\text { M-W } \\
810 .\end{array}$ \\
\hline NP VE & $G$ & .23 & NB & NB (NB*) \\
\hline FP VE G & 3.94 & .05 & NB (NS*) \\
\hline NP VE FP & 15.59 & .01 & .02 \\
\hline
\end{tabular}

Forprofits compared to government hospitals, the government sector had more Medicare days by 14226 . ANOVA results show statistical significance at . O5. Nonprofits compared to forprofits were significantly different, with forprofits having fewer Medicare days by 19524. This was statistically significant at.01. MannWhitney analysis confirm ANDUA results except for the comparison between the forprofit and government hospitals. There was no significant difference in the medians of the two hospitals.

Nonprofits have the highest mean number of Medicare days. This finding can be interpreted in three ways: (1) Nonprofit hospitals give care to Medicare patients from a fiduciary standpoint, i. e. social obligation to do so; this behavior is consistent with output maximization. (2) Fewer mean Medicare days in the forprofit hospitals in comparison to the nonprofit hospital could be "avoidance behavior" by this sector because of DRG reimbursement for Medicare patients. The forprofit hospitals have been known to follow 
legislative events closely and consequently are able to react to impending reimbursement rules quicker than nonprofits. The 1 imitations on reimbursement for Medicare patients make this market less attactive to profit-seeking hospitals. (3) Fewer mean Medicare days in the government hospitals compared to nonprofits may be due to physician practice patterns. (Note that when medians are examined, there is no significant difference). There could be preference or priority given to the treatment of trauma, emergency cases, or acute care rather than the chronic debilitation that characterizes Medicare recipients who are 65 years and over.

In the analysis on location, it was mentioned that certain geographic areas were found to have higher Medicare enrollees (highest in Palm Beach). Looking for further evidence to explain forprofit behavior, note Table $X X X I$ which shows no significant difference by location in terms of Medicare days. There are fewer forprofit hospitals than government hospitals in Palm Beach (Note earlier, Table II showed hospital ownership by location.). These findings show support of the "avoidance behavior" by forprofits or on the government side, the fiduciary obligation to meet the society's needs (output maximization) in areas where the private sector do not thrive. This may also imply that the 
elderly simply live in older communities where hospitals were established prior to the increase in the number of forprofit hospitals.

TAELE XXXI: MEDICARE DAYS BY LOCATION

LOCATION

PALM BEACH

BROWARD

DADE

GRAND MEAN
MEAN

37308

46137

44980
F-SCDRE

SIG.
2.74 NS

Medicaid. Note Table XXXII which indicates that government hospitals provided the most under Medicaid (16493). Eoth nonprofits and forprofits provided less.

TABLE XXXII: MEDICAID DAYS BY OWNERSHIP

\begin{tabular}{lcccc} 
OWNERSHIP & MEAN & MEDIAN & F-SCORE & SIG. \\
\hline NONPROFIT & 3469 & 3137 & & \\
GOVERNMENT & 16493 & 3802 & & \\
FORPROFIT & 2306 & 356 & & $<.01$ \\
GRAND MEAN & 4759 & & 27.05 & \\
\hline
\end{tabular}


Table XXXIII shows very interesting findings. According to the property rights theory, we should expect to see significantly more Medicaid days in nonprofit and

TABLE XXXIIII MEDICAID DAYS

\begin{tabular}{llllll} 
& $\begin{array}{l}\text { ANDVA } \\
\text { F-SCORE }\end{array}$ & $\begin{array}{c}\text { ANQVA } \\
\text { SIG. }\end{array}$ & $\begin{array}{l}\text { M-W } \\
8 I G .\end{array}$ \\
\hline NP VE G & 15.91 & $<.01$ & .05 & (NS*) \\
\hline FP VE G & 23.97 & $<.01$ & $<.01$ & $(<.01 *)$ \\
\hline NP VE (FP) & .93 & NS & NS & \\
\hline
\end{tabular}

government hospitals in comparison to forprofit hospitals. Further analyzing the data, no statistically significant difference was found between nonprofits and forprofits. Analysis of variance results controlling for bed size showed the F-score at .93 . Median levels were compared and results were not significant. It is very important to take note, here, that in our sample of 27 forprofit hospitals, 9 hospitals showed zero Medicaid days. There were 3 nonprofit hospitals out of 21 with zero Medicaid days as well. In both ANOVA and MannWhitney analyses, forprofits compared to government hospitals were statistically different at less than .01. Theoretically, nonprofit behavior patterns should reflect its fiduciary goals. Comparing nonprofit hospitals to government hospitals, nonprofit hospitals had significantly fewer Medicaid days. However, when a 
large county hospital is eliminated from the sample, the level of signficance fails to reach the. 05 level (significance at. 08 ). The provision of care to the indigents by government hospitals as evidenced by the number of Medicaid days was significantly higher than forprofit hospitals. The nonprofits, though, fail to demonstrate statistically higher Medicaid days compared to their forprofit counterpart.

Further analysis using multiple regression was done. With forprofit hospitals as the reference category, we regress Medicaid days on three predictors: bed size, nonprofit hospitals, and government hospitals. With $F$ square at $60.1 \%$, we found t-ratios $7.07,-1.08$, and 2.16 respectively. One government hospital outlier was removed. The $R$ square is lowered to $34.1 \%$ and $t-$ ratios were $3.98,-.36,2.17$ respectively.

The preceding analysis reaffirms our conclusion that government hospitals have significantly higher Medicaid days. The negative t-ratios for the nonprofit hospitals indicate that Medicaid days in this sector are less but are not statistically significant.

Dur earlier analysis on bad debts showed that nonprofits were similar to forprofits. Let us examine this in the light of Medicare and Medicaid. Is there reason to believe that the provision of care to Medicare and Medicaid patients might be related to bad debts. We 
regress bad debts on five predictors (nonprofit, government, bed size, Medicare, and Medicaid days). The F square is $47.5 \%$. Only government hospitals show a statistically significant t-ratio (4.44). Here, we fail to find evidence linking the amount of bad debts to Medicare and Medicaid days. However, one might suspect that differences in Medicare days and Medicaid days affect occupancy rates. We regress occupancy rates on five predictors (nonprofit, government, beds, Medicare days, and Medicaid days). T-ratios were revealing at $1.80,1.55,-3.85,4.82$, and 3.93 respectively. R square was $43.9 \%$. This finding could help explain the lower occupancy rates in the forprofit hospitals.

Uncompensated Care. The analyses of the percentage of uncompensated care provided by nonprofit, government, and forprofit hospitals show statistically significant differences at less than. 01 (Table XXXIV). It showed that the government hospitals provided the highest TABLE $X X X I V$, UNCOMPENGATED CARE

$\begin{array}{lrrrr}\text { OWNERBHIP } & \text { MEAN } & \text { MEDIAN } & \text { F-BCORE } & \text { 8IG. } \\ \text { NONPROFIT } & .87 & .70 & & \\ \text { GOVERNMENT } & 5.45 & 5.60 & & \\ \text { FORPROFIT } & .17 & .00 & & <.01 \\ \text { GRAND MEAN } & 1.18 & & 63.76 & \end{array}$
amount of uncompensated care and forprofit provided the least, followed clasely by the nonprofits. To 
determine whether or not the difference between nonprofits and forprofits was significant, both hospitals were compared. Table XXXV shows the results.

TABLE XXXV: UNCOMPENBATED CARE

\begin{tabular}{|c|c|c|c|c|c|c|}
\hline & & & $\begin{array}{l}\text { ANDVA } \\
\text { F-SCORE }\end{array}$ & $\begin{array}{l}\text { ANOVA } \\
\text { BIO. }\end{array}$ & $\begin{array}{l}M-W \\
\text { BIO. }\end{array}$ & \\
\hline NP & $v=$ & B & 21.55 & $<.01$ & NB & (NB*) \\
\hline FP & $v e$ & B & 39.29 & $<.01$ & $<.01$ & $(<.01 *)$ \\
\hline NP & $v E$ & FP & 10.53 & $<.01$ & $<.01$ & \\
\hline
\end{tabular}

The findings are significant. Nonprofit hospitals provided significantly more uncompensated care in comparison to the forprofit hospitals. However, differences between government and nonprofit hospitals were not significant. The finding for government hospitals is consistent with our expectation that these hospitals will show evidence of maximizing services to society. The forprofit hospital showed significantly less uncompensated care in comparison to both nonprofit and government hospitals. This is consistent with our expectation that forprofit hospitals are profitmaximizers and will avoid providing services for which financing is not available.

Conclusion. The supporting evidence for property rights and subsequent behavior among forprofit and government hospitals is clear. The Medicare days for 
nonprofit hospitals were more than forprofit hospitals. In terms of Medicaid days, the government hospitals had the most compared to both nonprofits and forprofits. In terms of uncompensated care, the government hospitals, again, provided the most.

Forprofits seek to maximize profits by limiting Medicare, Medicaid, and uncompensated Care. To the contrary, the government hospitals showed evidence of maximizing services. However, the nonprofits' behavior patterns are somewhat similar to the forprofits with regard to Medicaid. This is not consistent with the property rights theory. Dur current knowledge of nonprofits is that they have a historical mission to serve a charitable purpose, to serve the poor, and render a proportionate share of health services for free or without compensation. In fact these were partly the conditions for the financial assistance (for construction under the Hill-Burton Act) given to nonprofits. An analysis of hospital financial characteristics Florida indicates that nonprofit hospitals provided a disproportionate amount of charity and uncompensated care at $32.5 \%$ compared to government hospitals at $61.8 \%$. Forprofits provided a minute $5.7 \%$ (HCCB, 1984). By virtue of the tax-exempt status of the nonprofits, the natural extension of this would be the social purposes which must be served. 
If nonprofits are exempt from both property and income taxes, the expectation is that appropriate amounts of needed services are given. In this sample, we find that the number of Medicaid days given by nonprofits is not significantly different from the forprofits. A thought-provoking question is: do nonprofits provide services to Medicaid patients commensurate with their tax-exemption benefits? This, unfortunately, is not easily answered. Empirical data on taxes needed to make valid comparisons are not readily available or accessible. However, if we use the tax year 1983 as an example, the total revenues for community nonprofit hospitals in Florida was $\$ 89,462,795$ and total expenses were $\$ 85,637,108$ (HCCB, 1984). Their income, thus, amounts to $\$ 3,825,787$. If taxes were applied at a rate which invester-owned hospitals pay (24. $1 \%)$, federal taxes for which nonprofits were exempted wauld be clase to \$1million. This does not include property tax exemptions. When patterns such as the one seen in this study occur, justification for taxexemptions becomes difficult. In essence tax exemption is taxpayer subsidy of the hospital. Serious inquiry needs to be directed towards what is the proper role of the nonprofit hospital in addressing the needs of the community where they are located. Note that the landmark case of Utah $v$. Intermountain Health Care, Inc. 
in 1985 underscored the role of local governments in evaluating the extent to which expectations are met and to respond appropriately.

By the same token, what are the legal and moral obligations of the forprofit hospitals? From this vantage point, the fact that forprofit hospitals pay income taxes could be seen as discharging their duties accordingly. Therefore, they do not have to provide care to those who are unable to pay. For the individual who is sick and in need of care, with nowhere else to go, this is hardly reassuring. When hospitals turn away sick patients because they do not have insurance, serious jeopardy of life can occur. When this happens, the dollar value attached to measures of taxes, uncompensated care, and so on become irrelevant. This conflict can hardly be resolved. Obtaining empirical evidence in this regard will not be easy in comparing the benefits of tax-paying hospitals as opposed to tax-exempt hospitals who serve charitable purposes. As demonstrated in this study, it is difficult to assume that nonprofits do in fact serve the purposes for which they have been intended. The number of Medicaid days provided by the nonprofit hosptals in this study do not significantly differ from the forprofit hospital. Their charges per DRG do not approximate that of the government hospitals; and the 
amounts they were reimbursed are higher than that given to the government hospitals.

The government hospitals in this study show evidence along the lines of discharging their fiduciary responsibilities. Their behavior is consistent with output maximization, particularly with regards to Medicaid patients. The forprofit hospital behavior in this study demonstrates consistency with the property rights argument that the rights to residual profit for this sector means less provision of care to Medicaid patients and less uncompensated care.

The final stage of our analyses deal with quality of care. The following pages will present the results of the analyses.

\section{Quality of Cara}

Hospital ownership status and quality of care have been discussed in various studies (Chapters II and III). The property rights theory would predict that nonprofit and government hospitals may provide a better quality of care than forprofit hospitals. In theory, the quality of care in the government and nonprofit hospital is at a level that meets budget constraints. The forprofit hospitals, as profit maximizers, need to maintain their patient patronage. The quality of care in these hospitals, hence, would be at a level where profits are maximized and expenses minimized. Additionally, all 
three hospital types are subject to rules and regulations affecting the delivery of health care. Therefore, we examine for differences among nonprofit, government, and forprofit hospitals in this regard.

Death Rates Fer DRG [Hypathesis D1]. The index of quality used in this analysis is death rates per DRG. Table XXXVI shows twenty DRGs. Note that not in any one DRG was there a statistically significant difference. Mortality rate is a general measure of quality. However, the selection of this sample for this study identified hospitals which are accredited by the JCAH. Length of stay and manhours per patient day are 1 ikewise considered as indicators of quality. For this study, though, they were used as indices of efficiency. In practice, death rates remain a gross outcome measure of quality.

It was pointed out that the rationale for looking at death rates on twenty DRGs for the different ownership sectors was that organizational behavior may vary because of this cost-containment incentive. Specifically, that the forprofit sector's profitmaximizing behavior might be reflected in higher mortality rates for this sector. No support for this was evident. 
TABLE XXXVI: PERCENT OF DEATHS BY DRG BY OWNERSHIP TYPE

\begin{tabular}{|c|c|c|c|c|c|c|}
\hline DRE & $\begin{array}{l}\text { GRAND } \\
\text { MEAN }\end{array}$ & NONPROF & $\begin{array}{l}\text { CELL } \\
\text { GOUT }\end{array}$ & $\begin{array}{l}\text { EANS } \\
\text { FORPRDF }\end{array}$ & F-SCORE & 8IG. R2 \\
\hline$\underline{14}$ & 15.44 & 13.07 & 20.13 & 16.00 & 1.99 & ne \\
\hline$\underline{15}$ & .95 & .79 & .55 & 1.21 & .91 & $n=$ \\
\hline$\underline{92}$ & 17.85 & 17.34 & 19.22 & 19.16 & .01 & $n \in$ \\
\hline 8日 & 4.56 & 4.12 & 4.09 & 5.08 & .29 & $n=$ \\
\hline 89 & 9.87 & 7.67 & 11.98 & 11.98 & 2.64 & $n \in$ \\
\hline 96 & 1.21 & 1.03 & 1.08 & 1.09 & .14 & $n=.0$ \\
\hline 122 & 0 & 0 & 0 & 0 & 0 & $n=$ \\
\hline 127 & 8.38 & 7.76 & 10.83 & 0.13 & 1.21 & $n=.09$ \\
\hline 138 & 1.94 & 1.84 & 1.42 & 2.19 & .28 & $n=.0 B$ \\
\hline 140 & .34 & .54 & .42 & .14 & 2.37 & $n=.13$ \\
\hline$\underline{148}$ & 6.78 & 4.22 & 11.84 & 7.39 & 3.54 & $\mathrm{n}=.17$ \\
\hline 174 & 4.68 & 4.87 & 3.60 & 4.85 & .19 & $n=.01$ \\
\hline 182 & 1.09 & 1.04 & 1.28 & 1.07 & .10 & $n=.8$ \\
\hline 210 & 2.94 & 3.36 & 2.18 & 2.82 & 2.61 & $\mathrm{~ns} \quad .03$ \\
\hline 243 & .26 & .46 & .17 & .15 & .51 & $n=\quad .04$ \\
\hline 294 & 2.65 & 1.43 & 5.18 & 2.89 & 2.34 & $n=. c$ \\
\hline 296 & 0.66 & 5.44 & 9.11 & 6.93 & 1.41 & ne \\
\hline 320 & 2.69 & 2.88 & 3.26 & 2.35 & .25 & $n=$ \\
\hline 336 & .65 & .47 & .41 & .90 & .39 & $n=$ \\
\hline 468 & 8.95 & 9.07 & 18.09 & 6.04 & 2.13 & $n=. c$ \\
\hline
\end{tabular}

Conclusion. Numerous concerns have been raised when DRGs came into effect with regards to the risks posed on the care of the patient when limits are imposed 
on length of stay and 1 imitations on amounts of money reimbursed to hospitals for care delivered. One of them was that hospitals may discharge patients prematurely and cause quality of care to decline. Using death rates as an outcome indicator, no statistically significant difference was found among the three hospital types on twenty DRGs.

The intended outcome of DRGs was to increase competition among hospitals for patients and decrease length of stay, thereby ultimately controlling costs of health care. With the expanding presence of forprofit institutions, there is substantial concern regarding the pursuit of profits and quality care in the face of decreasing reimbursement monies. The findings in this study lend some reassurance that there is a minimum level of quality addressed by all three hospital ownership types. This is with respect to death rates. The author, as with other investigators in the field, would rather have the ideal way of measuring quality. This would be in terms of quality of life after discharge from the hospital, case-specific, with stratified sampling.

To date, very little is known about the relationships of organizational mission and patient care outcomes. This is not surprising. This author is fortunate to have seen health care systems in the 
Philippines, Australia, and in the last thirteen years in the United States, specifically in Florida.

Comparatively, this society has increasingly relied upon the judicial system to resolve many of its conflicts -from child custody, visitation rights, who should have prayer in schools and the like. No different is the hospital setting. The increasing malpractice rates and withdrawal of the two largest companies from underwriting malpractice insurance for physicians in Florida lend credence to this. Huge malpractice awards to patients have been contested by hospitals and physicians. The lawyers have successfully blocked legislation in capping monetary awards. It would seem logical that if the care given by a hospital or a physician reflects "quality," malpractice suits will be less likely in these hospitals. A recent florida statute required reporting of cases within 72 hours of "serious adverse events" via the hospital Risk Management Frogram. Clearly, all these indicate that problems remain regarding quality of care.

The difficulties associated with studying quality of care at the micro level spring from a protectionist attitude on the part of hospitals, physicians, and their personnel under threat of losing their jobs should they "blow the whistle." It is unlikely that information will be accessible to the point where valid studies can 
be made. An even greater problem is that the meaning of quality, and how a patient, a physician, and a lawyer perceives it would differ.

The following chapter will present a summary of the findings, its generalizability in the light of the study limitations, its utility from a practical and theoretical standpoint, and present a modification to the original analytical framework to be considered in future research. 


\section{CHAPTER VI}

\section{CONCLURION}

\section{Summary}

There were 56 JCAH accredited hospitals offering acute care, general services in this study. The framework for analysis described the relationships to be examined. Several hypotheses regarding hospital behavior were proposed. The results were presented, discussed, and conclusions drawn. Table XXXVII is presented (next page). For simplicity, the table does not include the analyses for location and length of stay, charges, reimbursements, and death rates on twenty DRG categories.

There were institutional variables which were explored. Bed size was higher in nonprofit hospitals in comparison to forprofit hospitals. Population density plays a role in the preference for location by the forprofit sector.

As indicators of efficiency, occupancy rates, ancillary service expenses, bad debts, manhours per patient day, salaries per FTE, length of stay per DKG, 
charges per DRG, and reimbursements per DRG were used. Some empirical support for the property rights theory was obtained. On three indicators out of eight TABLE XXXVII SUMMARY TABLE

\begin{tabular}{|c|c|c|c|c|c|c|c|}
\hline VAR I AELEE & $1 \quad N P$ & $V=F P$ & 8 & NP Ve & 음 & FP VE & B \\
\hline BEDS & & $\begin{array}{l}.02 \\
.03 \\
\end{array}$ & & $\begin{array}{l}\text { NS } \\
\text { NB }\end{array}$ & (NB) & $\begin{array}{l}\text { NS } \\
\text { NB }\end{array}$ & (NE) \\
\hline QCCUPANCY & & $\begin{array}{l}.05 \\
.052\end{array}$ & & $\begin{array}{l}\text { NS } \\
\text { NB }\end{array}$ & (NS) & $\begin{array}{l}<.05 \\
<.05 \\
\end{array}$ & $(.055)$ \\
\hline ANCILLARY & & $\begin{array}{r}.01 \\
<.05 \\
\end{array}$ & & $\begin{array}{r}r .01 \\
\text { NS }\end{array}$ & (NB) & $\begin{array}{r}r .01 \\
\text { NS } \\
\end{array}$ & (NB) \\
\hline BAD DEBTS & & $\begin{array}{l}\text { NS } \\
\text { NS }\end{array}$ & & $\begin{array}{r}.01 \\
<.01 \\
\end{array}$ & $(<.01)$ & $\begin{array}{l}<.01 \\
<.01 \\
\end{array}$ & $(<.01)$ \\
\hline MANHOURS & & $\begin{array}{l}<.01 \\
<.01 \\
\end{array}$ & & $\begin{array}{l}\text { NS } \\
\text { NS }\end{array}$ & (NB) & $\begin{array}{r}.01 \\
<.01 \\
\end{array}$ & $(<.01)$ \\
\hline SALARIES & & $\begin{array}{l}\text { NS } \\
\text { NS } \\
\end{array}$ & & $\begin{array}{l}\text { NS } \\
\text { NB }\end{array}$ & (NB) & $\begin{array}{l}\text { NS } \\
\text { NS }\end{array}$ & (NB) \\
\hline MED ICARE & & $\begin{array}{r}.01 \\
<.02 \\
\end{array}$ & & $\begin{array}{l}\text { NS } \\
\text { NS }\end{array}$ & (NB) & $\begin{array}{r}.05 \\
\text { NB }\end{array}$ & (NB) \\
\hline MEDICAID & & $\begin{array}{l}\text { NS } \\
\text { NS }\end{array}$ & & $\begin{array}{r}<.01 \\
<.05 \\
\end{array}$ & $(.08)$ & $\begin{array}{l}<.01 \\
<.01 \\
\end{array}$ & $(<.01)$ \\
\hline UNCOMP. CARE & & $\begin{array}{l}<.01 \\
<.01 \\
\end{array}$ & & $\begin{array}{r}.01 \\
\text { NS }\end{array}$ & (NS) & $\begin{array}{l}<.01 \\
<.01 \\
\end{array}$ & $(<.01)$ \\
\hline
\end{tabular}

[ Italics:

c Bold:

[ $($ ):
ANOVA analysis controlling for Beds, Loc.] Mann-Whitney Tests J

Mann-Whitney Test excluding 1 government hospital outlier with over 900 beds J

(bad debts, manhours per patient day, and charges per DRG), statistically significant differences were found. There were five indicators (occupancy rates, ancillary 
expenses, salaries per FTE, length of stay per DRG, and reimbursement per DRG) which showed no support for the property rights theory. In some ways, nonprofit hospitals mimic their forprofit counterpart (in terms of bad debts). We can only speculate on reasons why we failed to find support for the property rights theory on five variables (occupancy rates, ancillary expenses, salaries per FTE, length of stay per DRG, and reimbursement per DRG). Hospital occupancy rates are affected by the health needs within a community. Often even if discounted rates are offered, this does not produce a corresponding $r$ ise in hospital admissions. Hospital personnel salaries are broad indicators and do not take into account the possibility that bonuses, stock options, and other fringe benefits such as paid car allowances, housing, and holiday trips might have been provided in certain hospital ownership types. The length of stay per DRG and reimbursement per DRG analyses show results that reflect the response of hospitals to cost containment incentives. If these two variables were studied over time, one might observe a correlation between changes in length of stay, the retrospective reimbursement system, and the prospective payment system.

In the context of equity, Medicare days, Medicaid days, and the amount of uncompensated care provided by 
nonprofit, government, and forprofit hospitals were compared. The study findings were consistent with the property rights theory. Differences among the three hospitals on these variables were found to be significant. The implications of these differences were discussed in the earlier chapter. More Medicare days in the nonprofit compared to the forprofit hospital are consistent with output maximization. Nonprofit and forprofit hospitals show no statistically significant difference in terms of Medicaid. The nonprofit hospital behavior approximates that of the forprofit behavior in this regard -- a finding that leads us to suspect that there may be other factors other than restraint from rights to residual profits that affect nonprofit behavior. These were discussed in Chapter II. Forprofits provided significantly fewer Medicaid days than the government hospitals. This behavior is consistent with the property rights expectation. In terms of uncompensated care, the forprofits were significally lower and this evidence is also consistent with the property rights theory. The study revealed evidence on the relationship of ancillary service expenses, Medicare days, and Medicaid days. With hospitals differing significantly on Medicare and Medicaid days, it is worth noting that these account for $91.3 \%$ of the variation in ancillary 
services. This means that the changes in the target patient population of hospital services according to ownership categories (provision of services to Medicare and Medicaid recipients versus private payors) would be a definite area for future research. The variation on bad debts cannot be explained in terms of the variation in Medicare and Medicaid days. However, it can be explained by the amount of uncompensated care provided by the hospital.

Some interesting questions remain unanswered. Why do nonprofits have similar Medicaid days with forprofit. Government hospitals provided more in terms of Medicaid. Nonprofit hospital bad debts are not significantly different than the forprofits. Does this mean that nonprofits 1 imit their bad debts by limiting the number of Medicaid days? Are services provided in nonprofit and forprofit hospitals sufficiently different so that they can only admit certain types of patients? These interesting anomalies have not been fully investigated in this study. Certainly, these are avenues for continued investigation.

In the context of quality of care, the death rates for each of the top twenty DRGs common to all hospitals in the study were compared. No significant differences were found. However, there are other outcome indicators of quality which can be used in future evaluations. The 
difficulty lies in framing the analyses and the agreement on the definition of quality of care. A greater problem is access to information. This gray area remains even though the findings show that hospitals, regardless of ownership status, maintain a level of quality which does not compromise patient 1 i ves.

This study explored questions in the extremely complicated context of efficiency, equity, and quality of care provided in the nonprofit, government, and forprofit hospitals under DRGs. The property right arrangements were hypothesized to produce specific outcomes in hospital behavior. Government hospitals were found to be consistent with the characteristics expected with the present property right arrangement. Nonprofit hospital behavior shows some evidence of output maximization and mimics the forprofit hospital in certain ways. This reiterates the need to study the performance of this sector. Forprofit hospital behavior was consistent with profit maximization.

To conclude, the results of this study showed mixed support for the property rights theory in the context of efficiency, equity, and quality of care. The behavior of the nomprofit hospitals can not be fully explained and clearly remains an avenue for future researchers. The following discussion will focus on the 
potential utility of the study findings and suggestions for future research.

Our study sample included hospitals in South

Florida. There are both disadvantages and advantages. The disadvantages include the small sample size which limits generalizability. This limited the number of hospitals in each ownership category. The study area was limited to three counties. Nonetheless, the fiftysix hospitals in this study consisted of a majority for South Florida. A total of eight hospitals are in this area. Advantages in using the sample here include the following. The author is knowledgeable of the internal operations of some hospitals in the area; a complete data set for the variables and DRG categories were available; and the use of South florida eliminates area variation with regard to population densities, health status, and health care practice. In particular, this study could be done utilizing a similar model in other parts of florida. It would be interesting to see if the findings would support the property rights view. With this thought, let us follow this discussion with suggestions for future research on property rights and hospital behavior.

Having made the determination that DRG comparisons were not particularly revealing, the author recommends that future analyses be done on hospital buciget data 
only. This will allow inclusion of all the counties throughout the state of Florida. An analysis for several years: 1?85, 1986, and in a few months, 1987 would be posaible. With a larger sample, the study will allow classification of hospitals by service type using the model by Berry (1973); comparisons of different counties throughout the state; and within ownership types, subclassification of hospitals as forprofit chain or non-chain and so on. In addition to this, it is important to include classification of insurance payers i.e. private insurance versus Medicare or Medicaid.

The use of death rates per DRG is a gross indicator of quality. Recent developments regarding the reporting of serious incidents is now mandated by florida statute. It should be available from HRS for each hospital in Florida. Another alternative is to review the JCAH 1 ist of recommendations for each hospital, if this was obtainable. Having discussed some future research considerations, let us point out the utility of the study.

From a practical standpoint, the knowledge we now have regarding the behavior of hospitals in South Florida may help us identify what incentives produce specific outcomes. Local health administrators involved in shaping the structure of this community's health care system might consider the specific issues relating to 
the provision of care to Medicaid patients. Particularly important is the fact that if there are community health needs which are not being addressed, it would be wise to consider to what extent the forprofit and nonprofit sectors could be utilized to meet these needs.

From a theoretical standpoint, we found some evidence in support of the property rights theory. We focused on rights to residual profits in the forprofit sector and maximizing services to society subject to budget constraints in the nonprofit and government sector as the fundamental bases for the distinction in hospital behavior. The government and forprofit hospital behavior appear consistent with the theoretical expectations. The nonprofit hospitals, though, behave in certain ways 1 ike the forprofit hospital. It is important to reiterate, here, that nonprofit hospitals are not restrained from making profits. It is only the restraint on the accrual of profits to its governing body that is specifically delineated. In fact, voluntary hospital associations have separate corporations that handle investments for their nonprofit hospital members. We can only speculate what kind of ramifications this will have on the internal operations of the nonprofit hospital. The evidence in this study leads the author to believe that property rights theory 
can not be used to fully explain why this sector mimics the forprofits in certain respects. We might consider a modification to our original framework for analysis.

Let us think of property rights along a continuum. Over time, incentives change. The true nonprofit hospitals many years ago were run by religious orders and cared for those who need their service with little or no compensation. As incentives were created to encourage production of services to specific groups (such as children, pregnant women, elderly, indigents), we will find the inception of nonprofit organizations geared towards this. This author proposes that there are hospitals which are hybrid nonprofit firms falling somewhere along the property rights continuum. These hybrid organizations might be organized under the leadership of individuals who may have a variety of motivations: economic interests, prestige, achievement, self-actualization, etc. Some of these leaders may be doctors or consumer groups. Depending on how much control over the decision-making process the governing body has, the position of this nonprofit organization changes along this continuum. To investigate this possibility, this author proposes the following measures as indicators of efficiency: (1) total and operating margins, and (2) non-operating revenue. The operating margin will show the excess revenues generated primarily 
from patient charges before taxes and the total margin will show excess revenues generated from all sources after taxes. The non-operating revenue will include unrestricted income from endowment funds, retail operation revenue, unrestricted gifts, or gain from the sale of hospital properties. The equity measures should include the Medicare days, Medicaid days, and private or charge based patient days. Active participation of hospitals in teaching and research should also be used as measures of equity. Quality measures should include the number of serious incident reports, malpractice suits, and the number of recommendations by the Joint Commission on Accreditation of Hospitals. The confounding variables to be considered in this analysis should include the following: bed size, types of services, hospital location, hospital age, health policies, span of control/authority, and type of leadership.

Ideally, true nonprofits and forprofits stand completely on opposite sides of the continuum. However, because hospitals do not exist in a vacuum, various forces in the environment impact on their operations. This means that property rights research remains an ongoing process of verification. 


\section{BIBLIOGRAPHY}

Alchian, A. 1969). Corporate Hanagement and Property Rights in Manne, H. (ed.) Economic Policy and Regulation of Corporate Securities. Washington, D. C.: American Enterprise Institute pp. 337-343.

Alchian, A. and Allen, w. (1969). Exchange and Production: Theory in Use. California: Wadsworth Publishing Co., Inc. PP. 156-158.

American Haspital Association (1966). Factors to Evaluate in the Establishment of Hospital Charges. Chicago: American Hospital Association.

American Hospital Association (1979). Hospital Statistics. Chicago: American Hospital Association.

American Hospital Association (1982). Guide to the Health Care Field. Chicago: American Hospital Association.

American Hospital Association (1984). Guide to the Health Care Field. Chicago: American Hospital Association.

American Hospital Association (1980-1985). Data Book on Multihospital Systems. Chicago, Ill.: American Hospital Association.

American Hospital Association (1985). Hospital Data Center. Chicago, Ill.: American Hospital Association.

Andrews, F. Morgan, J., Sonquist, J. and Klem, L. (1973) Multiple Classification Analysis (2nd Ed.). Michigan: University of Michigan.

Bays, C. (1979). Cost Comparisons of For-Profit and Non-Profit Hospitals. Social Science and Medicine. 12

Bays, C. (1983). Why Host Private Hospitals are NonProfit. Journal of Policy Analysis and Management. $2(3): 366-385$. 
Baumol, W. (1959). Business Behavior, Value, and

Growth. New York: MacMilian and Co.

Ben-Ner, A. (1983). Non-Profits: Hhy Do They Exist in Market Economies? (Working Paper No. 51) Program on Non-Profit Organizations. Vale University.

Berry, R. (December, 1973). On Grouping Hospitals for Economic Analysis. Inquiry. $10(4): 5-12$.

Blau, P. and Scott, W. (1962). Formal Organizations: A Comparative Approach. San Francisco: Chandler

Fublishing Co.

Bower, R. and Roemer, M. (October 196.3). Medical Staff Organization in Saller Hospitals. Hospital Management. $96: 46-47$.

Brook, R. (1973) Journal of Medical Education 48:114134 .

Clark, R. (1980). Does the Non-Profit For Fit the Hospital Industry? Harvard Law Review. 93:1416.

Clarkson, K. (October 1972). Some Implications of Property Rights in Hospital Hanagement. Journal of Law and Economics. 15:363-373.

Daniel, W. (1978). Applied Nonparametric Statistics. Boston: Houghton Mifflin Co., 82-83.

Davis, K. (1972). Econolic Theories of Behavior in NonProfit Private Hospitals. Journal of Economics and Business. $24(2): 1-13$.

DeAlesi, L. (1969). Inplications of Property Rights for Government Investment Choices. American Economic

Review. 59

DeGendt, W. (1970). Five Approaches to Assessing the Quality of Care. Hospital Administration 15:21-39.

Demkovich, L. (June 26, 1982). Urban Voluntary Hospitals Caught in Prize Squeeze Face a Bleak future. National Journal 15: 1131 .

Demsetz, H. (1966). Some Aspects of Property Rights. Journal of Law and Economics. $\quad 9: 61$.

Demsetz, H. (May 1967). Toward a Theory of Property Rights. American Economic Review. 57:347. 
Donabedian, A. (1966) Evaluating the Quality of Medical Care. Milbank Memorial Fund Quarterly.

$44(3): 166-206$.

Donabedian, A. (May-June 1968). Evaluating the Quality of Patient Care. Medical Care 6:181-202.

Easley, D. and D'Hara, M. (1983). The Econoric Role of the Non-Profit Fir. The Bell Journal of Economics. $14(2): 531-538$.

Etzioni, A. (1961). A Comparative Analysis of Complex Organizations. New York: Free Press.

Federation of American Hospitals (1983). InvestorOwned Hospitals and Management Companies. Little Rock, Arkansas: FAH.

Federation of American Hospitals (1984). 1985 Directory, Investor-Owned Hospitals and Hospital

Management Companies. Little Rock, Ark.: Federation of American Hospitals.

Feldstein, P. (December 1971). Hospital Cost Inflation: A Study of Nonprofit Price Dynasics. American Economic Review. $51: 853-872$.

Ferber, B. (Spring 1971). Analysis of Chain-Operated Forprofit Hospitals. Health Services Research.

Finkler, S. (Summer 1983). The Hospital As A SalesMaxilizing Entity. Health Services Research. 18:2.

Florida Statistical Abstract ( 1985 and 1986$)$.

Frick, A., Martin, S. and Shwartz, M. (1985) Case-Mix and Cost Differences Between Teaching and Non-Teaching Hospitals. Medical Care 23(4):283-295.

Furabotn, E. and Pejovich, S. (December 1972). Property Rights and Econowic Theory: A Survey of Recent Literature. Journal of Economic Literature.

$10(4): 1137$.

Georgoupoulos, B. and Mann, F. (1962). The Community General Hospital. New York: MacMillan Publishing Co.

Gibbons, J. (1971) Nonparametric Statistical Inference. New York: McGraw-Hi 11 .

Griffith, J. (1978). Measuring Hospital Performance. Kansas: Allen Press. 
Goss, M. (December 1970). Organizational Goals and Quality of Medical Care: Evidence fro Comparative Research on Hospitals. Journal of Health and Social Behavior. 11:255-268.

Groner, P. (Summer 1979). Point of View: InvestorOwned Hospital Chain Concept: Challenge to the NonProfit Sector. Health Care Management Review.

Hansmann, H. (1980). The Role of NonProfit Enterprise. Yale Law Journal. 835.

Heydebrand, W. (1973). Hospital Bureaucracy: A Comparative Study of Organizations. New York: MacMillan Publishing Co.

Health Care Financing Administration (January 3, 1984). Department of Health and Human Services - Part VI. Code of Federal Register. Washington, D.C.: HCFA.

Health Council of South Florida (1985). Health Utilization Report.

Hospital Cost Containment Board (1984). 1984 Hospital Budget Data. Tallahassee: State of Florida Hospital Cost Containment Board.

Hospital Cost Containment Board (1985). 1985 Hospital Eudget Data. Tallahassee: State of Florida Hospital Cost Containment Board.

Hospital Data Center. American Hospital Association (1985). Chicago, Illinois.

Ingbar, M. and Taylor, L. (1968). Hospital Costs in Massachusetts. Cambridge, Mass.: Harvard University

Press.

Joint Commission on Accreditation of Hospitals (1987). Accreditation Manual for Hospitals. Chicago: JCAH.

Johnson, R. (August, 1982). The Resurgence of a TwOTier Health Care System. Action Kit Newsletter.

Pittsburgh: Action Kit for Health Law.

Jones, D. (1985) Investor-Owned Chains Continue Expansion, 1985 Survey Shows. Modern Healthcare 55 (June 7) : 75-90.

Lewin, Derzon, and Margolies. (July 1981). InvestorOwned and Non-Profits Differ in Economic Performance. 
Hospitals. 55.

Jones (1985). Predicting Hospital Charge and Stay Variation. Medical Care. $23(3)$.

Kane, R., Kasteler, J. and Gray, R. (1976). The Health Care Gap: Medical Services and the Poor. New York:

Springer. pp. 3-21.

Klarman, H. (1965). The Economics of Health. New York: Columbia University Press. p. 121.

Lin, M. (July 1971). A Conspicuous Production Theory of Hospital Behavior. Southern Economic Journal. 38:4858.

Long, M. (1964). Efficient Use of Hospitals in Economics of Health and Medical Care- Ann Arbor, Michigan: University of Michigan Press. pp. 21 1 -226.

Malloy, R. (1986). Equating Human Rights and Property Rights -- The Need for Moral Judgement in an Economic Analysis of Law and Social Policy. Ohio State Law Journal. 47:163.

Marmor,T. (1982). Congress Adopts Medicare: The Politifs of Legislative Uncertainty in Anderson, J. Cases in Public Policy-Making (2nd Ed.). New York: Holt, Rinehart, and Winston.

Modern Healthcare (1985b). Multi-Unit Providers. 15 (June 7): 75-160.

Moseley, S. and Grimes, R. (Summer, 1976). The Organization of Effective Hospitals. Health Care Management Review.

Mullner, R. and Hadley, J. (Summer, 1984). Interstate Variations in Growth of Chain-Owned Profit Hospitals 1973-82. Inquiry. 21:144-151.

Musgrave, R. and Musgrave, F. (1973). Public Finance in Theory and Practice. New York: McGr aw-Hill. p. 5.

Newhouse, J. (1970). Toward a Theory of NonProfit Institutions: An Econoric Hodel of a Hospital. American Economic Review. $60(1): 64-74$.

Nicols, A. (1967) Stock versus Mutual Savings and Loan Associations: Some Evidence of Differences of Behavior. American Economic Review. 57: 337-347. 
Nicals A. (1972) Management and Control in Mutual Savings and Loan Associations. Massachusetts: Lexington Books.

Nie, N., Hull, C., Jeckins, J., Steinbrenner, K., and Bent, D. (1975). SPSS. New York: McGraw-Hil1, Co.

akun, A. (1975). Equality and Efficiency: The Big Trade-Off. Washington, D. C.: The Brookings Institution.

Pattison, R. and Katz, H. (August 11, 1983). InvestorOwned and Not-For-Profit Hospitals--A Comparison Based on California Data. The New England Journal of

Medicine.

Pauly and Redisch. (1973). The Not-For-Profit Hospital as a Physician's Cooperative. American Economic Review. 87.

Payne, B. (August 14, 1967) Continuous Evaluation: A Syste of Hedical Care Appraisal. Journal of the American Medical Association (JAMA) 201:536-540.

Perrow, C. (1965) Hospitalsz Technology, Structure, and Goals in March, J. Handbook of Organizations.

Chicago: Rand McNally.

Professional Foundation for Health Care (1985). PRD Data on Hospitals for 1984. Tampa, Florida:

PFHC McGraw-Hill.

Rawls, J. (1967) Distributive Justice in Philosophy, Politics, and Society. Laslett, P. and Runciman, w. (Eds.) Oxford: Basil Blackwell.

Rawls, J. (1971) A Theory of Justice. Massachusetts: Bel knap-Harvard Press.

Relman, A. (1983) Investor-Owned Hospitals and Health Care Costs. The New England Journal of Medicine.

309: 370-2.

Rudov, M. and Santangelo, N. (1979) Health Status of Minorities and Low Income Groups. Washington: U. S. Government Printing Office DHEW.

Ruchlin, H., Pointer, D., and Cannedy, L. (December 1973). A Comparison of Forprofit Investor-Owned Chain and NonProfit Hospitals. Inquiry. 10.

Ryan, B., Joiner, B., and Ryan, T. (1985). Minitab. 
Bastan: Duxbury Press.

Samuelson, P. (1967). Economics (7th ed.). New York: McGraw-Hill.

Shortell, S. and Brown, M (Eds.) (1976). Organizational Research in Hospitals. Chicago: Blue Cross

Association.

Sorrentino, E. A. (1985). A Conparative Study of

Nonprofit, Government, and Forprofit Hospitals. An

Independent Study (Submitted to Dr. Stephen Loveless,

School of Public Affairs and Services - Florida

International University Miami, Florida).

Starfield, B. (1973). Health Services Research--A

Horking Mode1. New England Journal of Medicine. 289.

Watt, J. et. al. (1986). The Comparative Economic

Performance of Investor-Owned Chains and Not-For-Profit

Hospitals. The New England Journal of Medicine

314 (2) 89-96.

Weisbrod, B. (1977). The Voluntary Non-Profit Sector: An Economic Analysis. Lexington, Mass.: Lexington Books.

Weisbrod, B. (1980). Private Goods, Collective Goods: The Role of the Non-Profit Sector in Clarkson, K. and Martin, D. (eds.) The Economics of Nonproprietary Organization. Connecticut: JAI Press. pp. 139-177.

Williamson, 0 . (December 1981). The Modern Corporation: Origins, Evolution, Attributes. Journal of Economic Literature. 19:1537-1568.

United States Bureau of Census (1979). Statistical Abstract. 
VITA

Title of Dissertation:

Froperty Fights and Hospital Behavior Uncier DFiGs An Examination of Nonprofit, Government, and Forprofit Sectors

Fuil Name:

Eizabeth M. Andal Gorrentino

Flace and Date of Birth:

Manila, Fhilippines

September 16, 1955

Elementary and Secondary Education:

Espiritu Santo Farochial Schooi

Fhilippine Coilege of Commerce

University:

1968 - 1972 Graduate in Nursing - University of the

Philippines

1977 - 1979 Bachelor of Science in Nursing - Florida International University

1979 - 1983 Master of Science in Adult Education Florida Internationai University

Fublications:

November 28, 1987 - "Image or Imagery -- We Need Fositive Frojections" in The Florida Nursing News.

Ft. Lauderdale, Florida.

November, 1987 - "Nursing Chair Endowment for Excellence in Nursing Care" in Focus on the Nursing Shortage: Froblems and Possibilities. New York: National League of Nursing.

September, 1987 - "Making An Impact in an Institutional Setting - A Case Study" in Proceedings of the 1987 Third National Biennial Conference of FAWN. Wash., D. C.: Filipino-American Women's Network.

Spring, 1986 - "The Fight to Die" in Journal of Health and Human Resources Administration (Vol. 8).

June, 1983 - "Ferformance Appraisai" in The Fiorida Nursing News. Ft. Lauderdale, Fla. 